
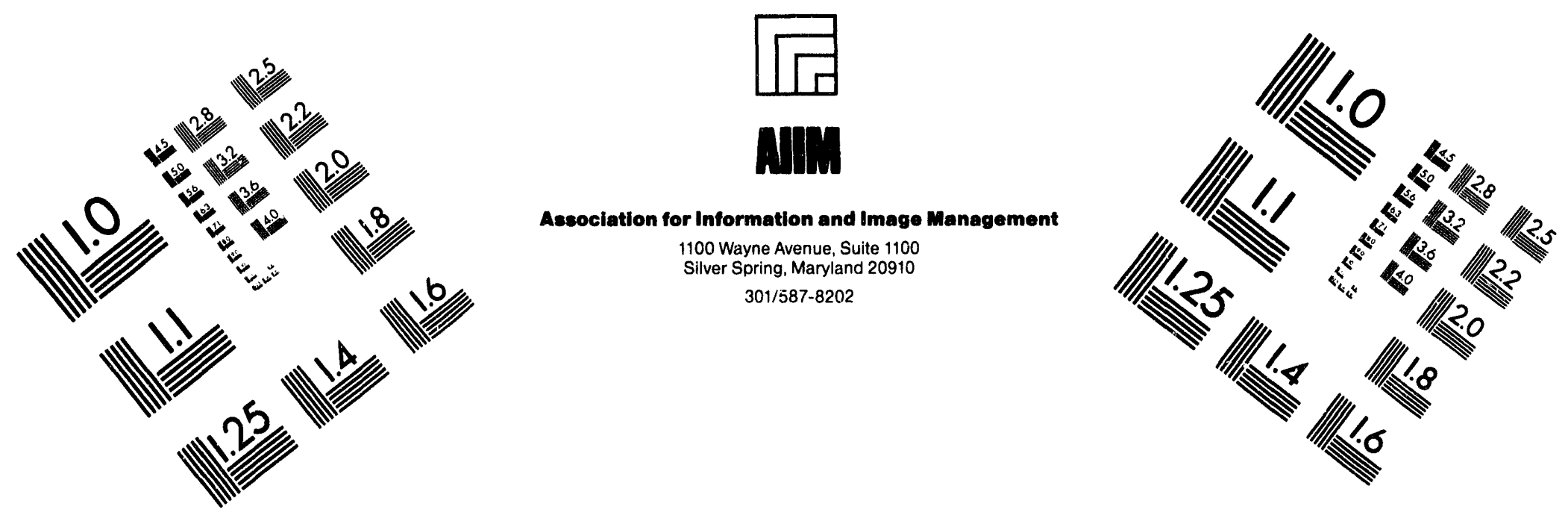

\title{
Centimeter
}

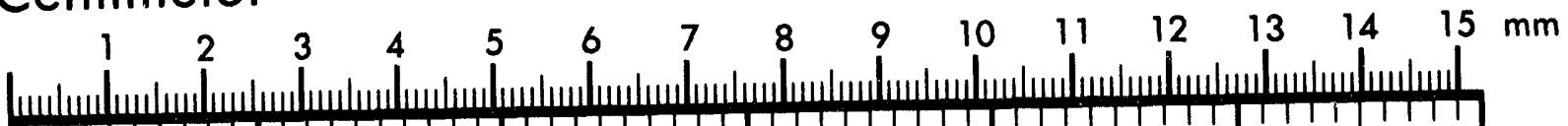

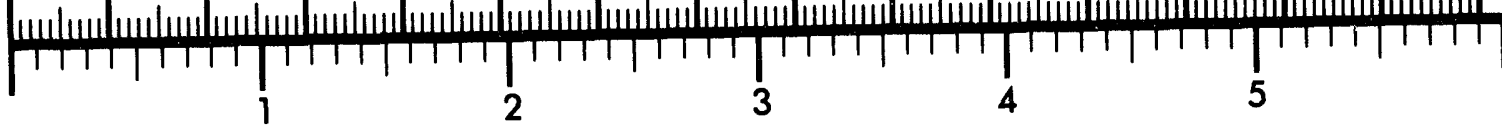
Inches

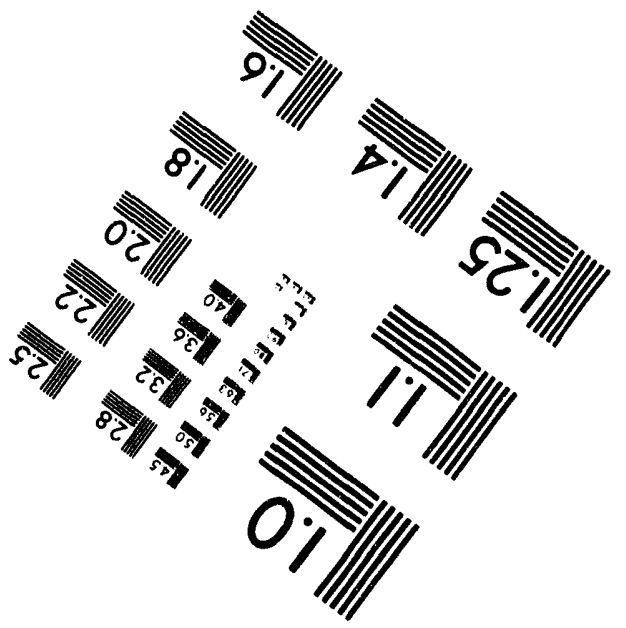

MANUFACTURED TO AIIM STANDARDS

BY APPLIED IMAGE, INC.

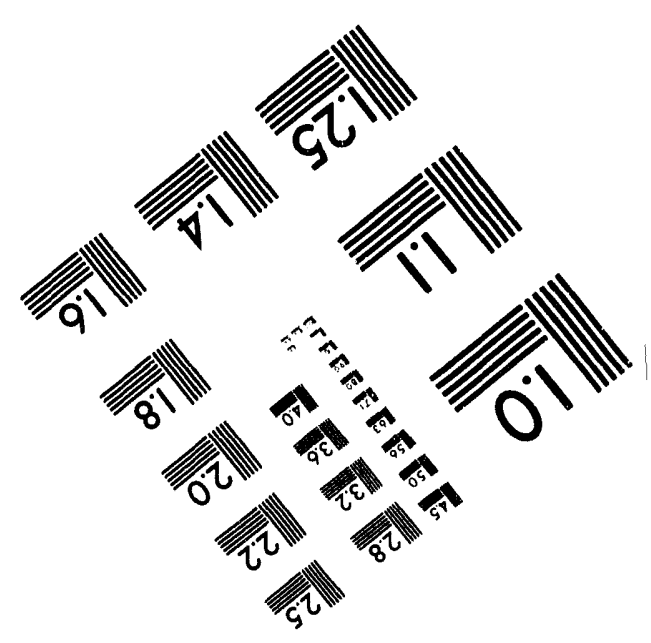



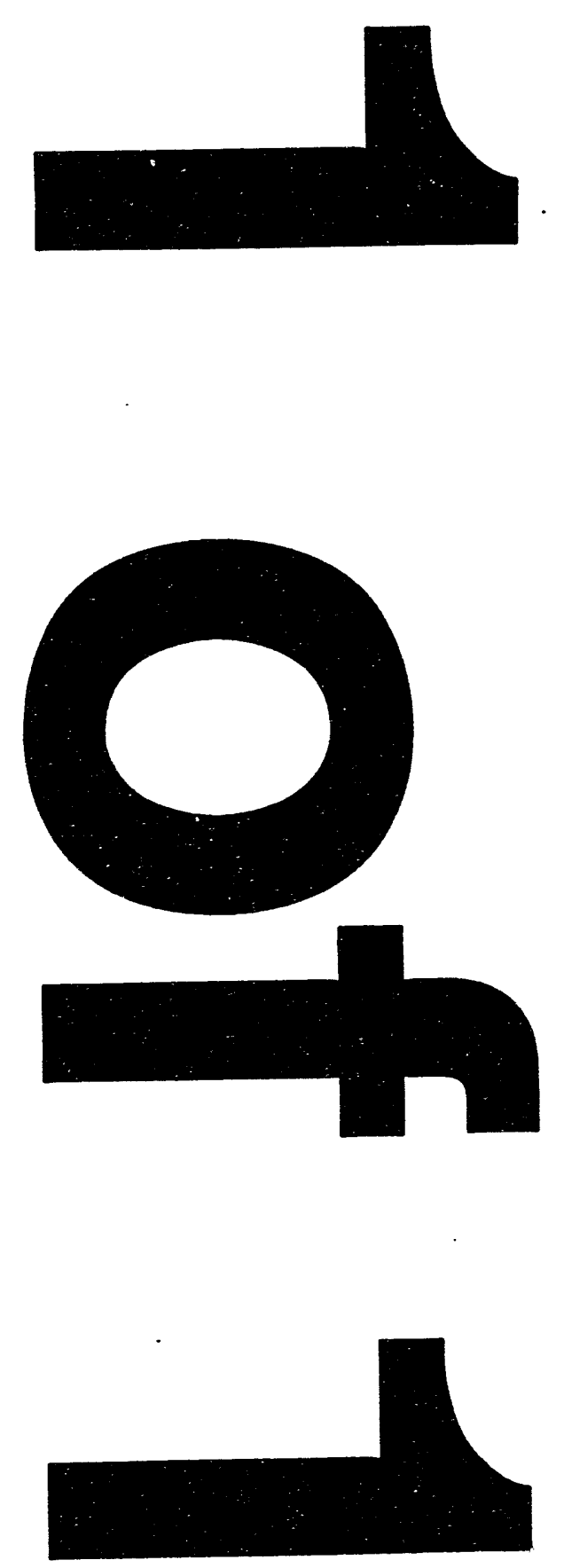
LA-UR-94-1361

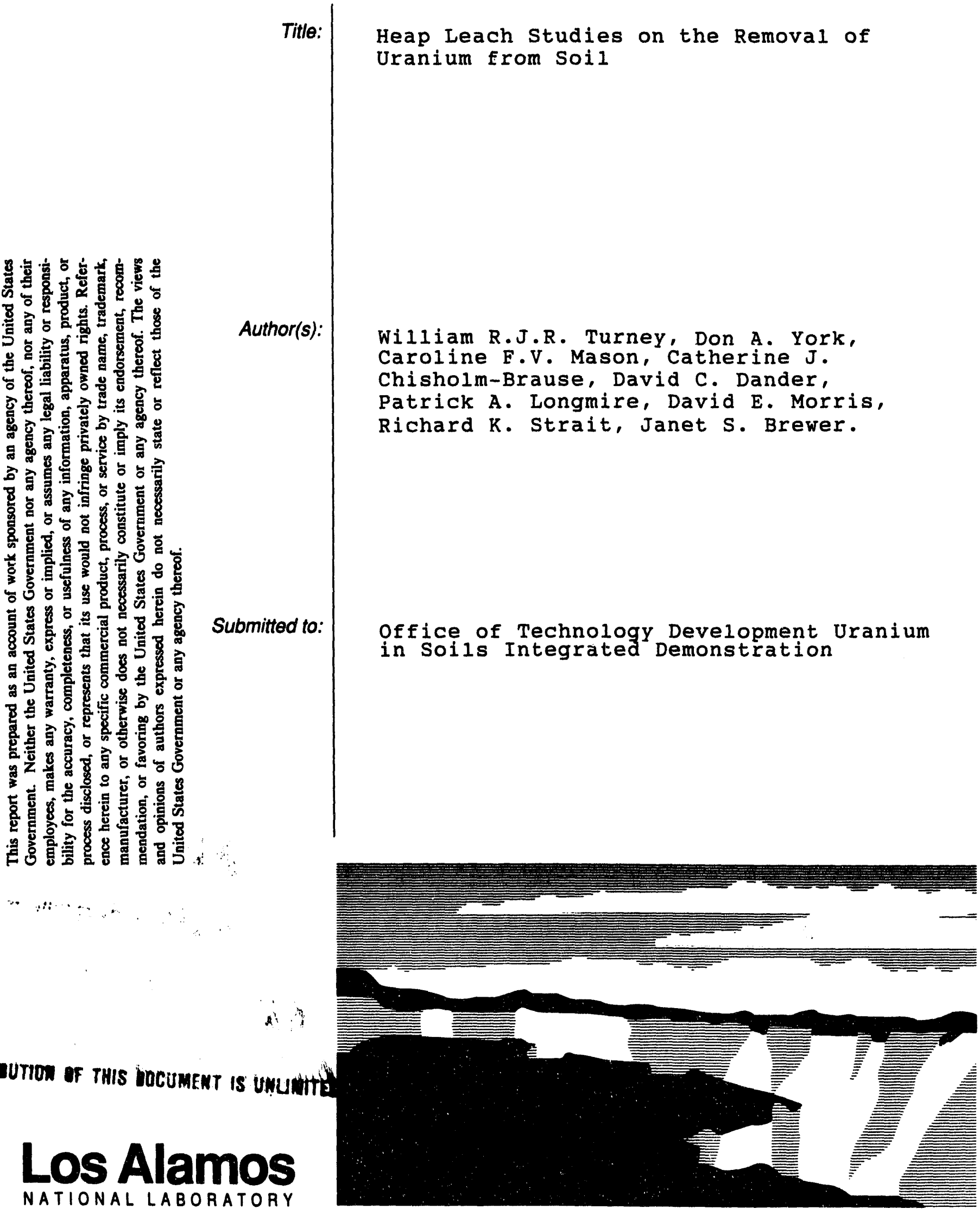

NATIONAL LABORATORY

Los Alamos National Laboratory, an affirmative actionvequal opportunity employer, is operated by the University of California for the U.S. Department of Energy under contract W-7405-ENG-36. By acceptance of this article, the publisher recognizes that the U.S. Government retains a nonexclusive, royalty-free license to publish or reproduce the published form of this contribution, or to allow others to do so, for U.S. Governmem purposes. The Los Alamos National Laboratory requests that the publisher identify this article as work performed under the auspices of the U.S. Department of Energy. 
LA-UR-94-1361

HEAP LEACH STUDIES ON THE REMOVAL OF URANIUM FROM SOIL

\section{REPORT OF LABORATORY-SCALE TEST RESULTS}

Technical Task Plan AL121121

Soil Decontamination Task Group

Uranium in Soils

Integrated Demonstration

May 1994

Prepared for the Office of Technology Development

(EW 4010)

Prepared by the

LOS ALAMOS NATIONAL LABORATORY

Los Alamos, New Mexico 87545

of the

UNIVERSITY OF CALIFORNIA

for the

U.S. Department of Energy

under contract W 7405 ENG 36 


\begin{abstract}
This report details the initial results of laboratory-scale testing of heap leach that is being developed as a method for removing uranium from uranium-contaminated soil. The soil used was obtained from the site of the Feed Materials Production Center (FMPC) near the village of Fernald in Ohio, which produced uranium metal and compounds from 1951 to 1989. After cessation of production, this site was renamed Fernald Environmental Management Project (FEMP). The testing is being conducted by the Los Alamos National Laboratory and is sponsored by the U. S. Department of Energy (DOE), Office of Technology Development through the Uranium in Soils Integrated Demonstration (USID) program. The USID was established to develop new technologies that will enable DOE to remediate large quantities of uranium-contaminated soils in a safe and economical manner.

The testing is being conducted on a laboratory scale, but it is intended that this methodology will eventually be enlarged to field scale where millions of cubic meters of uranium-contaminated soil can be remediated. The laboratory scale experiments show that, using carbonate/bicarbonate solutions, uranium can be effectively removed from the soil from initial values of around $600 \mathrm{ppm}$ down to $100 \mathrm{ppm}$ or less. The remaining uranium approximates to the uranium (IV) component with the uranium (VI) being completely removed. The maximum quantity of soil so far tested in a single batch is $10 \mathrm{~kg}$.
\end{abstract}

The goal of this research is to selectively remove uranium from the contaminated soil, without causing serious changes in the characteristics of the soil. It is also hoped that the new technologies developed for soil remediation at FEMP will be transferred to other sites (DOE, commercial, and private) that also have uranium-contaminated soil.

\title{
CONTRIBUTORS
}

William R. J. R. Turney

Don A. York

Caroline F. V. Mason

Catherine J. Chisolm-Brause

David C. Dander

Patrick A. Longmire

David E. Morris

Richard K. Strait

Janet S. Brewer 


\section{TABLE of CONTENTS}

$\begin{array}{lr}\text { Abstract } & 2 \\ \text { Table of Contents } & 3 \\ \text { List of Figures } & 4 \\ \text { List of Tables } & 4 \\ \text { Glossary } & 5 \\ \text { Acknowledgments } & 5\end{array}$

1. Introduction
A. Background
B. Objectives
C. Theory of Heap Leach
D. Approach

2. Experimental Methods \& Materials 10

A. Soil (i) Introduction 10

(ii) Characterization 13

(iii) Preparation 14

B. Laboratory Columns Simulated Heap Leach 15

3. Results 19

A. Carbonate/Bicarbonate Leach Tests 19

B. Soil Characteristics after Leach 27

4. Discussion 28

A. Leach Tests 28

(i) Chemical Removal 28

$\begin{array}{ll}\text { (ii) Physical Soil Characteristics } & 33 \\ \text { B. Agglomeration } & 33\end{array}$

C. Mathematical Models of Leaching Systems 35

5. Future Directions 37

A. Summary Plans 37

B. Optimization of Process 37

C. Pilot Scale Tests 38

$\begin{array}{ll}\text { 6. Conclusions } & 39\end{array}$

7. References 40

8. Appendices

A. Complete Data on Column Experiments A-1

B. Papers presented at the Waste Management ' $94 \quad$ B-1

(i) Predictive Geochemical Modeling of Uranium and other Contaminants in Laboratory Columns in Relatively Oxidizing, Carbonate-Rich Conditions

(ii) Carbonate Heap Leach of Uranium-Contaminated Soil

C. Cost Study of Heap Leaching and Batch Reactor Leaching

C-1 


\section{List of Figures}

Figure 1. Schematic of Heap Leach Process

Figure 2. Schematic of Laboratory Simulated Heap Leach

Figure 3. Diagram of FEMP Site, showing location of SP4 Samples

Figure 4. Diagram of FEMP Site, showing location of SP9 Samples

Figure 5. Photograph of $1 \mathrm{~kg}$ Column

Figure 6. Photograph of $10 \mathrm{~kg}$ Column

Figure 7. Uranium Removal as a Function of Time

Figure 8. Effect of Variation of Concentration of Sodium

Carbonate/Sodium Bicarbonate Solution

Figure 9. ppm of Uranium in Leachate

Figure 10. Uranium Removal as a Function of Time

Figure 11.

$\begin{array}{lll}\text { Figure 11. } & \text { pH as a Function of Time } \\ \text { Figure 12. } & \text { Eh-pH Diagram for part of the System U-C-O-H }\end{array}$

Figure 13. Eh-pH Diagram for part of the System Mg-O-H 31

Figure 14. Eh-pH Diagram for part of the System Fe-C-O-H 32

\section{List of Tables}

Table 1. Overall Results of the Column Experiments

Table 2.

Solution Chemistry as a Function of Time 


\section{Glossary}

$\begin{array}{ll}\text { AEC } & \text { Atomic Energy Commission } \\ \text { AEM } & \text { Analytical Electron Microscope } \\ \text { CFSTR } & \text { Continuous-Flow Stirred-Tank Reactor } \\ \text { DOE } & \text { Department of Energy } \\ \text { EPA } & \text { Environmental Protection Agency } \\ \text { FEMP } & \text { Fernald Environmental Management Project } \\ \text { FERMCO } & \text { Fernald Environmental Restoration Management Company } \\ \text { FMPC } & \text { Feed Materials Production Center } \\ \text { ICP } & \text { Inductively Coupled Plasma } \\ \text { LANL } & \text { Los Alamos National Laboratory } \\ \text { NRC } & \text { Nuclear Regulatory Commission } \\ \text { PFR } & \text { Plug-Flow Reactor } \\ \text { SAED } & \text { Selected-Area Electron Diffraction } \\ \text { USID } & \text { Uranium in Soils Integrated Demonstration }\end{array}$

\section{Acknowledgments}

We would like to acknowledge the following persons for their contributions to this project (in order of involvement):

Zohrab A. Samani, New Mexico State University

Adrain T. Hanson, New Mexico State University

Robert R. Ryan, LANL, CST-3, retired

James R. Brainard, LANL, CST-3

Bruce Thomson, University of New Mexico

David R. Janecky, LANL, CST-10

Robert Spangler, RUST Geotech

Beverly Dickinson, LANL, CST-10

Valerie Dixon, LANL, CST-10

Angela Chacon, LANL, CST-10 


\section{Heap Leach Studies on the Removal of Uranium from Soil.}

\section{INTRODUCTION}

\section{A. Background}

The post World War II growth of the nuclear industry in the United States was rapid and resulted in the founding of several new production facilities. The facility for producing uranium metal and uranium tetrafluoride was built at the U.S. Atomic Energy Commission's (AEC) Feed Materials Production Center (FMPC) near the village of Fernald, OH. It began operation in 1951. Subsequently, the FMPC was renamed the Fernald Environmental Management Project (FEMP) after uranium production was ceased in 1989.

The activities at FMPC, for which details are available elsewhere (USID August 1992) resulted in significant uranium contamination of the soils near Fernald. Estimates suggest that $2,000,000$ to $4,000,000 \mathrm{~m}^{3}$ of soil may have unacceptable levels of uranium contamination (Francis, 1992).

Current technologies for remediation of uranium-contaminated soil include (1) excavation and transportation of the uranium-contaminated soil to a repository, (2) immobilization of the uranium in place, (3) physical separation and removal of the more highly contaminated soil fractions from the balance of the soil, and (4) soil washing.

Heap leach is one method of soil washing currently being studied for remediation of uranium-contaminated soil. In a heap leach process, the contaminated soil is piled (heaped) on top of an impermeable pad built on the surface of the ground. An overhead sprinkler system sprays the heap with a solution which solubilizes (leaches) the uranium as the solution passes downward through the heap, as shown diagrammatically in Fig. 1. This method has been successfully implemented by the mining industry to recover precious metals from low grade ores (1 ppm, or less).

The benefits of this soil washing technique include (1) on-site cleanup, (2) conservation of repository space, and (3) elimination/reduction of long-term costs for monitoring, isolation, and habitat protection. In this way a permanent solution to the soil contamination problem is obtained rather than a relocation of the soil with a resultant increase in volume and expense for future care.

As of this writing, no approved regulatory cleanup level has been established for the Fernald soil. However, the maximum permissible level for contamination from uranium mill tailings established by the Nuclear Regulatory Commission (NRC) is $35 \mathrm{pCi} / \mathrm{g}$. The same screening level was adopted by the Soil Decontamination Task Group of the USID. This is equivalent to a uranium concentration of $52 \mathrm{mg} / \mathrm{kg}$ of soil, based on the distribution of uranium isotopes in naturally occurring uranium. 


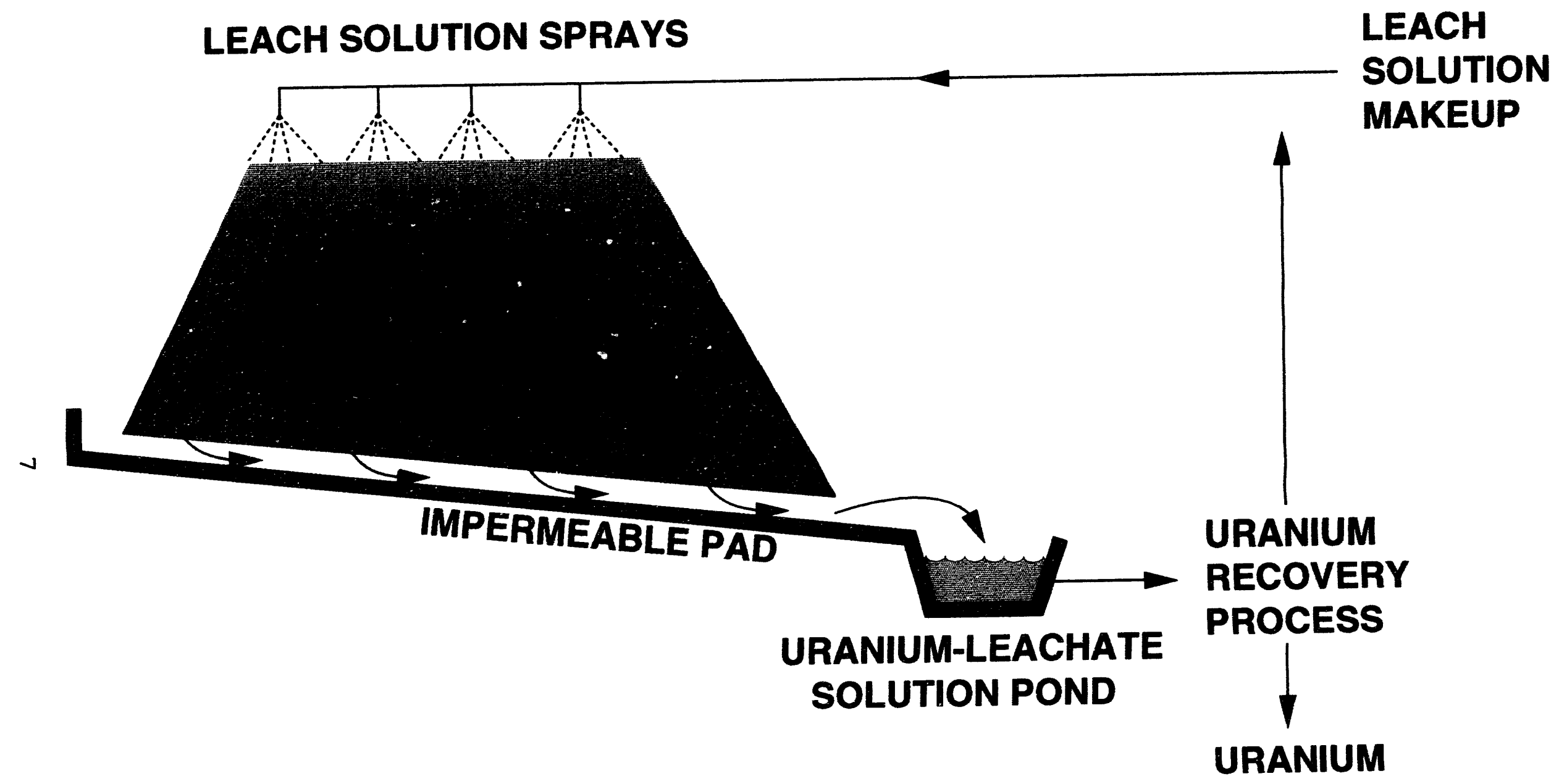

Figure 1 Field-Scale Heap Leach System. 


\section{B. Objectives}

The objective of this research is to develop heap leach technology for uranium removal from soil so that it can be used on a large scale at the FEMP site. Secondary objectives include having sufficient data to allow comparison with other soil washing techniques. The parameters affecting the process include (a) efficiency of removal, (b) soil degradation, (c) unwanted removal of other constituents, (d) cost, (e) recycling characteristics, (f) simplicity, and (g) size of secondary waste streams. This study, to date, mainly deals with the efficiency of removal, although the other parameters are briefly mentioned.

\section{Theory of Heap Leach}

Leaching of uranium ore is accomplished by crushing the host rock and leaching it with either a strongly acidic or strongly alkaline solution, see Fig. 1. Uranium can then be recovered from the leachate using either solvent extraction or ion exchange processes. Merritt (Merrit, 1971) prepared a comprehensive discussion of the technology that included flow diagrams of most of the major uranium mills in the U.S.

In a geologic setting, under reducing conditions, uranium is present as insoluble U(IV) with typical minerals be ing uraninite $\left(\mathrm{UO}_{2}\right)$, coffinite $\left(\mathrm{USiO}_{4}\right)$, and others (Brookins, 1977) . Under oxidizing conditions, $U(V I)$ is stable and usually is present as the uranyl moiety $\left(\mathrm{UO}_{2}{ }^{2+}\right)$ in both solids and solution. Uranyl forms strong aqueous complexes with carbonate, sulfate, chloride, and other anions. The objective of the milling process is to change the solution chemistry in the crushed ore from reducing conditions near neutral $\mathrm{pH}$ where uranium is insoluble, to oxidizing conditions at either low $\mathrm{pH}$ where aqueous $\mathrm{UO}_{2}{ }^{2+}$ is stable, or at high $\mathrm{pH}$ where the anionic uranyl tri-carbonate complex $\left(\mathrm{UO}_{2}\left(\mathrm{CO}_{3}\right) 3^{4-}\right)$ is dominant.

At many uranium-contaminated sites, the major form of uranium as a soil contaminant is in the U(VI) oxidation state, specifically often in the form of schoepite, $\mathrm{UO}_{2}(\mathrm{OH})_{2} \mathrm{H}_{2} \mathrm{O}$ (or $\mathrm{UO}_{3} .2 \mathrm{H}_{2} \mathrm{O}$ ). (Ebinger, 1994) This is in contrast to the uranium being an integral part of the geology. This is consistent with the knowledge that much of the contamination at FEMP originated as small uranium particles from exhaust stacks in the form of $\mathrm{UF}_{4}$ and $\mathrm{U}_{3} \mathrm{O}_{8}$, which oxidize in the atmosphere. (Radiological Assessments Corporation, 1993

\section{Approach}

For a simulated heap leach approach, the soils, which were received from the FEMP center, were placed in laboratory-scale leach columns. A solution of the reagent that was expected to solubilize the uranium (in this case, an equimolar mixture of carbonate/bicarbonate) was dripped into the top of the column. Uranium analyses were performed on the soil both before and after leaching. Uranium analyses were also performed on the leachate (the solution emerging from the bottom of the column). A diagram of the system is shown in Fig. 2. 


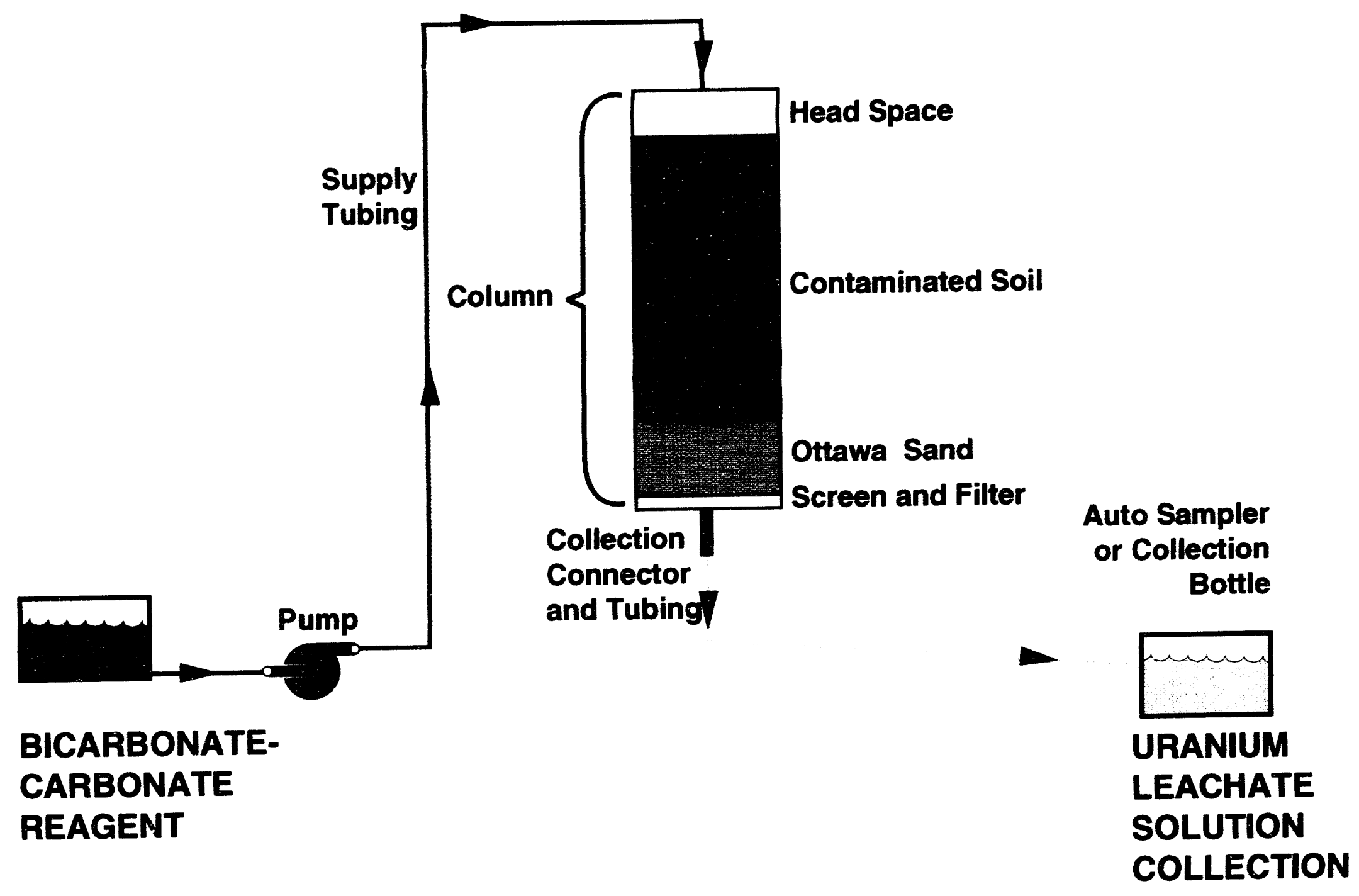

Figure 2. Flow Diagram of Column Study. 


\section{EXPERIMENTAL METHODS AND MATERIALS}

\section{A. Soil (i) Introduction}

Our initial column experiments were conducted on homogenized soil samples that were prepared in large batches at FEMP for the Treatability Subtask Group of the USID. All investigators in this Subtask Group (i.e., at Oak Ridge, Los Alamos, Savannah River, and Argonne National Laboratories) used soil samples from the same batch insuring test results that would be comparable. Later experiments at Los Alamos were conducted on heterogeneous soil samples.

We have received three different batches of soil from the FEMP site (with initial uranium concentrations of $\sim 540$ to $\sim 640 \mathrm{mg} / \mathrm{kg}$ of soil) with which to conduct heap leach experiments:

1. The first batch of soil, was taken from an area near the Plant 1 Storage Pad Area, designated SP4, see Fig. 3. The storage pad area is thought to be contaminated with uranium product spills ( S.Y. Lee, January 1992). Activities that were conducted at Plant 1 and the Storage Pad Area include shipping, receiving, milling and classifying isotopic composition of uranium materials, sampling and analysis of incoming materials, and storage of materials awaiting off-site shipment. Throughout this document this soil is referred to as SP4.

2. The second batch of soil was taken from an area adjacent to the Incinerator Area, designated SP9, see Fig. 4. It was received from FEMP in 1993. SP9 is located a few hundred yards east of the main Fernald production area. The Incinerator Area of FEMP (Lee, January 1992) was chosen in order to investigate airborne dust contamination. In this case, the airborne contamination came from both the incineration process and the nearby milling and machining operations. Throughout this report this soil is referred to as SP9(93).

3. The third batch of soil was taken from the same area as the second batch and was received in January 1994. This is being used for scale up experiments since the previous batches of soil had been exhausted. Throughout this report this soil is referred to as SP9(94). 


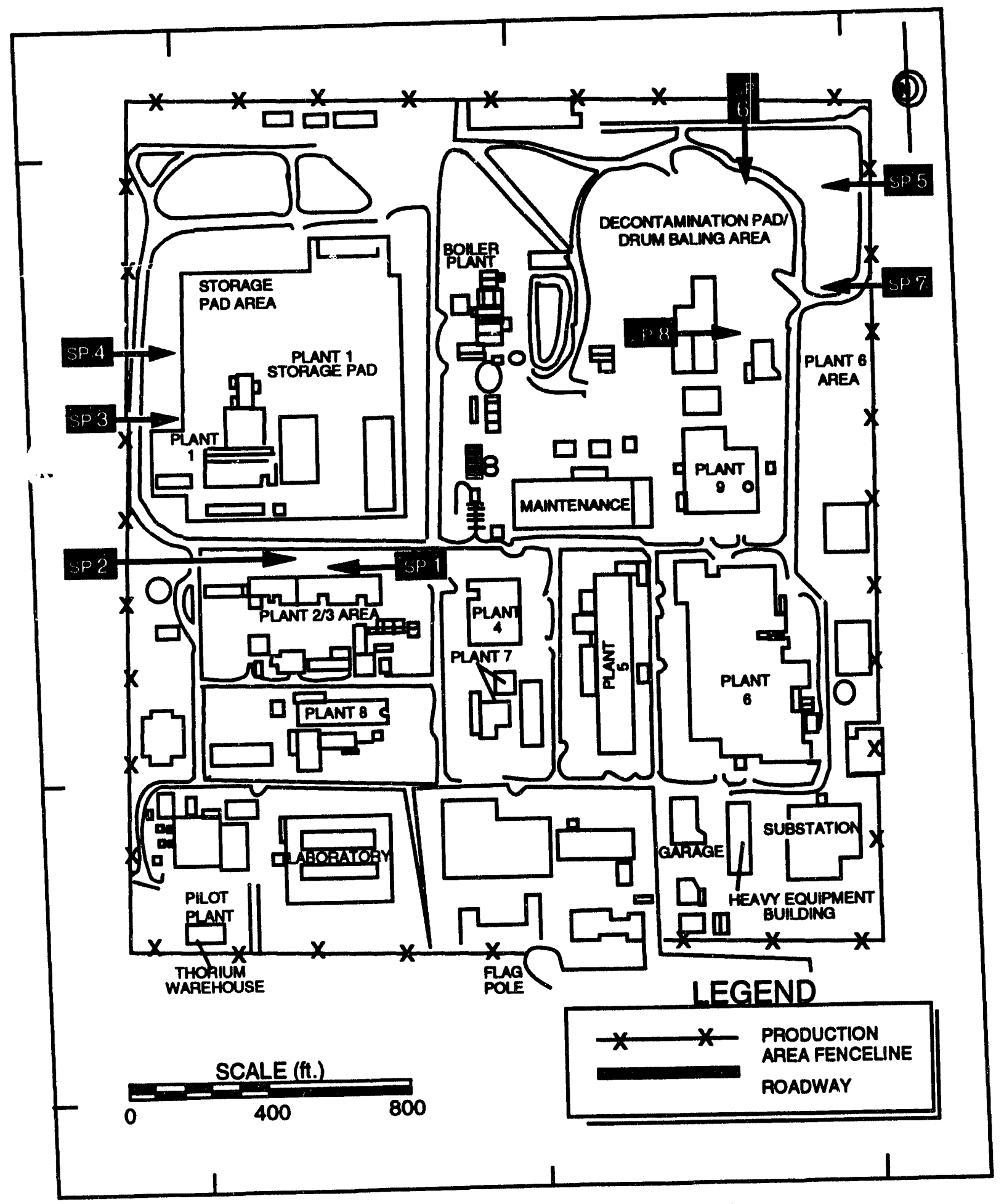

Figure 3. Sample Sites in Production Area 


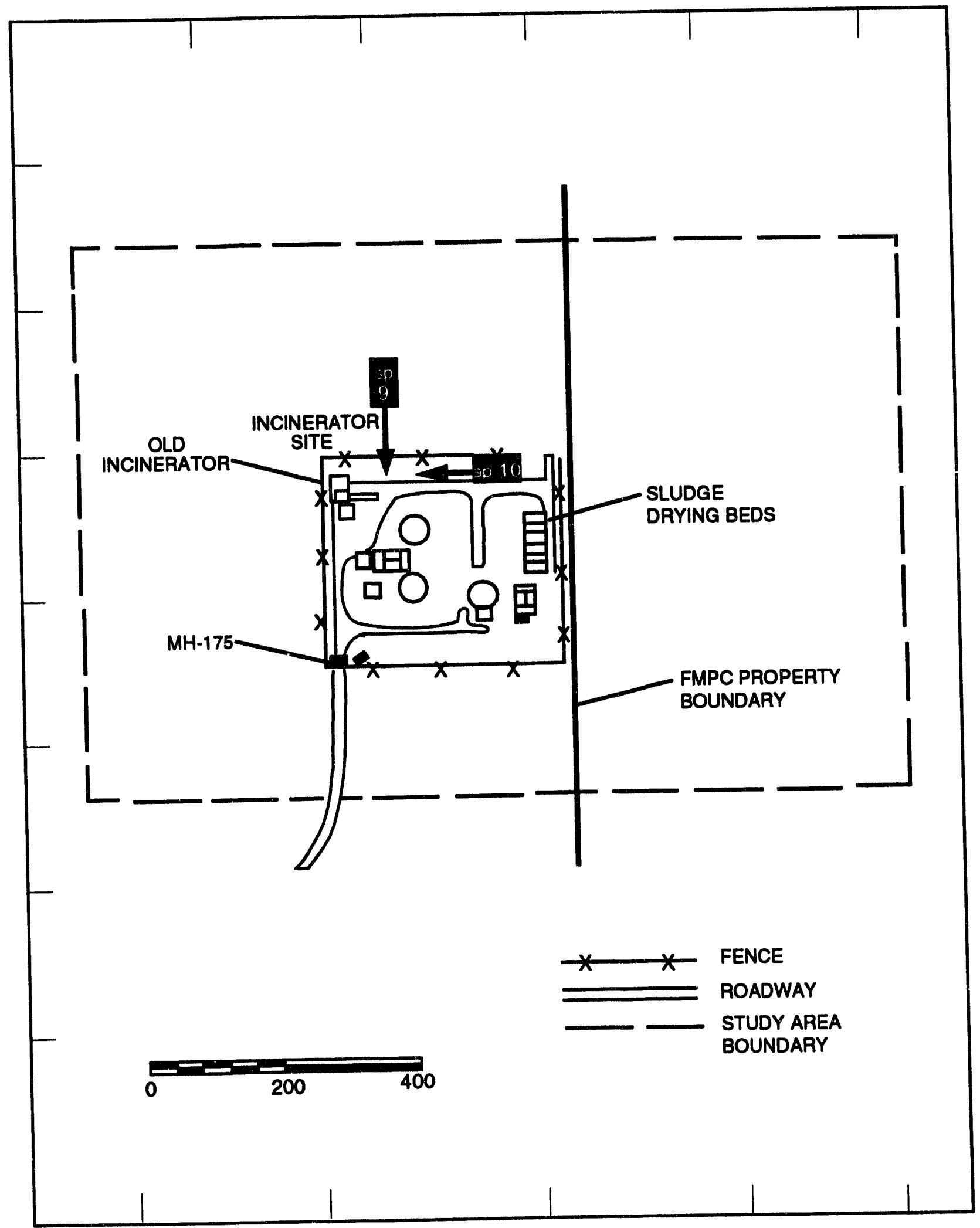

Figure 4. Sample Sites near Incinerator Area 


\section{A. (ii) Characterization}

The single most significant finding from the speciation characterization work thus far is the prevalence of the hexavalent oxidation state in the uranium-contaminated soils. Based on $\mathrm{x}$-ray absorption spectroscopy, the uranium in all samples examined thus far exists principally (80-90\%) in the hexavalent oxidation states (USID August, 1992).

Based on the mineralogical analyses and scanning electron microscopy of ten different samples from five sites at FEMP, the uranium phases are found to be similar throughout the site, although the distribution and size of the particulates vary. Uranium-bearing phases identified by various methods [e.g., analytical electron microscopy (AEM), selected-area electron diffraction (SAED)] include: uranium silicates, uranium phosphates, uranium oxides and hydroxides, calcium uranium oxide, and uranium contained within a calcium fluorite phase. Results suggest that the majority of these phases contain uranium in the (VI) oxidation state, however small $(<10 \mu \mathrm{m})$ particles of uranium (IV) phases have also been identified, including uranium silicide ( $\mathrm{USi}_{2-\mathrm{x}}$ ) and uranium oxide $\left(\mathrm{UO}_{2}\right)$. Even though these phases have all been identified, these results give no information as to the relative abundance of the different phases.

\section{SP4 Soil}

This soil is thought to be contaminated mostly by uranium spill products. More than $80 \%$ of the uranium is associated with the sand and silt fractions. These fractions make up about 74\% of the soil. Three major phases were found; a calcium phase, an iron oxide phase and uranium oxide particles. In addition, a uranium phosphate phase was identified.

\section{SP9 Soil}

Since this site was chosen in order to study airborne emissions, the major primary contaminants are $\mathrm{U}_{3} \mathrm{O}_{8}, \mathrm{UF}_{4}$, (the forms of uranium released from the stacks), and weathered products of these primary contaminants. Uranium oxide $\left(\mathrm{UO}_{2}\right)$ particles were detected in the soil samples. A major phase found was a uranium phosphate phase, identified by SAED as an autunite $\left[\mathrm{Ca}\left(\mathrm{UO}_{2}\right)_{2}\left(\mathrm{PO}_{4}\right)_{2}{ }^{\circ} \mathrm{xH}_{2} \mathrm{O}\right]$. The majority of the autunite was present as distinct particles. In cases, however, autunite appeared to be connected to uranium oxide, suggesting that it was an alteration product of primary $\mathrm{UO}_{2}$. Autunites, as well as gummite $\left(\mathrm{UO}_{3} \cdot \mathrm{H}_{2} \mathrm{O}\right)$ and uranyl silicates, are well-known alteration products of uraninite $\mathrm{UO}_{2}$ (cr) (R.J. Finch,1992). Thus, by inference, $\mathrm{UO}_{2}$ in the Fernald soils near the incinerator may have undergone weathering, accounting in part for the above described phases being observed in the vicinity of the incinerator.

In general, the surface soil in the SP9 area consists of $13 \%$ gravel, $21 \%$ sand, 53\% silt, and $13 \%$ clay. Although in the past the soil was mixed with limestone gravel, the texture of the SP9 soil was similar to other less disturbed soils inside the plant. (Lee, January 1992) 


\section{A (iii). Soil Preparation}

The first two batches of soil [i.e., SP4 and SP9(93)] were not "as excavated". Before the samples were shipped, the soils were tumbled in a mixer with just sufficient water to control dust emissions. During the tumbling process, the clays and silts were unintentionally rolled up around the coarser soil particles to form small agglomerates (one to two $\mathrm{cm}$ in diameter). This soil is referred to as Homogenized soil (although this description is not strictly true).

The third batch of soil is referred to as Heterogeneous soil. This soil was "as excavated" that is, not treated before shipment to Los Alamos. It contains small amounts of organic matter including sticks, grass, etc.

In none of the three soils [(i.e., SP4, SP9(93), and SP9(94)] can the uranium contamination, or the soil structure itself, be considered homogeneous. It was agreed early in the testing that representative samples would be difficult to obtain without crushing and blending all of the soil inventory first. This was not desirable because it would change the physical characteristics of the soil.

The soil was not separated into its size fractions (i.e., gravel, sand, silt, and clay) before it was placed into the columns, although some pretreatment was carried out. See Table 1 . (Results Section)

After arrival at LANL, some of the SP4 and SP9(93) soil was further agglomerated with a cement additive of $\approx 0.6 \% \mathrm{CaO}$ by weight. This soil is termed Agglomerated with Cement soil. Column experiments carried out in 1993 included both homogenized soil and agglomerated with cement soil. Agglomeration is discussed later.

The last batch of soil [i.e., SP9(94)] received, was tumbled with water to form agglomerates prior to being placed into the leach columns. This soil is referred to as

Agglomerated with Water soil. Initially, this was done by rolling the soil in polyethylene bottles but later this process was carried out in a laboratory-scale agglomerator. 


\section{B. Laboratory Column Leach System}

A laboratory-scale column testing system was designed and built to simulate a field-scale heap leach operation, see Fig. 1. The Plexiglas columns were approximately $9 \mathrm{~cm}$ I.D. and varied in height from $15 \mathrm{~cm}(-6 \mathrm{in})$ to $150 \mathrm{~cm}(\sim 60 \mathrm{in})$. Initially, the columns were intentionally small but, after the early successes, scale up columns are now being used. These are discussed later. Leaching solutions were prepared by dissolving appropriate amounts of (ACS reagent-grade) $\mathrm{Na}_{2} \mathrm{CO}_{3}$ and $\mathrm{NaHCO}_{3}$ in double-deionized ("Milli-Q") water in large polyethylene dewars. All column experiments were conducted at room temperature and pressure under non saturated, aerobic conditions.

Between 1 and $10 \mathrm{~kg}$ of soil were used in each experiment. The soil was not separated into its size fractions or otherwise treated (except for use of agglomerated soils in certain experiments) before being introduced into the leach columns. The soil was placed into the columns from the open top and held in the column at the bottom with a cellulite filter over a wire-mesh screen. The filter was covered with a layer of filtering (Ottawa) sand approximately $3 \mathrm{~cm}$ thick (Fig. 5). No attempt was made to compact the soil.

The carbonate/bicarbonate leaching reagent was introduced at the top of the column. Continuous uniform flow was achieved by use of a peristaltic pump to transfer leaching reagent from the reagent dewars through Tygon tubing to the top of the column. The reagent flowed downward by force of gravity. The loading rate of the reagent was typically of the order of $0.01 \mathrm{ml} / \mathrm{cm}^{2} / \mathrm{min}$ (or, $\sim 1$ liter $/ 24 \mathrm{hr}$ period over an area $8.5 \mathrm{~cm}$ in diameter). For convenience purposes, this flow rate was named 1X. This flow rate was selected (1) to mimic flow rates typically used in heap leach of precious metals, and (2) to keep the ratio of liquid-to-solid as low as practical. This would minimize the volume of the waste stream. Other tests were conducted at $\mathbf{0 . 3 X}$ and $2 \mathrm{X}$.

The conditions in the column can be described as unsaturated. Following initial breakthrough of the leachate, which occurred within several hours, the leachate output flow rate approximated to input flow rate. Flowing liquid was not visible through the walls of the column; however, the soil became noticeably wetter during the course of the experiment. Often the soil compacted slightly during the first six hours of the experiments. This was shown by a decrease in the height of the soil column by as much as $20 \%$ in the columns. 


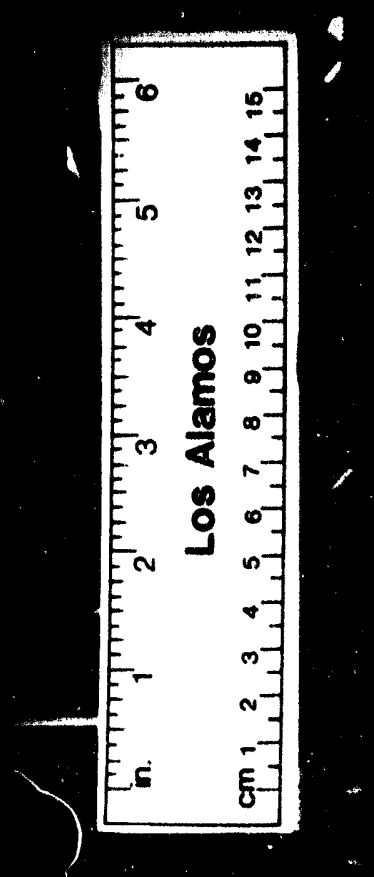

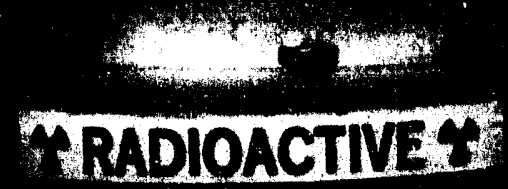

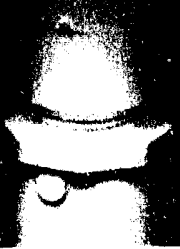

Figure 5. $15 \mathrm{Cm}$ Column Experiment 
The leachate was collected from the bottom of the column for subsequent analysis. No attempt has been made yet to regenerate the reagent and recirculate the carbonate/bicarbonate leach solution back to the inlet of the column (this is done in the mining industry as a normal course of action). During the first 72 hours of leaching, leachate samples were taken at regular intervals $(\sim 1 / 2$ to $1 \mathrm{hr})$ using a fraction collector. After about three 24-hr days, the samples were collected in larger bottles that were manually changed every 1 to 2 days. Leaching was continued 7 days/week. The high frequency of sampling in early experiments enabled us to determine the uranium release as a function of time. In later experiments sample collection times were longer.

The volume, $\mathrm{pH}$, and uranium concentration were measured for the leachate fractions. Uranium analyses were performed on a Varian Liberty 200 Inductively Coupled Plasma (ICP) spectrophotometer. Triplicate measurements at two different uranium absorbance lines were taken for each sample. Uranium concentration of the leachate was determined by comparison with concentration-intensity curves for calibration standards at regular intervals. Calibration standards were prepared by diluting $10000 \mathrm{ppm}$ stock uranium in a bicarbonate/carbonate solution of an appropriate concentration to minimize matrix effects. The total quantity of uranium in each sample was then calculated using the concentration of uranium and volume of the collected leachate sample. The total quantities of uranium (in each successive sample) were then integrated to calculate the total amount of uranium removed from the soil, as a function of time.

At the conclusion of leaching, the column setup was dismantled and samples of the leached soil were recovered for uranium and other elements. The samples were taken at different radial and vertical locations (1) to establish the distribution of the residual (remaining) uranium and (2) to determine if any column-wall effects existed. The uranium content of the leached and starting soils was determined by delayed neutron counting and/or by neutron activation analysis. One set of analyses was performed for elements (other than uranium) that may have been simultaneously leached from the soil. Selected samples of the leached soil have been given to the members of the Characterization Subtask Group of the USID for complete characterization of the soils.

Slight differences in procedure were used for the SP4 soil, as noted below:

(i) $\mathrm{K}_{2} \mathrm{CO}_{3}$ and $\mathrm{KHCO}_{3}$ were used in place of $\mathrm{Na}_{2} \mathrm{CO}_{3}$ and $\mathrm{NaHCO}_{3}$.

(ii) All samples were collected manually.

(iii) Uranium analyses for the leachate were determined using a Direct Current Plasma Spectrometer. Fifteen measurements at a single uranium absorbance line were taken for each sample.

Because of the success with leaching the $15 \mathrm{~cm}$ tall columns, we have extended this study to include $30 \mathrm{~cm}, 75 \mathrm{~cm}$, and $150 \mathrm{~cm}$ tall columns thus far using the $S P 9(94)$ soil. The $30 \mathrm{~cm}$ column was constructed by placing $15 \mathrm{~cm}$ units on top of each other, whereas the $75 \mathrm{~cm}$ column is as shown in Fig. 6. Apart from being taller, these columns were treated in the same way as has been previously described. 


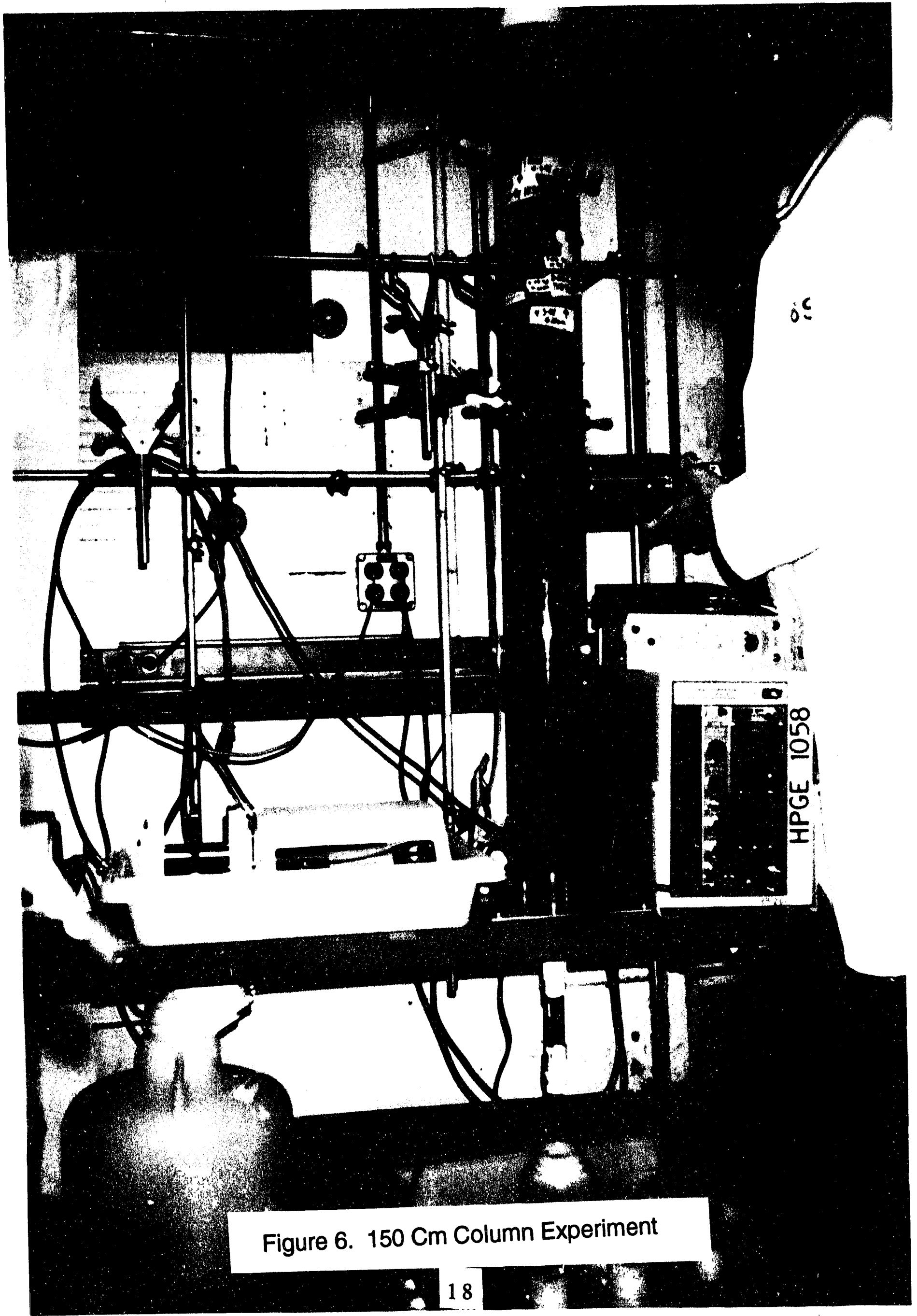




\section{RESULTS}

\section{A. Carbonate/Bicarbonate Leach Tests}

Table 1 lists the all the column experiments performed. Selected results of the uranium concentration in the leachate are shown in Fig. 7-10 while Fig. 11 shows the variation in $\mathrm{pH}$ as a function of time. Complete lists of all the results are presented in Appendix A. Breakthrough times for the initial leachate were approximately proportional to the height of the columns. Leach time was not proportional to the height of the columns.

Table 2 lists the ions and concentrations that were found in the leachate. These have been used in modeling calculations, which are fully reported in Appendix B(i).

The results of the characterization of the soils after uranium removal and some of the neutron activation analysis measurements on the soil have not yet been received. The neutron activation analyses that have been received show that uranium results are 5-7 \% higher than analysis by wet digestion and ICP mass spectrometry.

Electrical energy consumption during lab scale testing was negligible. As an example the only electrical energy used to leach $1 \mathrm{~kg}$ of soil was enough to lift 1 to $2 \mathrm{~L}$ of leached solution 1 ' vertically every 24 hours. 
TABLE 1

SUMMARY OF COLUMN EXPERIMENTS

PERFORMED IN FY 93 \& FY 94

\begin{tabular}{|c|c|c|c|c|c|c|c|}
\hline & $\begin{array}{l}\text { Column } \\
\text { Number }\end{array}$ & $\mathbf{M}$ & $\begin{array}{c}\text { Carbonate } \\
\text { Salt }\end{array}$ & $\begin{array}{l}\text { Flow } \\
\text { Rate }\end{array}$ & $\begin{array}{l}\text { Mass } \\
\text { (kg) }\end{array}$ & Soll & Proparation \\
\hline 1 & C021193 & 0.1 & \multicolumn{5}{|c|}{ salt nato $(\mathrm{kg})$} \\
\hline 2 & $\mathrm{C} 052593$ & 0.1 & $\begin{array}{l}\text { Polassium } \\
\text { Sodium }\end{array}$ & $\begin{array}{l}1 X \\
1 X\end{array}$ & 1 & SP9(93) & $\begin{array}{l}\text { Homogenized } \\
\text { Homogenized }\end{array}$ \\
\hline 3 & C100193 & 0.1 & Sodium & $1 x$ & 1 & SP9(93) & Homogenized, Agglomerated w/ cement \\
\hline 4 & $C_{100293}$ & 0.1 & Sodium & $1 x$ & 1 & SP9(93) & Homogenized \\
\hline 5 & C092893 & 0.1 & Sodium & $2 x$ & 1 & SP9(93) & Homogenized \\
\hline 6 & $\mathrm{CO60493}$ & 0.20 & Sodium & $1 x$ & 1 & SP9(93) & Homogenized \\
\hline 7 & $\mathrm{C} 082693$ & 0.25 & Sodium & $1 x$ & 1 & SP9(93) & Homogenized \\
\hline 8 & $\mathrm{C} 082793$ & 0.25 & Sodium & $1 x$ & 1 & SP9(93) & Homogenized \\
\hline 9 & C060393 & 0.5 & Sodium & $1 X$ & 1 & SPg(93) & Homogenized \\
\hline 10 & $\mathrm{CO81693}$ & 0.5 & Sodium & $1 x$ & 1 & SP9(93) & Homogenized \\
\hline 11 & $\mathrm{C} 081793$ & 0.5 & Sodium & $1 X$ & 1 & SP9(93) & Homogenized, Agglomerated w/ cement \\
\hline 12 & C091393 & 0.5 & Sodium & $2 X$ & 1 & SPg(93) & Homogenized \\
\hline 13 & $\mathrm{C} 091493$ & 0.5 & Sodium & $2 \mathrm{X}$ & 1 & SP9(93) & Homogenized \\
\hline \multicolumn{8}{|c|}{ apo(01) Hatam } \\
\hline 1 & $\mathrm{C} 012694$ & 0.5 & Sodium & $1 x$ & 1 & SP9(94) & Heterogeneous, \\
\hline 2 & C012794 & 0.5 & Sodium & $1 x$ & 1 & SP9(94) & Heterogeneous, Agglomerated with water \\
\hline 3 & $\mathrm{CO20494}$ & 0.5 & Sodium & $0.3 x$ & 1 & SP9(94) & Heterogeneous, Agglomerated with water \\
\hline 4 & C020594 & 0.5 & Sodium & $0.3 x$ & 1 & SP9(94) & Heterogeneous, Agglomerated with water \\
\hline 5 & $\mathrm{C} 012894$ & 0.5 & Sodium & $1 x$ & 3 & SP9(94) & Heterogeneous, Agglomerated with water \\
\hline 6 & $\mathrm{C} 030894$ & 0.5 & Sodium & $1 x$ & 3 & SP9(94) & Heterogeneous, Agglomerated with water \\
\hline 7 & $\mathrm{C} 022394$ & 0.5 & Sodium & $1 x$ & 10 & SP9(94) & Heterogeneous, Agglomerated with water \\
\hline 8 & $\mathrm{C} 032594$ & 0.5 & Sodium & $1 X$ & 10 & SP9(94) & Heterogeneous, Agglomerated with water \\
\hline
\end{tabular}




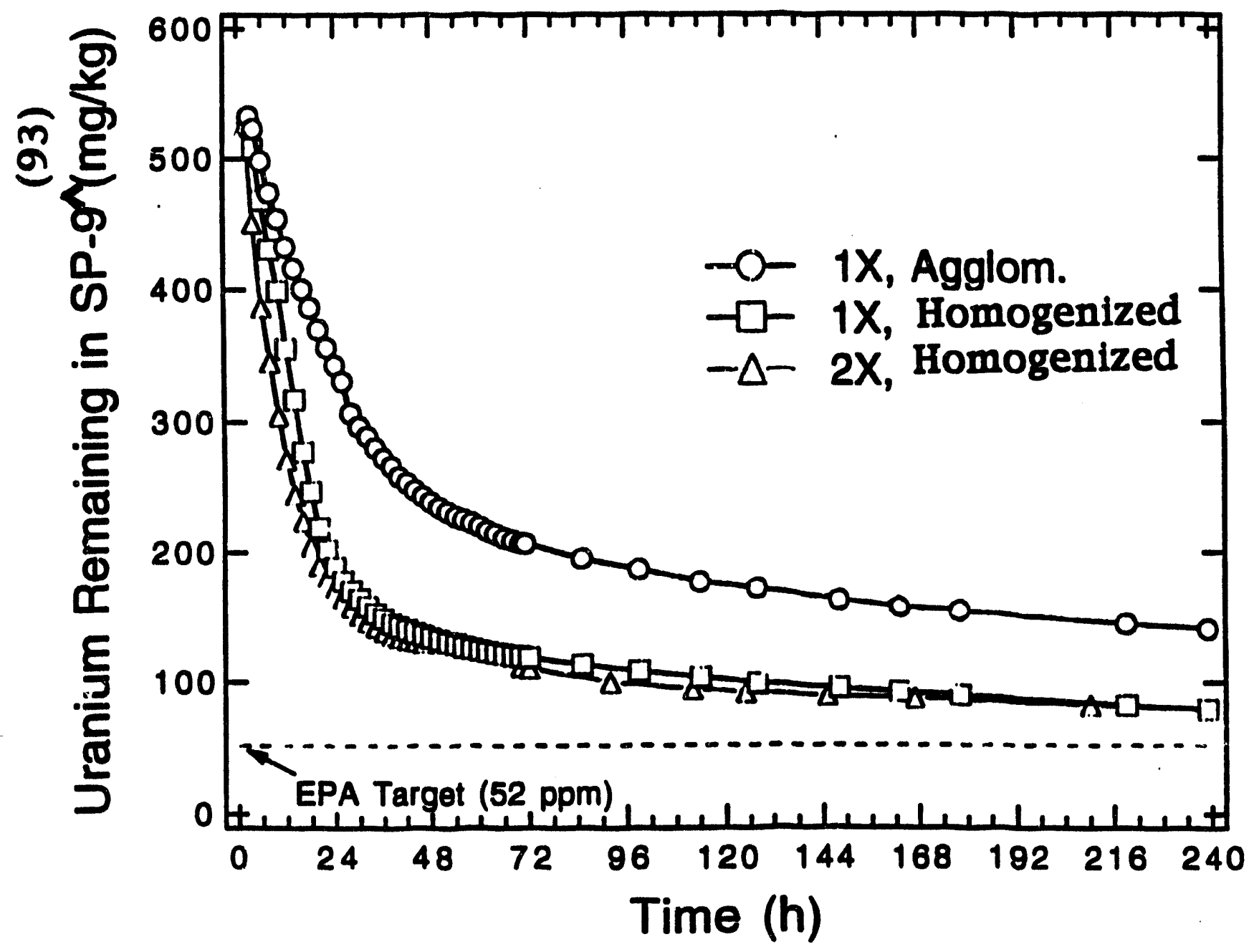

Figure 7. Uranium Removal as a Function of Time. Results Using SP9(93) Soil, $\mathrm{X}=$ Loading Rate $(\mathrm{X})=0.01 \mathrm{ml} / \mathrm{Cm}^{2} / \mathrm{min}$. 


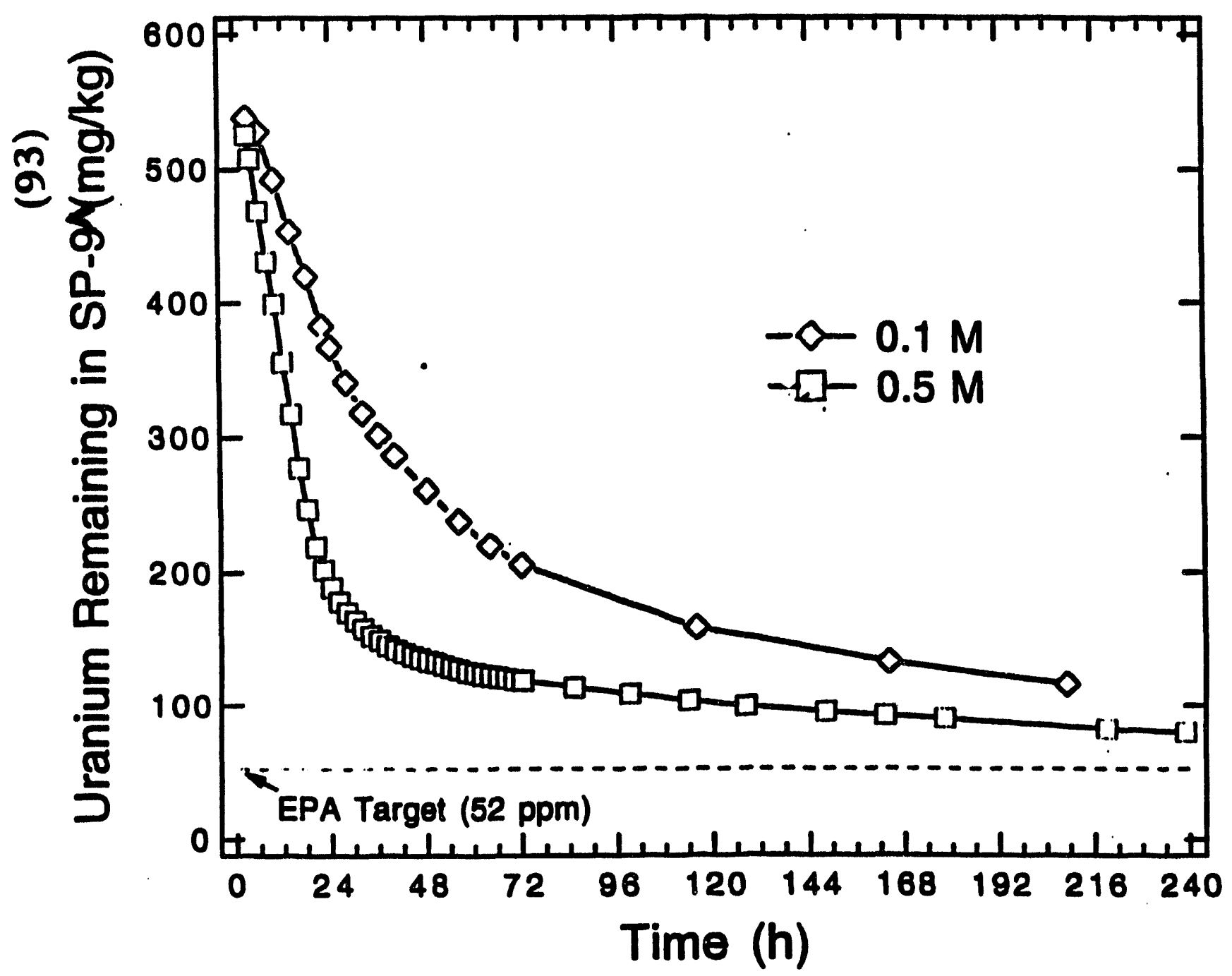

Figure 8. Effect of Variation of Concentration of Sodium Carbonate/Sodium Bicarbonate Solution. Results Using SP9(93) Soil, $X=$ Loading Rate $(X)=0.01 \mathrm{ml} / \mathrm{Cm}^{2} / \mathrm{min}$. 


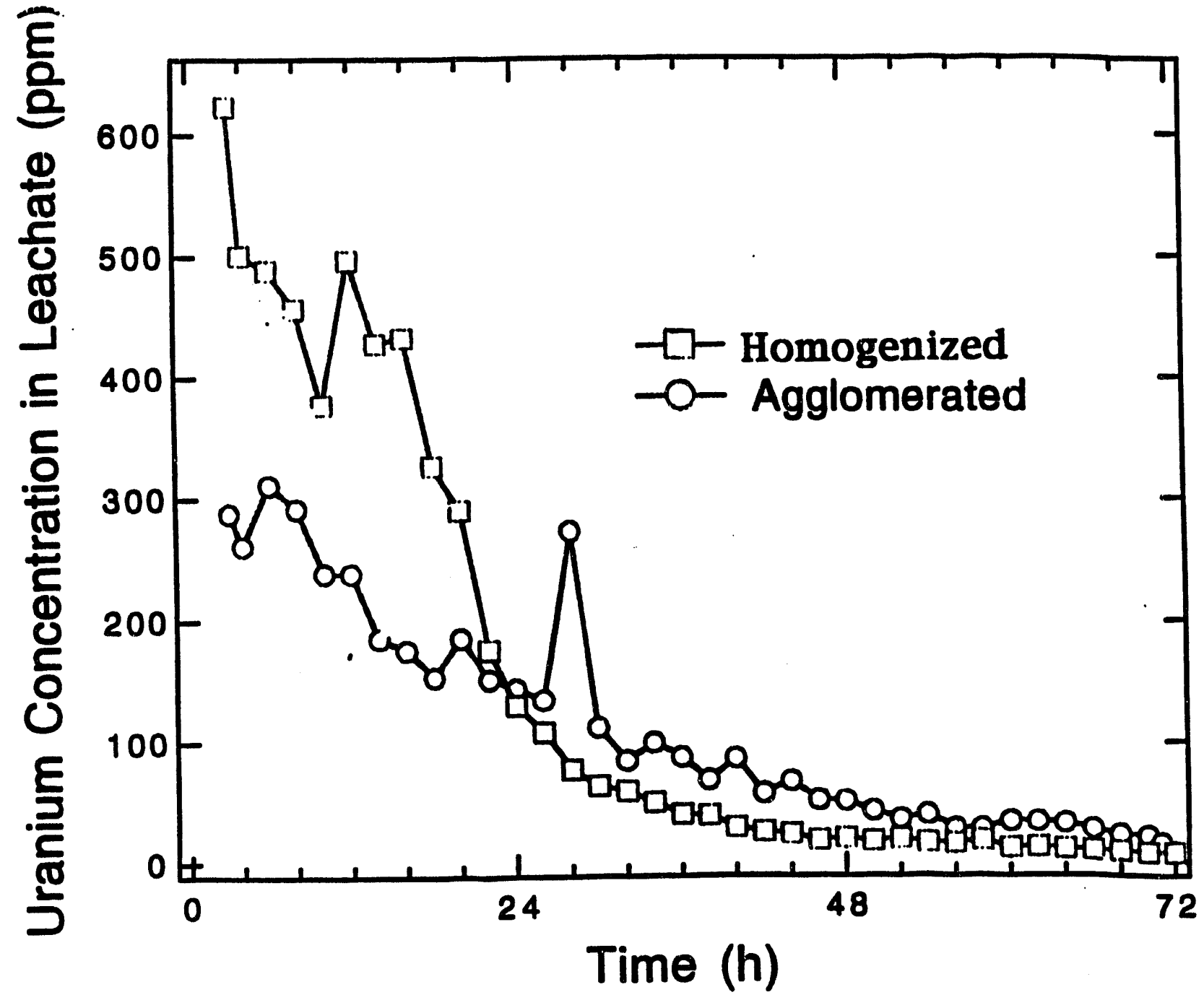

Figure 9.

ppm of Uranium in Leachate, Using SP9(93) Soil, $\mathrm{X}=$ Loading Rate $(\mathrm{X})=0.01 \mathrm{ml} / \mathrm{Cm}^{2} / \mathrm{min}$. $\left(0.5 \mathrm{M} \mathrm{Na}_{2} \mathrm{C} \mathrm{O}_{3} / \mathrm{NaHCO}_{3}\right)$ 
mg U / L leachate

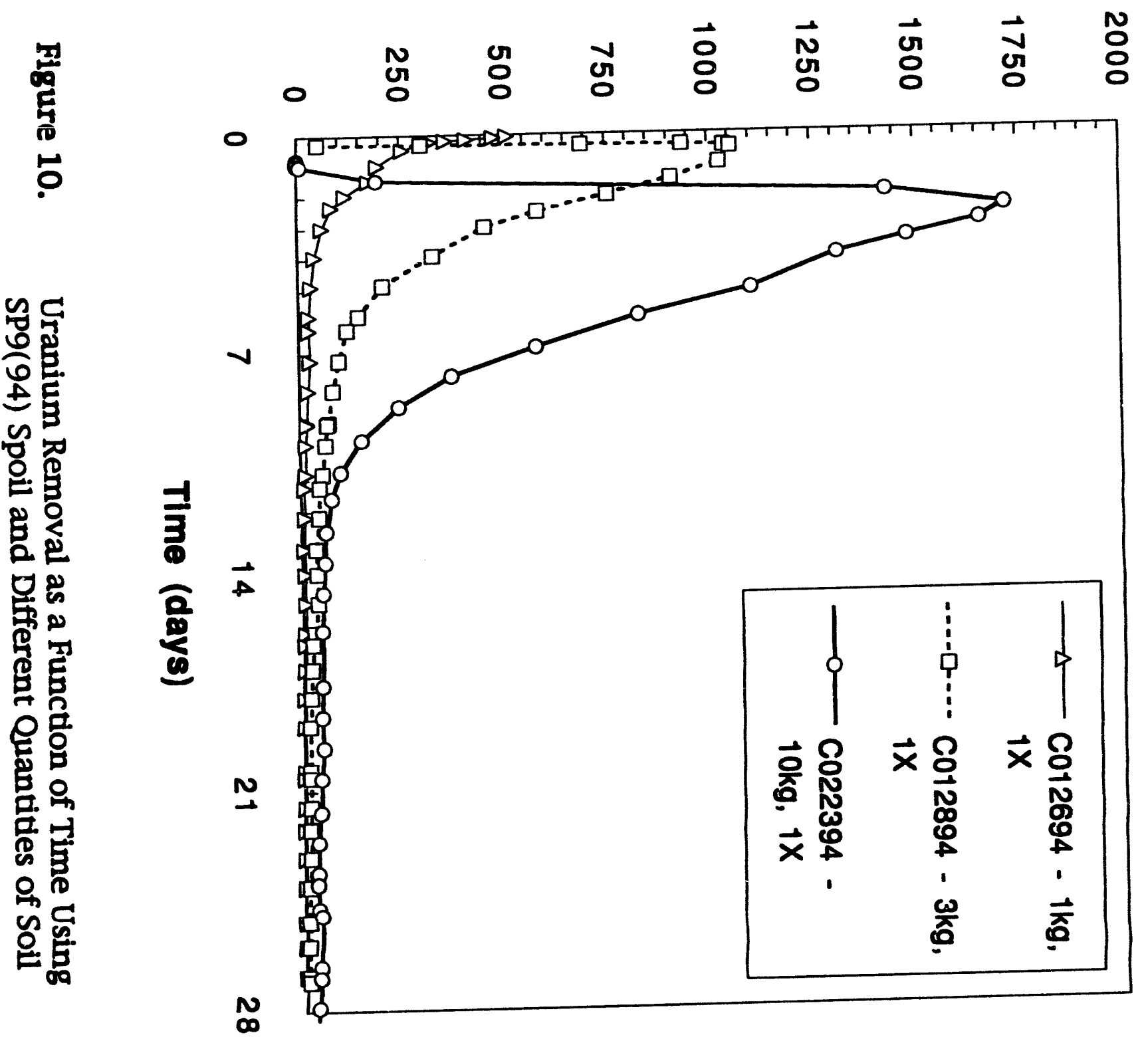




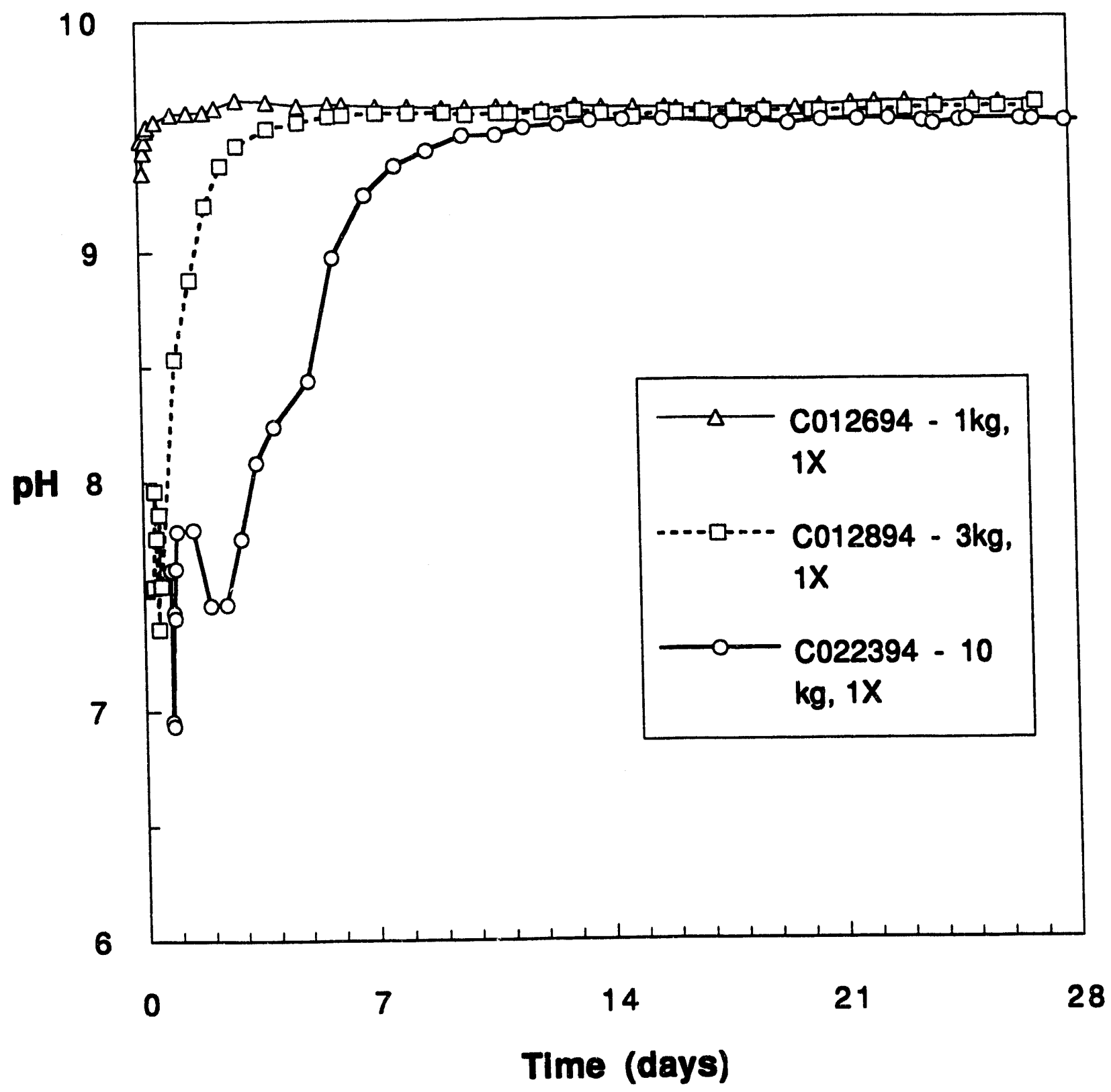

Figure 11. $\quad \mathrm{pH}$ as a Function of Time Using

Sp9(94) Soil During Uranium Removal 
Table 2. Solution Chemistry of Column Effluents Using SP9(93) Soil Fernald, Ohio.

(All values in ppm except where noted, pHI values in standand units)

\begin{tabular}{|c|c|c|c|c|c|c|c|c|c|c|}
\hline $\begin{array}{l}\text { Cumulative } \\
\text { Enfuent } \\
\text { Vol (L) }\end{array}$ & $p e l$ & pH & $\mathbf{C a}$ & $\mathbf{A}$ & $\mathbf{U}$ & $\mathbf{F e}$ & M8 & $\mathbf{K}$ & $\mathrm{H}_{4} \mathrm{SOO}_{4}$ & $\begin{array}{l}\text { Allealinity } \\
\text { (mg/L CaCO})\end{array}$ \\
\hline 0.027 & 1.76 & 9.58 & 20.27 & 0.50 & 289 & 3.11 & 20.37 & 720 & 4060 & 25,300 \\
\hline 0225 & 1.47 & 9.64 & 2259 & 0.83 & 292 & 8.63 & 18.06 & 6.10 & 3780 & 26,900 \\
\hline 0.545 & 1.41 & 9.68 & 33.80 & 0.70 & 176 & 866 & 17.90 & 630 & 2060 & 32,600 \\
\hline 1.105 & 1.41 & 9.70 & 31.63 & 0.90 & 112 & 7.80 & 13.21 & 240 & 20330 & 36,600 \\
\hline 2.665 & 1.51 & 9.73 & 19.97 & 0.59 & $21 . \pi$ & 437 & 9.48 & 250 & 2530 & 37,300 \\
\hline 3.630 & 1.61 & 9.73 & $12 \pi$ & 0.59 & 10.00 & $2 \pi$ & 634 & 0.30 & 2490 & 38,500 \\
\hline 4.720 & 1.64 & 9.73 & 9.90 & 0.51 & 7.00 & 233 & 6.13 & 080 & 2280 & 36,200 \\
\hline 5.065 & 1.64 & 9.73 & 1050 & 049 & 5.00 & 237 & 6.53 & 600 & 2430 & 38,100 \\
\hline
\end{tabular}

1. pe a negative log of the electron activity. pe is culculated from strming and tathing the avenge of $\mathrm{H}_{2} \mathrm{O}_{2} \mathrm{O}_{2}$ and $\mathrm{Fe}^{2+} / \mathrm{Fe}(\mathrm{OH})_{3}$ redox couples. 


\section{B . Soil Characteristics after Leach.}

Soils in the columns were used without removing the larger particles or plant fragments. The homogenized material consists primarily of granular soil aggregates. Kneff (Kneff,1992) reports that 83 (range 72 to 89)\% and 70 (range 50 to 82)\% of the particles of the SP4 and SP9 soils, respectively, were greater than $2 \mathrm{~mm}$ in size. However, these large particles are primarily aggregates of smaller particles, as suggested by the markedly different size distribution measured after wet sieving these homogenized soils. Specifically Francis (Francis, 1992) reports that $>93 \%$ of the wet sieved soils were less than $2 \mathrm{~mm}$. However, the wet -sieved SP9 soil still contained a fraction of aggregates within the $<2 \mathrm{~mm}$ fraction which are thought to form during the incineration process. The homogenized soils also have a high organic content; some organic matter was removed during the column studies resulting in a light to medium dark brown leachate after several hours of experiment. In general the leachate was darker for higher carbonate concentrations. During the course of the experiments, the soil in the columns also became noticeably more yellow which is consistent with the removal of organic matter. The homogenized soil was carefully loaded into the column, retaining the original aggregate structure. However, the texture of the soils changed during the course of the experiment. Within the first six hours, the columns compacted slightly, as shown by a 10 to $20 \%$ decrease in height. After this initial compaction, very further compaction was seen. The aggregates also appeared to become deformed and there was a slight increase in fines. The soil had to be forced from the column on completion of the experiment and separated as a single slug. After removal from the column, the soil noticeably slumped but remained intact as a block. These properties indicate that the soil lost some of its structural rigidity and became more plastic during the experiments. Furthermore, the soil became visibly wet during the course of the experiments and the final moisture content was 11/2 to 2 times greater than the starting material.

Agglomerating the homogenized soil in our laboratory with cement resulted in soil aggregates which, on average, were slightly larger than the initial material. The textural changes were slightly different and the agglomerated soil compacted much less. In addition, the agglomerated soil retained more of its structural rigidity. This is supported by the time of breakthrough ( first appearance) of the L ziviant in the agglomerated columns which was earlier than for the untreated soils indicating less retention and possibly a more direct path for fluid flow.Concerns about swelling of the clays in the soil were found not to be valid.

Because the whole purpose of this study is to be able to return the soil to its original use, i.e., supporting vegetative growth, we planted both radish and com seeds in some of the leached soil, without further treatment of the soil. All the seeds germinated. When the soil was mixed one-to-one with potting soil the seeds produced seedling plants. This shows that the soil can be usefully returned to the environment. A full description of these experiments will be reported later. 


\section{DISCUSSION}

\section{A. Leach Tests}

\section{(i) Chemical removal}

In all the column experiments so far completed, over $80 \%$ of the uranium was removed. This is true for all the parameters measured; column heights, flow rates, change in associated cation (i.e.. potassium in place of sodium) and change in molarity of lixiviant. Irrespective of the column height, most of the uranium removal was accomplished in the first ten days, (See Fig. 11). It is apparent from Fig. 10 that, when the columns become larger, ( $3 \mathrm{~kg}$ or greater), a large increase in removal is first seen prior to the regular decreases which were found in the small one $\mathrm{kg}$ column.

From the chemistry of uranium, we know that the uranium (VI) will be easily solubilized to a carbonato complex whereas the uranium (IV) will be unaffected by the presence of carbonate. The stages of solubilization have been documented by (Grenthe 1992):

$$
\begin{aligned}
& \mathrm{UO}_{2}^{2+}+\mathrm{CO}_{3}^{2-}=\mathrm{UO}_{2} \mathrm{CO}_{3}(\mathrm{aq}) \\
& \mathrm{UO}_{2}^{2+}+2 \mathrm{CO}_{3}^{2-}=\mathrm{UO}_{2}\left(\mathrm{CO}_{3}\right) 2^{2-} \\
& \mathrm{UO}_{2}^{2+}+3 \mathrm{CO}_{3}^{2-}=\mathrm{UO}_{2}\left(\mathrm{CO}_{3}\right)^{4-}
\end{aligned}
$$

It is possible that we are successfully removing all the (VI) while leaving the (IV) attached to the soil. The initial forms of contaminant are airborne $\mathrm{UF}_{4}$ and $\mathrm{U}_{3} \mathrm{O}_{8}$ forms (Radiological Assessments Corporation, 1993). These will become oxidized and weathered in the atmosphere. The oxide emitted is already $66 \%$ in the oxidized state. However we lack data as the relative amounts of $\mathrm{UF}_{4}$ and $\mathrm{U}_{3} \mathrm{O}_{8}$ was emitted. Suffice to say that some oxidation will take place, although, demonstrably, this is incomplete.

Data collected during the course of experiments included concentrations of $\mathrm{U}, \mathrm{Ca}, \mathrm{Al}, \mathrm{Fe}$, $\mathrm{Mg}, \mathrm{K}, \mathrm{Is}, \mathrm{pH}$ and alkalinity in the column effluents (e.g. Table 2), along with $\mathrm{U}, \mathrm{Fe}$ and $\mathrm{pH}$ analysis of the soils before and after leach experiments. From these data several relationships can be observed, giving rise to possible explanation of the chemical processes taking place during leach experiments.

Initially, the $\mathrm{pH}$ of the unleached soil is 6.9 . The starting $\mathrm{pH}$ of the approximately $0.5 \mathrm{M}$ sodium-carbonate-bicarbonate $\left(\mathrm{Na}_{2} \mathrm{CO}_{3}-\mathrm{NaHCO}_{3}\right)$ leach solutions $(25 \mathrm{~g} \mathrm{NaHCO} / \mathrm{L}+25$ $\mathrm{g} \mathrm{Na}_{2} \mathrm{CO}_{3} / \mathrm{L}$ ) was 9.6. In virtually all of the FY94 experiments, the $\mathrm{pH}$ of the soil at completion of the leach tests was 9.6 as well. This suggests that the natural buffering capacity of the soil was surpassed at some point during the leach process, and the carbonate-bicarbonate controlled the $\mathrm{pH}$ by the completion of each experiment.

Maximum $U$ concentration in the leachate occurs in the $10 \mathrm{~kg}$ column experiments at $\mathrm{pH} \approx 7.5, \mathrm{U} \approx 1720 \mathrm{ppm}$. Uranium concentration of the $3 \mathrm{~kg}$ experiment leachate is greatest at $\mathrm{pH} \approx 8$ with $\mathrm{U} \approx 1100 \mathrm{ppm}$. U concentration of the $10 \mathrm{~kg}$ column effluent is also about $1100 \mathrm{ppm}$ at $\mathrm{pH}=8$. Maximum $\mathrm{U}$ concentration in the $1 \mathrm{~kg}$ column occurred at $\mathrm{pH}$ $9.4, U=500 \mathrm{ppm}$. Concentration of the $3 \mathrm{~kg}$ and $10 \mathrm{~kg}$ columns were also about $500 \mathrm{ppm}$ at $\mathrm{pH} \approx 9.4$. 
$\mathrm{pH}$ analysis of leachates from all of the FY94 columns show that $U$ concentration of the leachate is greatest between $\mathrm{pH}=7.5$ and $\mathrm{pH}=9$. Above $\mathrm{pH}=9$, uranium concentrations decrease sharply by as much as two orders of magnitudes to its lowest concentrations at $\mathrm{pH}=9.6$.

Analysis of various FY94 leachate samples for $\mathrm{Fe}$ and $\mathrm{Mg}$ show moderate concentrations at pH $9\left(10^{-2} \mathrm{M}\right.$ and $10^{-3.5} \mathrm{M}$, respectively). Fe concentrations almost double between $\mathrm{pH}=9$ and $\mathrm{pH}=9.5$ to about $10^{-3.3} \mathrm{M}$. $\mathrm{Mg}$ concentrations remain steady up to $\mathrm{pH} 9.6$ where it dramatically drops two orders of magnitudes to $10^{-4} \mathrm{M}$.

This suggests that $\mathrm{pH}$ is controlling the $\mathrm{U}$ dissolution process.

Brookins (1987) shows the stability fields of $\mathrm{U}$ (Fig. 12), with $\mathrm{UO}_{2} \mathrm{CO}_{3}$ (Eq. 1) between $\mathrm{pH}=5$ and $\mathrm{pH}=6.25, \mathrm{UO}_{2}\left(\mathrm{CO}_{3}\right)_{2}{ }^{2-}$ (Eq. 2) between pHs 6.25 and 8.5 and $\mathrm{UO}_{2}\left(\mathrm{CO}_{3}\right) 3^{4-}$ at $\mathrm{pH}$ greater than 8.5. Greatest $U$ removal in SP9(94) would therefore have $U$ in the $\mathrm{UO}_{2}\left(\mathrm{CO}_{3}\right)_{2}{ }^{2-}$ phase.

$\mathrm{Mg}(\mathrm{OH})_{2}$ occupies the stability field above $\mathrm{pH}=9$ (Fig. 13). Brookins (1987) explains that at concentrations of $\mathrm{Mg}$ less than $10^{-3} \mathrm{M}, \mathrm{MgCO} 3$ will likely substitute for $\mathrm{Mg}(\mathrm{OH})_{2}$. This could well be the case in our leach solutions, and could further explain the reason that the carbonate is complexing with $\mathrm{Mg}$ and not necessarily with the $\mathrm{U}$ at those pHs.

Longmire (1994) reports that the dissolved Fe concentration may be controlled by the precipitation of $\mathrm{FeCO}_{3}$ (siderite). Precipitation of siderite is possible through reductive dissolution of $\mathrm{Fe}(\mathrm{OH})_{3}$. Fig. 14 shows $\mathrm{FeCO}_{3}$ occupying a small field between pHs 6.8 and 9.4, separating $\mathrm{Fe}{ }^{2+}$ from $\mathrm{Fe}(\mathrm{OH})_{2}$, and encroaching slightly on the $\mathrm{Fe}(\mathrm{OH}) 3$ field. This could explain the increase in Fe concentration between the pHs of 9 and 9.5. Uraninite ( $\mathrm{UO}_{2}$ ) becomes oxidized, forming schoepite $\left(\mathrm{UO}_{3} \cdot 2 \mathrm{H}_{2} \mathrm{O}\right.$ ), as $\mathrm{Fe}(\mathrm{OH})_{3}$ becomes reduced. Schoepite undergoes rapid dissolution within the alkaline $\mathrm{pH}$, carbonate rich leach solutions.

Further reduction of the collected data should provide a means by which to mathematically model the desorption and dissolution process that takes place during the heap leach process. This should further enable us to more accurately predict what the effects of scaling the process up to pilot and full size heap leach are on the carbonate-bicarbonateuranium chemistry. 


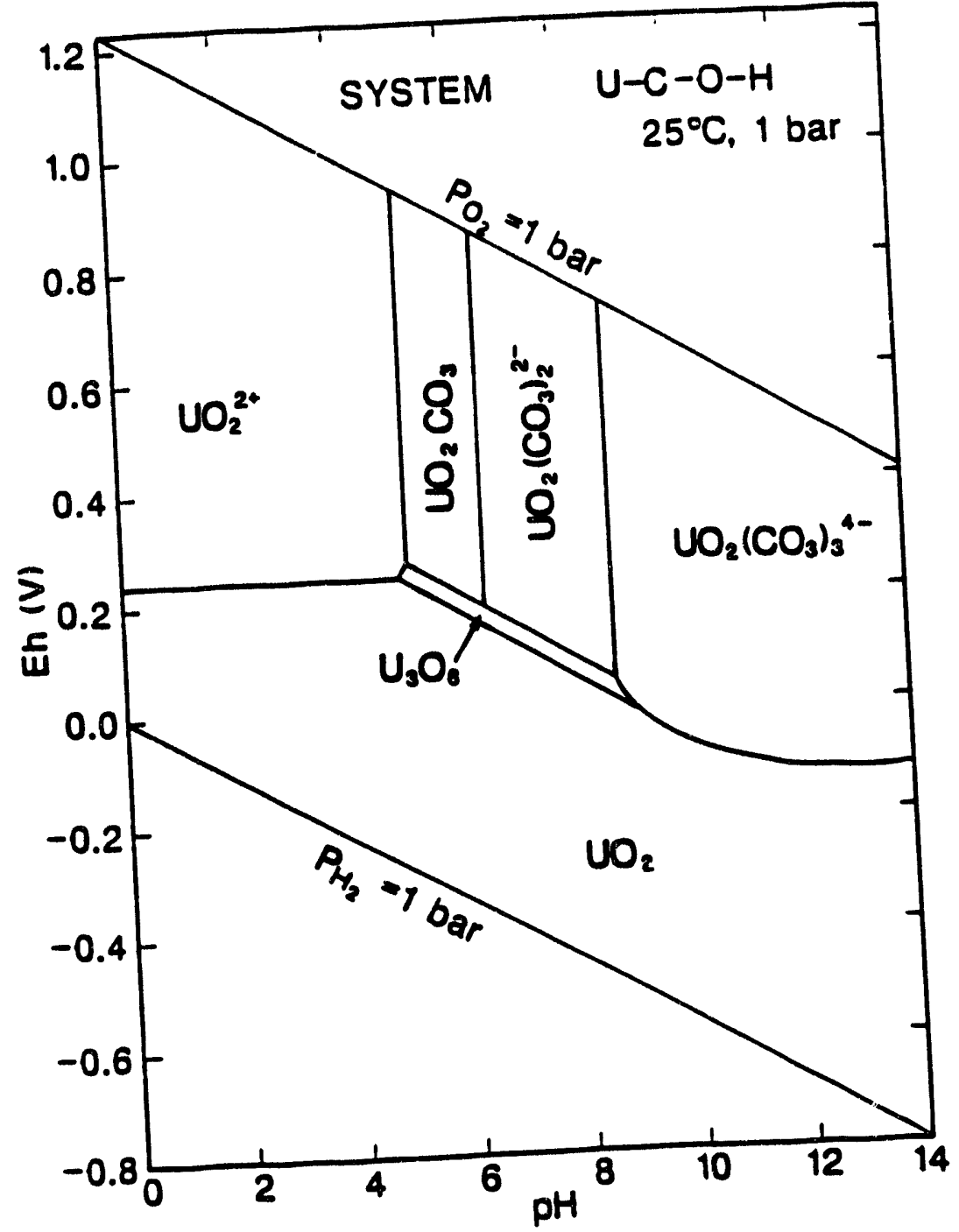

Figure 12. Eh-pH diagram for part of the system U-C-O-H. Assumed activities for dissolved species are
Broolins 1987 


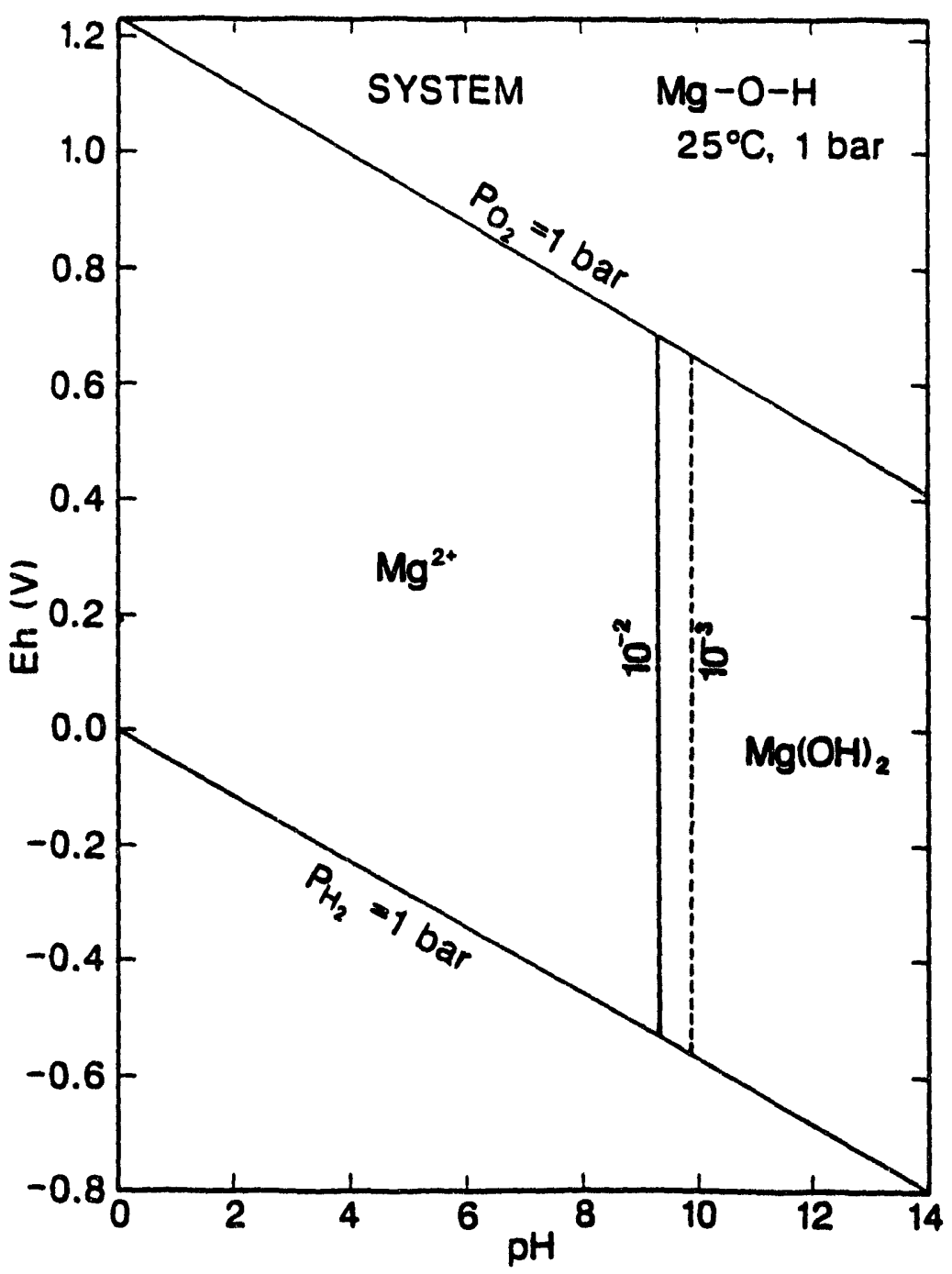

Figure 13 Eh-pH diagram for part of the system Mg-O-H. Assumed activity of dissolved $\mathrm{Mg}_{\mathrm{g}}=10^{-2}-3$. See text for discussion Brookdns 1987 


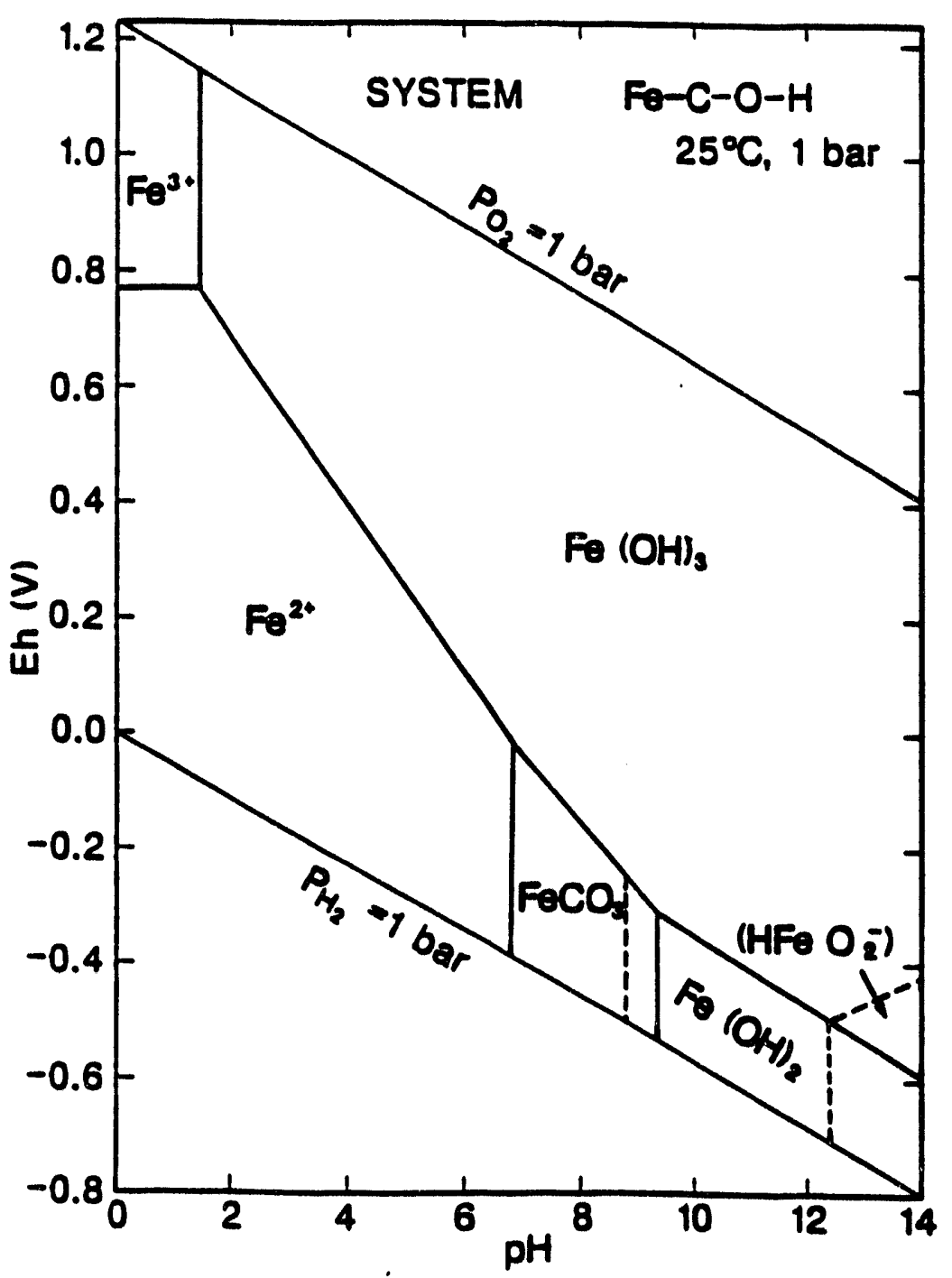

Figure 14. Eh-pH diagram for part of the symeen Fe-C-O-H. Assumed activities of dissolved species are Fe $=10^{-6}, \mathrm{C}=10^{-3}$. Brookins 1987 


\section{(ii) Physical Soll Characteristics}

Thus far, in our laboratory column experiments, we have been able to maintain adequate hydraulic conductivity through the soil. The two exceptions were columns FY94, 7. and 8., see Table 1 . In these columns the solution pooled above the mid-height filter, but this is thought to be a filter problem and not a soil conductivity problem. Most of the Fernald tests were conducted with agglomerated soil. Some soils were agglomerated with water only. Other soils were agglomerated with water and a binding agent, i.e., Type I Portland cement.

It was demonstrated in our tests that there is a penalty associated with using Portland cement as a binding agent. The uranium removal efficiency was slightly lower when Portland cement was used than when it was not used.

The agglomerates made with the Portland cement in the laboratory had a water content of approximately $20 \%$. Once the agglomerates were formed, they were cured before leaching was started, that is the cement was allowed to hydrate. The agglomerates must not be allowed to dry out. If allowed to dry, they will lose their structure when rewetted with the leaching solution. Therefore, agglomerates were either kept in a humidor or were loaded directly from the agglomerator into the leaching column.

\section{B. Agglomeration}

Agglomeration (i.e., the process of rolling ore into pellets) has been demonstrated by the mining industry to (1) increase hydraulic conductivity within a heap and (2) eliminate preferential flow paths within a heap. This is particularly true when leaching ores, and presumably soils, that are high in clay content. Fernald soil is known to be high in silt and clay. (Lee, January 1992)

As stated earlier, there is a penalty associated with using Portland cement as a binding agent for our tests. The uranium removal efficiency was slightly lower when Portland cement was used than when it was not used.

While Portland cement is an acceptable agglomerating agent for gold leaching, it is probably not the ideal agglomerating agent for removing uranium from soil. Most gold leaching solutions have a pH of approximately 11. Our solutions had a pH of 9.3 to 9.5. The Portland cement was added to the Fernald soil at the rate of $12 \mathrm{lb}$ cement/ton of soil (i.e. $0.6 \%$ by weight). Recent information indicates that uranium leaches best at a $\mathrm{pH}$ of 7.5 to 9.0. (Carpenter, 1994) This may explain the penalty experienced with using Portland cement. Therefore, a binding agent with a lower $\mathrm{pH}$ than Portland cement will be sought.

Agglomeration with a binding agent has not been necessary thus far in our testing effort. However, as the columns get taller there is a possibility of loss, or impairment, of hydraulic conductivity. As the column height is increased to $150 \mathrm{~cm}(5 \mathrm{ft})$, and then to 3.5 $\mathrm{m}(12 \mathrm{ft})$, the agglomerates at the bottom of the column may be crushed by the overburden weight. If and when this occurs, it may be necessary to agglomerate the soil with a binding agent to give the agglomerates added strength. If agglomeration is not required in $3.5 \mathrm{~m}$ tall columns, it still may be required for pilot-scale and/or field-scale leaching. Here, for the first time, the operation will not be conducted in laboratory conditions. The uncertainties introduced by large equipment, equipment operators, and weather may make agglomeration with a binding agent necessary. 
Agglomerates made with water only maintain their structural integrity in natural water containing electrolytes, at least at the column heights and $\mathrm{pH}$ tested. However, if a nonionic solution, such as distilled and hydraulic conductivity is lost or severely impaired. From this experience, we concluded that:

(1) If field-scale leaching of water-agglomerated soil is performed in the outdoors, water from rain storms and/or snow could stop or severely degrade the process effectiveness.

(3) If field-scale leaching of water-agglomerated soil is performed indoors, there is a chance that the soil might not have to be agglomerated with a binding agent.

(3) The optimization process, regardless of column height, should be performed on the correct soil type, i.e., water-agglomerated vs. agglomerated with a binding agent. Otherwise, the optimization is not being performed under the correct physical and chemical conditions.

Although our experience with agglomeration is limited, we can draw upon the experience of the precious metals mining industry. In that industry, the ore is crushed down to typically $3 / 8^{\prime \prime}$. This produces a lot of fines that can stop up the heap. So, they agglomerate the fines to the $3 / 8^{n}$ course material. The agglomerating mixture is formed by mixing 10 $20 \mathrm{lb}$ of Portland cement with one ton of ore. This represents a $0.5 \%$ to $1 \%$ addition, by weight, to the ore. The mixture is then tumbled in a rotating vessel while liquid, normally water, is added in coarse drops (sometimes the leaching solution itself is used instead of water). As the agglomerating machine turns, the material inside tries to climb the rotating side of the agglomerator but eventually slides and rolls down an inclined surface by gravity. The water drops sprayed on the material, serve as a nuclei and causes the fine materials to stick together and roll up around the course material into pellets or balls, i.e., agglomerates. The agglomerates are normally placed on the heap with a retreating stacker and are allowed to cure for approximately 24 hours before leaching is started. The agglomerates are a very poor grade of concrete and are intended to maintain their shape and consistency only long enough to permit the leaching. Most of the physical structure is destroyed when the agglomerates are removed from the leaching pad and returned to the ground. From this knowledge of precious-metals-ore agglomeration, we hope to build a knowledge base for agglomerating uranium-contaminated soil.

As reported by McClelland, (McClelland, 9034) the optimal values of the parameters governing agglomeration are:

1. Using a drum agglomerator, or disc pelletizer, for the mechanical tumbling of agglomeration.

2. Using equal proportions of agglomerating agent (lime and cement). In the study reported, 25: $25 \mathrm{lb}$ per ton of tailings gave the best results (strength, permeability, minimum additions). Percolation rate was approximately unaffected by binder additions of $15: 15 \mathrm{lb}$.

3. The quantity of water added was best between $20-25 \%$.

4. The time between agglomeration and the leach process increased the percolation rate up to about $24 \mathrm{hr}$, beyond which there was little change.

Our collaborators at New Mexico State University have determined that most information of agglomeration is empirical in nature. Little experimental data have been found on 
compressive and sheer strengths of agglomerates. Agglomeration seems to be more of an art than a science.

Within a properly agglomerated heap, there should be no "preferred pathways", because all "pathways are preferred".

\section{Mathematical Models of Leaching Systems}

The objective of the laboratory column studies is to determine the behavior of the heap leach system in response to external and internal inputs. It is important to be able to predict the chemical and hydraulic performance of the system. In predicting hydraulic performance, it has become common practice to use models that have been developed to describe the hydraulic characteristics of reactors to carry out chemical and biological reactions.

The leaching reactor models that are of interest are (1) the batch reactor, (2) the completemix reactor, (3) the plug-flow reactor, and (4) the cascade of complete-mix reactors.

\section{Batch Reactors}

A reactor in which flow is neither entering nor leaving is defined as a batch reactor. Batch reactors can be used to model vat leaching.

\section{Complete-Mix Reactors}

In the complete-mix reactor, fluid particles that enter the reactor are instantaneously dispersed throughout the reactor volume. The fluid particles leave the reactor in proportion to their statistical population. In the field of chemical engineering, the complete-mix reactor is known as the continuous-flow stirred-tank reactor (CFSTR). The complete-mix model is used to study reservoirs, such as those used in vat leaching, with continuous inputs and outputs.

\section{Plug-Flow Reactors}

In a plug-flow reactor (PFR), fluid particles pass through the reactor and are discharged in the same sequence in which they entered the reactor. Each fluid particle remains in the reactor for a time period equal to the theoretical detention time. Plug-flow models can be used to study heap leach systems.

\section{Cascade of Complete-Mix Reactors}

The cascade of complete-mix reactors is used to model the flow regime that exists between the hydraulic flow patterns corresponding to the complete-mix and plug-flow reactors. If the cascade is composed of one reactor, the complete-mix flow regime prevails. If the cascade consists of an infinite number of reactors in series, the plug-flow regime results.

Plug-flow reactors (PFRs) are ideally mixed in the lateral direction and unmixed longitudinally. Although this is an unrealistic assumption for most real-world systems, the PFR is used to define a limit and, as will be shown, can be approximated closely. Because longitudinal mixing does not occur in a PFR, the mean hydraulic residence time, $q H$, is the true hydraulic residence time. An effluent tracer signal is exactly the same as the input, except that it is transposed in time $q H$. 
A materials balance on a reactive material must be made on an incremental volume, $D V=A D x$ because a longitudinal concentration gradient exists. For the Reaction $A E B$, the mass balance over the increment is given by (Tchobanoglous, 1987):

$$
\begin{aligned}
& \frac{\partial C_{A}}{\partial t} \Delta V=\left.\left(Q C_{A}\right)\right|_{x}-\left.\left(Q C_{A}\right)\right|_{x}+\Delta x+n \Delta V \\
= & \text { Accumulation }=\text { Inflow }- \text { Outflow + Generation }
\end{aligned}
$$

where $C_{A}=$ concentration of material $A$ in volume element

$\forall=$ volume

$Q=$ volumetric flow rate

$r_{A}=$ rate of reaction reactant $A$

Because $D V=A D x$, the above equation can be written as follows by taking the limit as $D x$ approaches zero:

$$
\frac{\partial C_{A}}{\partial t}=-\frac{Q}{A} \frac{\partial C_{A}}{\partial x}+r A
$$

Generally, the flow rate $Q$ is nearly constant, and the following transformation can be made:

$$
\frac{1}{A} \frac{\partial C_{A}}{\partial t}=-\frac{Q}{A} \frac{\partial C_{A}}{\partial x}=\frac{\partial C_{A}}{\partial \theta_{H}}
$$

where

$$
\frac{A \partial x}{Q}=\partial \theta_{H}
$$

After substitution of the above transformation into $\mathrm{Eq}(4)$, the steady-state

$$
\frac{\partial C_{\lambda}}{\partial \theta_{H}}=a
$$

PFRs are more efficient than CFSTRs for most reaction systems because the average reaction rate is higher. If the reaction rate was calculated at various points along the length of a PFR, or in this case the depth of the heap, the values would gradually decrease. The lowest value would be at the outlet, or at the bottom of the heap, where the reactant concentration was the lowest. Comparing this situation with the CFSTR, where the reaction rate must be the same everywhere, and therefore must be the lowest value, explains why PFRs are more efficient than CFSTRs. 


\section{Future Directions}

\section{A. Summary Plans}

1. Investigate oxidation of $U(I V)$ to $U(V I)$ to improve overall uranium leachability.

2. Determine the need for agglomeration at field-scale using a binding agent.

3. Search for a better agglomerating (binding) agent than Portland cement, if necessary.

4. Complete optimization of the leaching process using the correct soil, i.e., agglomerated with water only vs. agglomerated with a binding agent (determined in 2 above).

5. Scale up process in columns $\sim 38 \mathrm{~cm}(15$-in) diam. $x \sim 150 \mathrm{~cm}(5-\mathrm{ft})$ tall.

6. Pilot-Scale Testing

a. Scale up process at Los Alamos in columns $\sim 38 \mathrm{~cm}$ (15-in) diam. $\mathrm{x} \sim 366 \mathrm{~cm}$ (12-ft) tall

b. Conduct pilot-scale tests at FEMP (Fernald, $\mathrm{OH}$ ) with 1 cubic meter and 800 to 1000 cubic meters on impermeable pad.

7. Conduct a $5 \mathrm{~kg}$ column $(\sim 5 \mathrm{ft})$ in order to analyze the mechanisms of uranium removal, for comparison with the data displayed on Fig. 10.

Until now, the volume of the columns has been kept small deliberately, until the primary chemistry of the process can be understood. As soon as that is accomplished, the engineering for the large scaleup of the process will be added to the chemistry and the two reconciled with each other.

\section{B. Optimization of Process}

Investigations into optimizing the process will be continued. The first investigation will involve the possible use of an oxidizer to convert U(IV) to U(VI) before leaching with carbonate. It is hypothesized that the current process is removing most, or all, of the U(VI), but not substantially affecting the U(IV). Several oxidizers will be considered, e.g., hydrogen peroxide, hypochlorite.

As stated in the section on agglomeration, it must be determined if agglomeration is needed at field scale. The need depends upon (1) the strength of agglomerates made with water only and their ability to withstand column heights of $366 \mathrm{~cm}(12 \mathrm{ft})$, or greater and (2) the possible requirement by regulators to conduct field-scale leaching indoors for reasons of safety and esthetics. If agglomeration is needed, a search for a better agglomerating agent will be conducted. It is possible that a neutral $\mathrm{pH}$ agglomerating agent might be found that does not penalize leaching efficiency. This is discussed more fully in the Agglomeration section. 


\section{Pilot Scale Tests}

The first phase of pilot scale testing will be conducted in Los Alamos, NM. At least two columns $\sim 38 \mathrm{~cm}$ (15-in) diam. $x \sim 366 \mathrm{~cm}(12-\mathrm{ft})$ tall will be leached.

The second phase of pilot-scale testing will be conducted at FEMP. This test will involve a one-cubic meter test. A test will be conducted to cleanup about 800 to 1000 cubic meters of soil on a tennis court-size leach pad. This second phase of the testing will be conducted by FERMCO and its subcontractors under the technical direction of Los Alamos.

The pilot-scale test design will be performed in Los Alamos. The design of the pilot-scale test will include a leaching pad ( 50 by $50 \mathrm{ft}$ ) with a leachate collection sump at the bottom of the heap, a reagent distribution system for the top of the heap, a leachate regeneration system, and instrumentation. The need for containment of airborne pollutants will be evaluated and, if necessary, suitable measures will be designed.

All scientific equipment and materials for the 1 cubic meter and pilot-scale tests will be procured by Los Alamos or its collaborators. All non-scientific equipment and materials for the tests will be procured by FERMCO, based upon design information supplied by Los Alamos. FERMCO will obtain the necessary federal, state, and local permits to conduct the tests at Femald, $\mathrm{OH}$.

The scientific equipment will be assembled and bench-tested in Los Alamos while the leach pad and containment structure (if necessary) are being constructed by FERNiCO. The scientific equipment will be shipped to FERMCO and installed, in modular fashion, by FERMCO under Los Alamos direction.

The pilot-scale tests will be conducted on an impermeable and properly sloped pad. The leachate will be collected at the low point on the pad (in a sump) and will be regenerated for reuse. The exact method for regeneration will be determined until the successful leaching reagent is selected. This method will be simple and economical, such as adjusting the $\mathrm{pH}$ and causing precipitation of the uranium. The pad and all leachate collection and regeneration equipment will be constructed and tested before any soil is excavated.

Before the large pilot-scale test is performed, a small heap will be constructed on the pad and test-leached. This test will involve about 1 cubic meter of contaminated soil. This test will serve as an intermediate step to check out the newly activated equipment, the agglomeration process, the proposed heap geometry, the reagent application method, and test instrumentation.

When all is ready, soil for the large pilot-scale test will be excavated under controlled conditions, agglomerated, and the heap will be constructed, using a retreating stacker. The pilot-scale heap will be 12 to $16 \mathrm{ft}$ in height, depending upon several things such as the strength of the agglomerates, the kinetics of the chemical reaction, and the economics of operation. Numerous samples of the soil will be collected as the heap is being constructed.

The reagent dispensing system (i.e., a modified sprinkler, or drip-irrigation system) will be added to the top. The progress of the tests will be evaluated by measuring the integrated volume of leachate and the concentration of the waste within the leachate. A mass balance will be established (that is, how much uranium was in the original heap less the amount that was removed) to determine the amount of uranium remaining in the heap. Additionally, core samples will be taken from the heap at planned intervals to measure progress of the test and to confirm the mass balance. The leaching phase of each test will probably take 2 to 4 months to meet EPA criteria for uranium in soil. Currently, the 
maximum limit for uranium in soil has not been officially established. For testing purposes it is assumed to be $35 \mathrm{pCi} / \mathrm{gm}$ or $52 \mathrm{ppm}$. This estimate of leaching time is based on experience of the precious metals mining industry. The leaching time is related to many parameters, e.g., height of heap, hydraulic conductivity, rate of application of reagent, speed of chemical reaction, outdoor temperature. At the conclusion of the test, the heap will be dismantled, visually inspected, and chemically tested, to further verify that the soil has met the criteria for clean soil.

Technical direction of all the testing, i.e., laboratory-scale and pilot-scale, will be the responsibility of Los Alamos. This would involve active participation (and approval authority) in the test planning, test execution, data analysis, and reporting. Actual day-today testing effort would be conducted by FERMCO personnel. Los Alamos will issue the scientific report of results.

At the end of the pilot-scale tests, FERMCO personnel should be able to continue the process or supervise the site cleanup by a subcontractor.

\section{CONCLUSIONS}

We have shown that uranium can be removed from the specific uranium contaminated soil from the FEMP site using a simulated heap leach process in the laboratory. These results suggest that the process may be applicable on a larger column scale and also in a real time heap leach scenario. 


\section{REFERENCES}

D. G. Brookins, 1977. D. G. Brookins. Uranium Deposits of the Grants Mineral Belt. Geochemical Constraints. Rocky Mtn. Assoc. Geol. Gdbk, pp 337-352

D. G. Brookins, 1987. D. G. Brookins Eh-pH Diagrams for geochemistry Springer- Verlag, 1988

Carpenter, 1994. Don Carpenter, Personal Communication, April 1994

Ebinger, 1994. Mike Ebinger, Personal Communication, February 1994

R. J. Finch,1992. R. J. Finch and R. C. Ewing, Alteration of Natural $\mathrm{UO}_{2}$ under Oxidizing Conditions from Shinkolobwe, Katanga, Zaire: A Natural Analog for the Corrosion of Spent Fuel, Radiochimica Acta, 53/54, 391 (1992).

Francis, 1992. C. W. Francis, A. J. Mattus, L. L. Farr, M. P. Elless, S. Y. Lee, Selected Leaching of Uranium from Uranium Contaminated Soils, Draft. ORNL,ORNLTM-12177 August 1992

Grenthe, 1992. I. Grenthe, Chemical Thermodynamics of Uranium, North-Holland, 1992, p. 315

Kneff, 1992. D. W. Kneff, G. Subbaraman, R. J. Tuttle, Homogeneity Evaluation of Fernald Soils Prepared for Treatability Studies, ETEC/GEN-ZR-0018, June, 1992

Lee, January 1992. S. Y. Lee, J. D. Marsh, Jr., Characterization of Uranium Contaminated Soils from DOE Fermald Environmental Management Project Site: Results of Phase I Characterization, ORNL/TM-11980, Jan., 1992

Longmire, 1994 . P. Longmire, W.R.J. R.Turney, C. F. V. Mason, D. A. York, D. Dander, Predictive geochemical Modeling of Uranium and other Contaminants in Laboratory Columns in Relatively Oxidizing, Carbonate-Rich Solutions. Waste Management '94, Tucson, February 1994. (Reproduced here in Appendix B).

McClelland, 9034. G. E. McClelland, D. L. Pool, A. H. Hunt and J. A. Eisele, Agglomeration and Heap Leaching of Finely Ground Precious Metal-Bearings Tailings Information Circular 9034, Bureau of Mines.

Merritt, 1971. R. C. Merritt, The Extractive Metallurgy of Uranium, Col. School of Mines Res. Inst. Golden, CO, pp. 337-353

Radiological Assessments Corporation, 1993. The Fernald Dosimetry Reconstruction Project, RAC Report No. CDC-5, November 1993

Tchobanoglous, 1987. G. Tchobanoglous, E. D. Scroeder, Water Quality. Addison Wesley, Reading Mass. 1987.

USID August, 1992. Uranium in Soils Integrated Demonstration: Soil Characterization Project Report, August 1992 


\section{APPENDICES}

\section{Appendix A.}

\section{Complete Data on Column Experiments}

Table A1.1. lists all the column experiments completed in FY 1993. This is followed by the complete set of data which are linked to Table A1.1 by the column number. The same linkage is true for Table A1.2 for the FY 1994 results. 
TABLE A 1.1

SUMMARY OF COLUMN EXPERMENTS

PERFORMED IN FY 03

\begin{tabular}{|c|c|c|c|c|c|c|c|}
\hline & $\begin{array}{l}\text { Column } \\
\text { Number }\end{array}$ & $\mathbf{M}$ & $\begin{array}{c}\text { Carbonato } \\
\text { Salt }\end{array}$ & $\begin{array}{l}\text { Flow } \\
\text { Rate }\end{array}$ & $\begin{array}{l}\text { Mass } \\
\text { (kg) }\end{array}$ & Soll & Preparation \\
\hline 1 & $\mathrm{Co21193}$ & 0.1 & Potassium & $1 x$ & 1 & SP4 & Homogenized \\
\hline 2 & $\mathrm{Co52593}$ & 0.1 & Sodium & $1 x$ & 1 & SP9(93) & Homogenized \\
\hline 3 & C100193 & 0.1 & Sodium & $1 x$ & 1 & SP9(93) & Homogenized, Agglomerated $w /$ cement \\
\hline 4 & C100293 & 0.1 & Sodium & $1 x$ & 1 & SP9(93) & Homogenized \\
\hline 5 & $\mathrm{Co92893}$ & 0.1 & Sodium & $2 x$ & 1 & SP9(93) & Homogenized \\
\hline 6 & $\mathrm{C060493}$ & 0.20 & Soctium & $1 x$ & 1 & SP9(93) & Homogenized \\
\hline 7 & $\mathrm{Co82693}$ & 0.25 & Sodium & $1 x$ & 1 & SP9(93) & Homogenized \\
\hline 8 & $\mathrm{Co82793}$ & 0.25 & Sodium & $1 x$ & 1 & $\operatorname{SPg}(93)$ & Homogenized \\
\hline 9 & $\mathrm{C060393}$ & 0.5 & Sodium & $1 x$ & 1 & SP9(93) & Homogenized \\
\hline 10 & $C 081693$ & 0.5 & Sodium & $1 x$ & 1 & SP9(93) & Homogenized \\
\hline 11 & C081793 & 0.5 & Sodium & $1 x$ & 1 & SP9(93) & Homogenized, Agglomerated w/ cement \\
\hline 12 & $\mathrm{Co91393}$ & 0.5 & Sodium & $2 x$ & 1 & SP9(93) & Homogenized \\
\hline 13 & C091493 & 0.5 & Sodium & $2 x$ & 1 & SP9(93) & Homogenized \\
\hline
\end{tabular}




\begin{tabular}{|c|c|c|c|c|c|c|c|c|c|c|c|}
\hline & $u(367)$ & $U(385)$ & U(AVE) & SAMPE & UAEOVED & TOTAL U & EXPE $3 \pi$ & U(AVG) & EPPE & UREMINIS & EPAACTION \\
\hline Sample & $(m g / L)$ & $(m q / L)$ & $(\mathrm{m} / \mathrm{lL})$ & VOL (L) & $(m q)$ & REMOVED (ma/kg) & TIE (day) & $(\mathrm{mg} / \mathrm{L})$ & TINE (hr) & NoOLnN & ㄴ.T \\
\hline S02119301 & 46.910 & 46.960 & 47 & 0.072273 & 4.06 & 4.06 & 0 & 47 & 5.0 & 416 & 52 \\
\hline 502119502 & 0.914 & 0.948 & 186 & 0.607147 & 135.14 & 139.19 & 1 & 186 & 20.9 & 281 & 52 \\
\hline 502119303 & 1.069 & 1.055 & 212 & 0.137730 & 34.97 & 174.16 & 1 & 212 & 24.7 & 246 & 52 \\
\hline 502119304 & 0.983 & 1.014 & 200 & 0.109860 & 26.22 & 200.38 & 1 & 200 & 27.5 & 220 & 52 \\
\hline 502119305 & 1.000 & 0.960 & 196 & 0.104773 & 24.55 & 224.94 & 1 & 196 & 30.3 & 195 & 52 \\
\hline 502119306 & 0.559 & 0.602 & 116 & 0.752290 & 104.48 & 329.42 & 2 & 116 & 49.8 & 91 & 52 \\
\hline$\$ 02119307$ & 23.040 & 22.430 & 23 & 0.098293 & 2.67 & 332.09 & 2 & 23 & 52.4 & 88 & 52 \\
\hline 502119308 & 9.363 & 8.376 & 9 & 0.781350 & 8.28 & 340.37 & 3 & 9 & 73.4 & 80 & 52 \\
\hline 502119309 & 5.601 & 5.776 & 6 & 0.092874 & 0.63 & 341.00 & 3 & 6 & 75.9 & 79 & 52 \\
\hline 502119310 & 6.645 & 6.481 & 7 & 0.074390 & 0.58 & 341.59 & 3 & 7 & 77.9 & 78 & 52 \\
\hline 502119311 & 4.314 & 4.092 & 4 & 1.411020 & 7.09 & 348.68 & 5 & 4 & 117.3 & 71 & 52 \\
\hline 502119312 & 3.690 & 3.669 & 4 & 0.095855 & 0.42 & 349.10 & 5 & 4 & 120.0 & 71 & 52 \\
\hline 502119313 & 3.225 & 3.202 & 3 & 0.117342 & 0.45 & 349.55 & 5 & 3 & 123.1 & 70 & 52 \\
\hline 502119314 & 3.023 & 3.108 & 3 & 0.086334 & 0.32 & 349.87 & 5 & 3 & 125.4 & 70 & 52 \\
\hline 502119315 & 2.900 & 2.929 & 3 & 0.634188 & 2.21 & 352.08 & 6 & 3 & 142.5 & 68 & 52 \\
\hline 502119316 & 2.848 & 2.818 & 3 & 0.108574 & 0.37 & 352.44 & 6 & 3 & 145.4 & 68 & 52 \\
\hline $\mathbf{S 0 2 1 1 9 3 1 7}$ & 2.739 & 2.754 & 3 & 0.130624 & 0.43 & 352.87 & 6 & 3 & 148.9 & 67 & 52 \\
\hline 502119318 & 2.431 & 2.508 & 2 & 0.705800 & 2.08 & 354.96 & 7 & 2 & 168.7 & 65 & 52 \\
\hline $\mathbf{S 0 2 1 1 9 3 1 9}$ & 2.206 & 2.232 & 2 & 0.084880 & 0.23 & 355.18 & 7 & 2 & 171.0 & 65 & 52 \\
\hline 502119320 & 2.148 & 2.171 & 2 & 0.096790 & 0.25 & 355.43 & 7 & 2 & 175.5 & 65 & 52 \\
\hline S02119321 & 1.986 & 2.067 & 2 & 0.703041 & 1.70 & 357.13 & 8 & 2 & 192.2 & 63 & 52 \\
\hline $\mathbf{S 0 2 1 1 9 3 2 2}$ & 2.070 & 2.085 & 2 & 0.141977 & 0.35 & 357.49 & 8 & 2 & 196.2 & 63 & 52 \\
\hline 502119323 & 2.180 & 2.225 & 2 & 0.865116 & 2.28 & 359.76 & 9 & 2 & 220.3 & 60 & 52 \\
\hline 502119324 & 2.127 & 2.088 & 2 & 0.839700 & 2.12 & 361.88 & 10 & 2 & 244.7 & 58 & 52 \\
\hline 502119325 & 1.595 & 1.692 & 2 & 0.647526 & 1.27 & 363.15 & 11 & 2 & 264.0 & 57 & 52 \\
\hline $\mathbf{S 0 2 1 1 9 3 2 6}$ & 1.508 & 1.440 & 1 & 0.854603 & 1.51 & 364.66 & 12 & 1 & 288.0 & 55 & 52 \\
\hline 502119327 & 1.291 & 1.277 & 1 & 0.819714 & 1.26 & 365.92 & 13 & 1 & 311.6 & 54 & 52 \\
\hline SO2119328 & 1.153 & 1.171 & 1 & 0.839779 & 1.17 & 367.08 & 14 & 1 & 336.3 & 53 & 52 \\
\hline
\end{tabular}




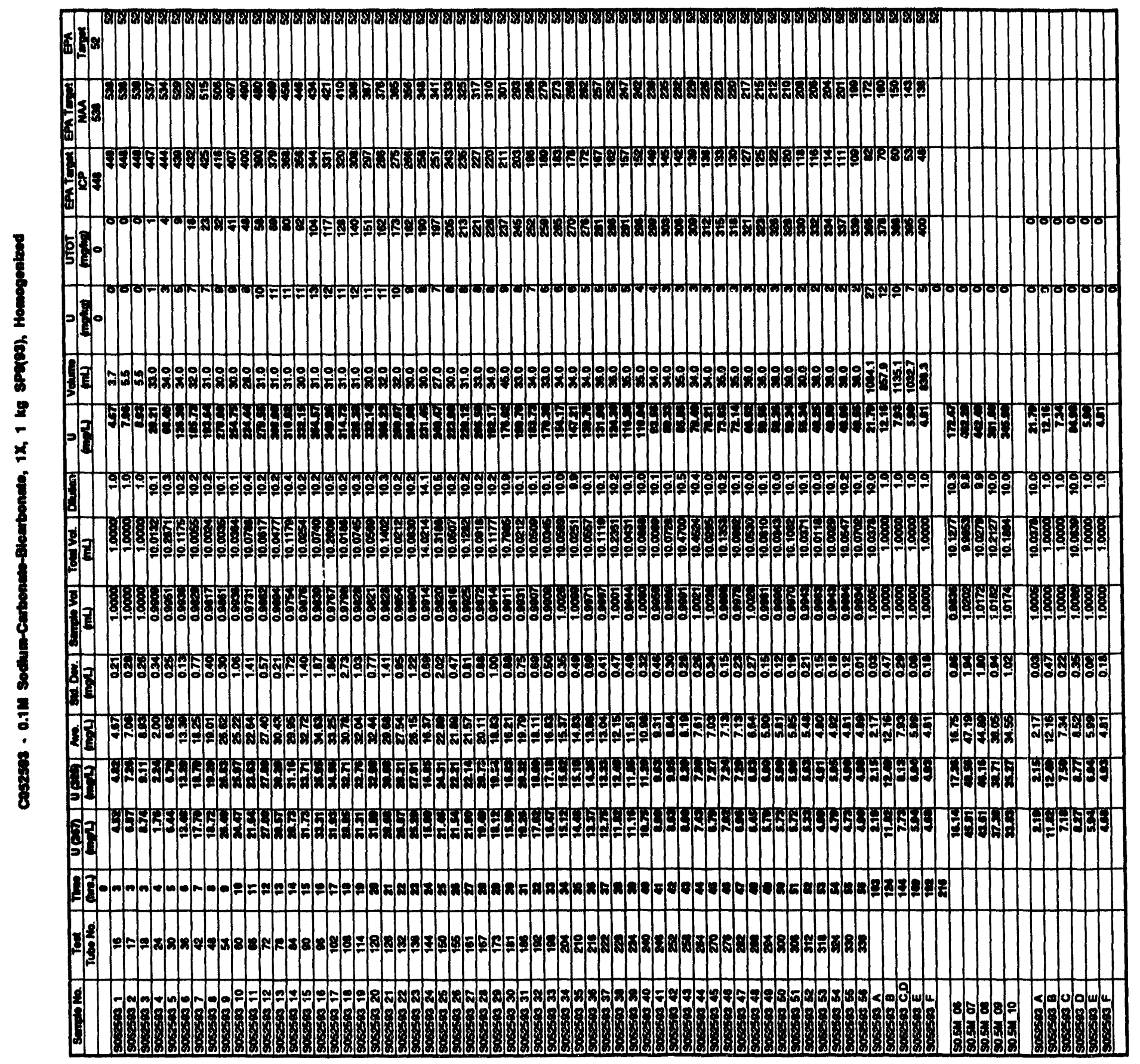


Coseses - 0.5 in Sodtum-Garbonate-Elearbonate, 1X, $1 \mathrm{~kg}$ Spe(e3), Homogentzed

\begin{tabular}{|c|c|c|c|c|c|c|c|c|c|c|c|c|c|c|c|c|}
\hline Samphon. & Twat & $\frac{\pi n}{(n+e)}$ & $\frac{\pi}{(10 x)}$ & प(E) & $\frac{0(E)}{(m a)}$ & $\frac{A m p}{(m \cdot 2)}$ & $\frac{\sec 00 v}{(m, 2)}$ & $\frac{\text { Sang Vd }}{(\mathrm{mL})}$ & 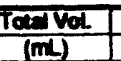 & Dintion & $\frac{0}{\operatorname{lng} 4}$ & \begin{tabular}{|l|} 
Volum \\
$(\min )$ \\
\end{tabular} & $\frac{U}{(m-\sqrt{n})}$ & 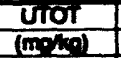 & $\mathrm{Nm}$ & 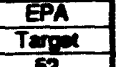 \\
\hline & & & & & & & & & & & & & & & & \\
\hline 50603034 & 24 & 4 & 0 & รल) & 20 & 31.5 & 0.0 & 0.0000 & 10.140 & 10.2 & $m$ & 30 & 112 & 11 & 520 & \\
\hline 50603035 & 30 & 5 & 0 & 350 & 5.0 & 30.27 & 1.81 & 0.0006 & 10.1600 & 10.2 & 50 & 30 & 13.4 & 25 & 512 & 5 \\
\hline 50603038 & 33 & 6 & $\frac{\pi}{0}$ & ज5: & 50 & 35.68 & 1.50 & 0.0036 & 10.127 & 10.3 & 5 & 30 & 12.6 & 37) & 500 & 52 \\
\hline 50003037 & 42 & 7 & 0 & 201 & 5300 & 33.81 & 1.00 & 1.0202 & 9.033 & 0.2 & 51 & 30 & 11.4 & 40 & 480 & 52 \\
\hline 50603038 & 48 & 8 & 0 & 506 & 525 & 34.15 & 1.56 & 1.0172 & 10.0279 & 2.9 & 57 & 30 & 11.6 & 6 & 477 & 52 \\
\hline 50003039 & 54 & 9 & 6 & 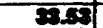 & 5.00 & 34.47 & 1.32 & 1.0182 & 10.2127 & 10.0 & 5 & 30 & 11.9 & 72 & 485 & 52 \\
\hline $5000303_{10}$ & 60 & 10 & 0 & 5at & 53 & 34.46 & 1.41 & 1.0174 & 10.1084 & 10.0 & 30 & 30 & 11.9 & Ba & 55 & 52 \\
\hline 900030311 & 68 & 11 & 0 & भूज & s.5. & 35.55 & 1.30 & 1.0220 & 10.1248 & Q.9 & 20 & 30 & 12.1 & का & 411 & 5 \\
\hline 500030312 & 72 & 12 & 1 & 50 & 3.0 & 34.67 & 1.63 & 0.5040 & $10.00<0$ & 19.8 & 9 & 30 & 23.6 & 120 & 497 & 52 \\
\hline 500050313 & 78 & 13 & 1 & 5A7 & 35.00 & 34.51 & 1.47 & 0.5140 & 10.0030 & 19.6 & की & 30 & 232 & 143 & 304 & 52 \\
\hline 5000393.14 & 84 & 14 & 7 & 5320 & म.2 & 33.94 & 0.0 & 0.5009 & 10.0614 & 20.0 & En & 30 & 232 & 160 & 371 & 5 \\
\hline 500030315 & $\infty$ & 15 & $T$ & 30.0 & 350 & 35.35 & 1.00 & 0.5040 & 10.1725 & 202 & 73 & 30 & 24.5 & 100 & 347 & 52 \\
\hline 50.0503116 & 9 & 16 & $i$ & $2 . \pi$ & 51.73 & 30.72 & 1.44 & 0.5018 & 10.2000 & 20.3 & 20 & 30 & 21.4 & 212 & 320 & 5 \\
\hline $50003 \times 3$ 17 & 102 & 17 & 1 & 200 & 500 & 32.65 & 0.82 & 0.00 & 10.0171 & 20.1 & है & 30 & 22.5 & 234 & 300 & 5 \\
\hline 506030318 & 108 & 10 & 1 & 52.10 & 3xa & 33.20 & 1.53 & 0.5015 & 10.1104 & 202 & (n) & 35 & 20.9 & 201 & 278 & 5 \\
\hline 50000303 19 & 114 & 10 & 1 & ISI & 5.57 & 32.48 & 1.20 & 1.0001 & 10.1020 & 10.0 & $m$ & 36 & 130 & 274 & 203 & 52 \\
\hline 500030320 & 120 & 20 & 1 & भग & 50 & 32.40 & 1.56 & 1.0008 & 10.1105 & 10.0 & 2 & 35 & 13.0 & 207 & 250 & 5 \\
\hline 5000003,10 & 60 & $2 !$ & 1 & Iल & 202 & 20.72 & 1.04 & 1.0174 & 10.1629 & 10.0 & $E$ & 35 & 11.9 & 20 & 203 & \\
\hline 506030311 & 68 & 22 & 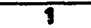 & 2803 & 20.02 & 28.40 & 0.81 & 1.0220 & 10.124 & 2.9 & 20 & 35 & 10.5 & 310 & 227 & 52 \\
\hline 500050312 & 72 & 22 & 1 & 1200 & 12.6 & 12.67 & 0.28 & 0.5060 & 10.0000 & 198 & 20 & 35 & 10.0 & $3 \geq 0$ & 217 & 52 \\
\hline 9000303 13 & 78 & $\overline{2}$ & 1 & 1131 & 10.5 & 10.00 & 0.45 & 0.5100 & $10.0 \times 3$ & 19.6 & हत & 35 & 8.8 & 320 & 200 & \\
\hline 506030314 & 84 & 20 & 1 & 10.12 & 2.51 & 8.82 & 0.40 & 0.5002 & 10.0614 & 20.0 & 10 & 35 & 7.8 & 323 & 201 & \\
\hline Soscsos_15 & $\infty$ & 2 & 1 & 8.n & का & 8.51 & 0.20 & 0.5040 & 10.1725 & 202 & 172 & 35 & 8.9 & 34 & 194 & \\
\hline 500039316 & 86 & $\overline{27}$ & 1 & $\cos$ & 700 & 7.91 & 0.16 & 0.5018 & 10.2030 & 20.3 & 16i & 35 & 6.4 & 350 & 187 & 52 \\
\hline $50603: 0317$ & 102 & $\overline{2}$ & 1 & 721 & CSO & 7.10 & 0.17 & 0.400 & 10.0171 & 20.1 & 10 & 35 & 5.7 & 335 & 182 & \\
\hline 500039318 & 108 & $\overline{2}$ & 1 & S.70 & हत्त & 5.60 & 0.18 & 0.5015 & 10.1194 & 202 & 110 & 35 & 4.5 & 300 & 177 & \\
\hline 5060393 18 & 114 & 50 & 1 & 105 & 10.12 & 10.25 & Q.18 & 1.0001 & 10.1020 & 10.0 & 100 & 35 & 4.1 & 334 & 173 & \\
\hline 500030320 & 120 & ง & 1 & 10.51 & 10.02 & 10.20 & 0.25 & $1.00 \%$ & 10.1105 & 10.0 & 10 & $\overline{35}$ & 4.1 & 360 & 189 & 52 \\
\hline 500039321 & 126 & 5 & 1 & 201 & o.ch & 9.7 & 0.17 & 1.0009 & 10.1313 & 10.0 & 0 & 35 & 30 & 372 & 165 & \\
\hline 5000393222 & $\frac{100}{132}$ & 5 & 1 & 0 & 0.00 & 0.21 & 0.27 & 1.0274 & 10.0146 & 0.7 & 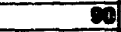 & 35 & 3.8 & 370 & 181 & 54 \\
\hline 500030323 & 138 & $\overline{34}$ & 1 & $a=$ & 20 & 8.56 & 0.37 & 1.0221 & 10.0821 & 2.9 & (2) & 35 & 3.4 & 370 & 153 & 52 \\
\hline 500039324 & 144 & 35 & 1 & ans & 720 & 7.03 & 0.13 & 1.0025 & 10.0416 & 10.0 & 7 & 35 & 3.2 & 302 & 155 & 5 \\
\hline 500039325 & 150 & 35 & 2 & 7.03 & 7.15 & 7.30 & 0.22 & & 10.0233 & 10.0 & 7 & 35 & 29 & 305 & 152 & \\
\hline 5060053326 & 158 & 9 & 2 & 7.04 & 6.7 & 6.91 & 0.21 & 0.9050 & 10.263 & 10.3 & 7 & 35 & 20 & 300 & 140 & 52 \\
\hline 5000503227 & 162 & 3 & $\overline{2}$ & 6.7 & क.जी & 6.67 & 0.00 & 1.0012 & 10.0171 & 10.0 & G) & 35 & 27 & 391 & 146 & $\sqrt{2}$ \\
\hline 500030328 & 168 & 5 & 2 & $\mathrm{CSO}$ & 8.06 & 6.15 & 0.27 & 1.0004 & 10.0265 & 10 & 2 & $\overline{35}$ & 25 & 300 & 144 & 5 \\
\hline 500030320 & 174 & $\infty$ & 2 & 500 & 5.5. & 5.60 & 0.20 & 1.0000 & 10.0365 & 10.0 & 57 & 35 & 2.3 & 305 & 142 & 52 \\
\hline 500030330 & 180 & 41 & 2 & 5.7 & 5.5 & 5.65 & 0.11 & 1.0053 & 10.2443 & 10.2 & 5 & 35 & 2.3 & 300 & 130 & $=$ \\
\hline 506030331 & 188 & 2 & 2 & Sor & का & $4 \infty$ & 0.11 & 1.0 & 10.3251 & 10.3 & 5] & 35 & 21 & $\infty$ & 137 & 52 \\
\hline 500000332 & 102 & 9 & 2 & 5.00 & a) & 40 & 0.01 & 1.0065 & a4 & 0.9 & 5 & 35 & 2.0 & 402 & 135 & 5 \\
\hline $\operatorname{cosec03} 33$ & 198 & M & $\overline{2}$ & 474 & कीज & 4.66 & 0.12 & 1.0280 & 10.8 & 2.8 & $\overline{40}$ & 35 & 1. & 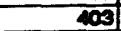 & 1394 & 5 \\
\hline $5000 \cos ^{34}$ & 204 & 85 & $\overline{2}$ & (5) & $a$ & 4.44 & 0.00 & 1.0033 & 10.0327 & 10.0 & 4 & 35 & 1.8 & 405 & 132 & 5 \\
\hline 500000356 & 210 & 4 & $\overline{2}$ & Cas & Q17 & 4.21 & 0.00 & 1.0006 & 10.0067 & 10.0 & 2 & 35 & 1.7 & 407) & 130 & 52 \\
\hline 500000336 & 218 & 4 & $\overline{2}$ & $3 \sqrt{3}$ & 200 & 3.42 & 0.13 & 1.0006 & 10. & 10.1 & 9 & 35 & 1.4 & 400 & 120 & 5 \\
\hline $50605 \times 337$ & 222 & 8 & 2 & क्ता & 20 & 3.68 & 0.02 & 1.0070 & 10 & 10 & 5 & 35 & 1.6 & 410 & 127 & 5 \\
\hline $50003 \times 353$ & $\overline{228}$ & 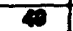 & 2 & $2 \pi$ & 2.70 & 3.71 & 0.07 & 0.9087 & 10.0034 & 10.1 & 3 & $\overline{35}$ & 1.5 & 411 & 126 & 52 \\
\hline 5000303 & $\overline{234}$ & 5 & $\frac{\pi}{2}$ & 25A & 274 & 3.64 & 0.14 & 1.0050 & 10.1389 & 10.1 & ज] & 35 & 1.5 & 413 & 124 & 52 \\
\hline 50000.0340 & 240 & 51 & $\frac{5}{2}$ & $3 \sqrt{2}$ & 343 & 3 & $\overline{a . c}$ & 1.0 & 10.0234 & 10.0 & 34 & 35 & 1.4 & 414 & 123) & 52 \\
\hline 500050341 & 246 & 5 & 2 & 20 & 220 & 3.27 & a. & 1.0052 & 10. & 10.0 & 3 & 35 & 1.3 & 416 & 121 & 52 \\
\hline socos:3 42 & 252 & 5 & 2 & 210 & 217 & 3.14 & 0.05 & 1.0022 & 10.0130 & 10.0 & 3) & 35 & 1.3 & 417 & 120 & 52 \\
\hline 500000343 & 258 & Sa & 2 & $2 \pi$ & 210 & 3.25 & 0.0 & 1.0157 & 10.0300 & 9.9 & 2 & 35 & 1.3 & 410 & 119 & 52 \\
\hline 500000344 & 234 & 8 & 2 & 210 & 36-i & 3.20 & 0.16 & 1.0120 & 10.1104 & 10.0 & 20 & 35 & 1.3 & 410 & 118 & 52 \\
\hline $50000 \cdot 9345$ & 270 & 5 & 2 & 20. & S11 & 3.18 & 0. & 1.0 & 10. & 8.9 & ज1 & 35 & 1.3 & (21) & 116 & 52 \\
\hline 500009348 & 276 & 57 & $\overline{2}$ & 20 & 20 & 200 & 0.00 & 1.0171 & 69 & 10.0 & 2 & $\overline{35}$ & 1.1 & 222) & 115 & 5 \\
\hline & 202 & 5 & $c$ & $2 \pi$ & $2 \pi$ & 270 & 0.02 & 1.0131 & 10.1727 & 10.0 & 8 & 35 & 1.1 & 23 & 114 & 52 \\
\hline 50000.0340 & 200 & 5 & $\frac{1}{2}$ & 27 & 2जा & 2 & 0.05 & 1.0230 & 10.1455 & 9.9 & $2 \pi$ & 36 & 1.1 & 24 & 113. & 52 \\
\hline 500050340 & 24 & C & 3 & $2 \pi$ & हले & $\overline{2}$ & a. & 1.0130 & 10.4066 & 10.3 & 27 & 35 & 1.1 & 25 & 112 & 504 \\
\hline 50005350 & 300 & G & 3 & 205 & 200 & 233 & 0.03 & 1.01 & 10. & 10.0 & 23 & 35 & 0.9 & 20 & 111 & 5 \\
\hline $500 \times 51$ & 300 & 2 & $=$ & 210 & 200 & 2.00 & 0.02 & 1.0 & 10.0 & & 8 & 35 & 0.8 & 2 & 110 & 5 \\
\hline 50005 & 312 & $\overline{6}$ & 3 & 1.2 & 100 & 1.00 & 0.06 & 1.0036 & 10.0057 & 10.0 & 10 & 35 & 0.8 & 420 & 100 & 52 \\
\hline$\frac{500303}{53}$ & $\frac{116}{318}$ & $\bar{c}$ & 3 & ant & 1.00 & 0.97 & 0.05 & 20526 & 20.1921 & 9.8 & 10 & 35 & 0.4 & (28) & 109 & 52 \\
\hline $500003 \mathrm{~A}$ & 324 & $\infty$ & 4 & 20 & $2 \pi$ & 257 & 0.25 & 2.0203 & 10.0005 & 5.0 & 13 & 767 & 11.3 & 430 & क) & 52 \\
\hline $5000 \times 38$ & 330 & 117 & 5 & 1.41 & $1 . m$ & 1.50 & 0.25 & 1.9870 & 10.2198 & 5. & a & 1005 & 8.4 & 44 & 88 & 52 \\
\hline 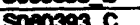 & 320 & 177 & $=$ & 00 & 100 & 0.98 & 0.06 & 20075 & 10.0494 & 5.0 & S & 1025 & 5.7 & 85 & 83 & \\
\hline
\end{tabular}


50 (a)

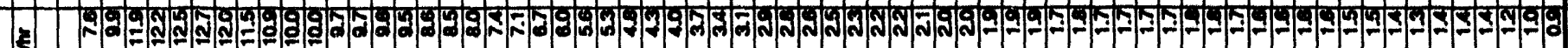
$p$

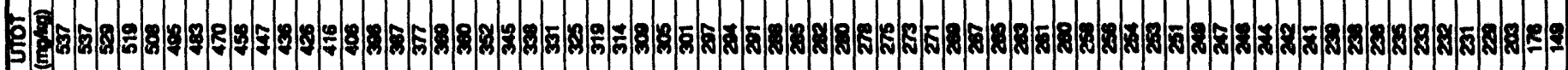

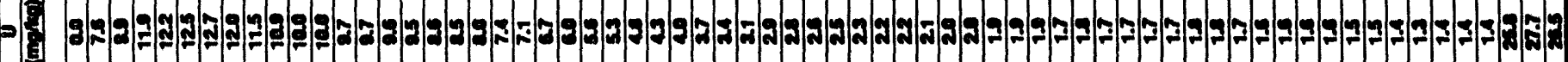

1 . (= Fon $\Rightarrow$ 酎

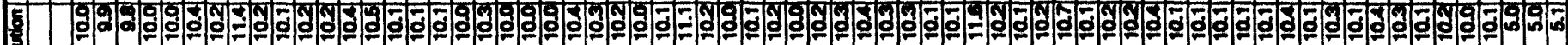

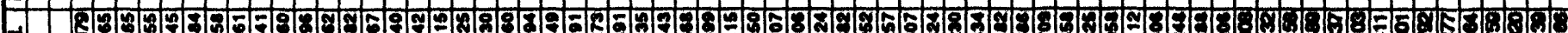

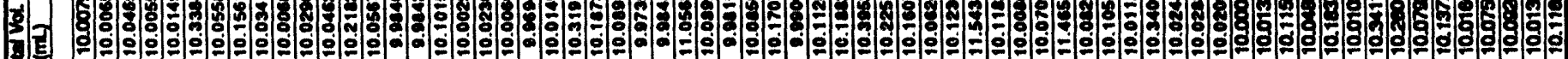
:

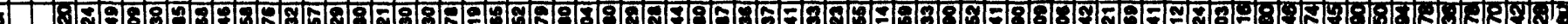

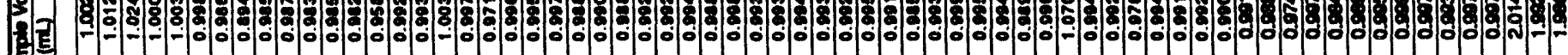
s. 20\% 8 \%

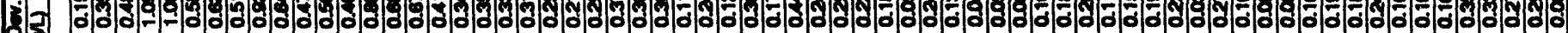
E 1:

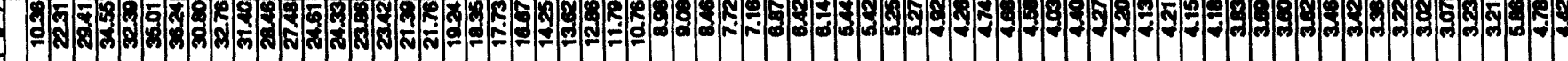
50 -

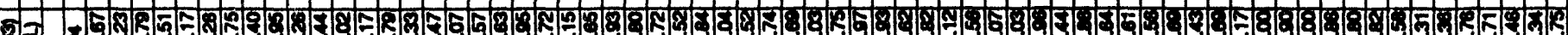
氧 4 든

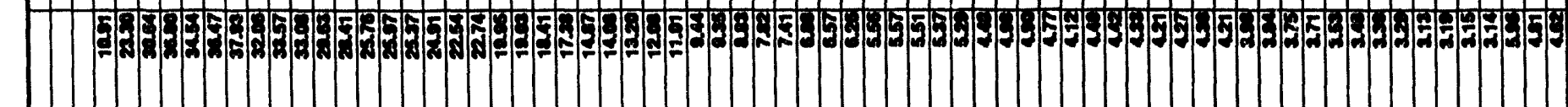

न 80 年

: .0 .0 .0 .0 .0

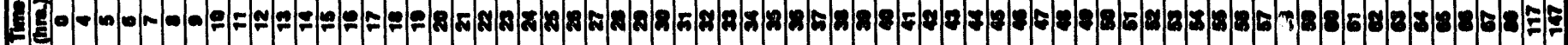

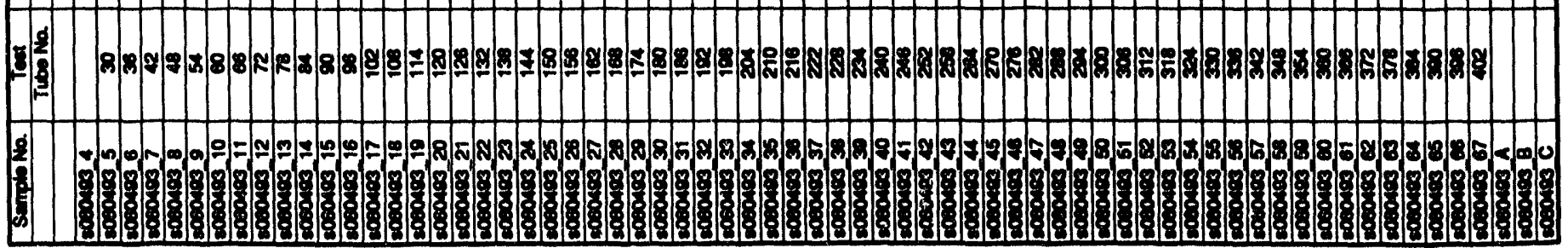




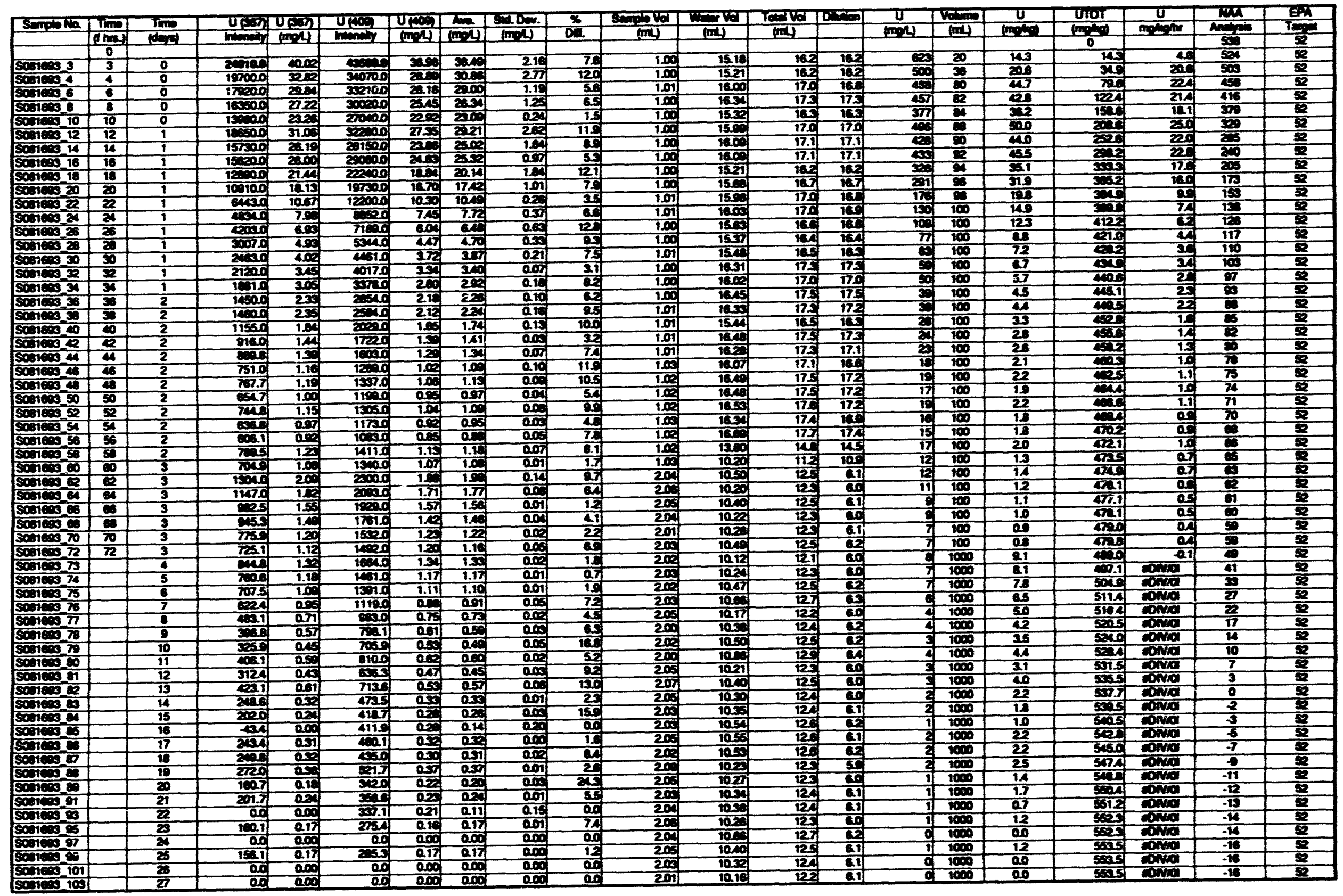




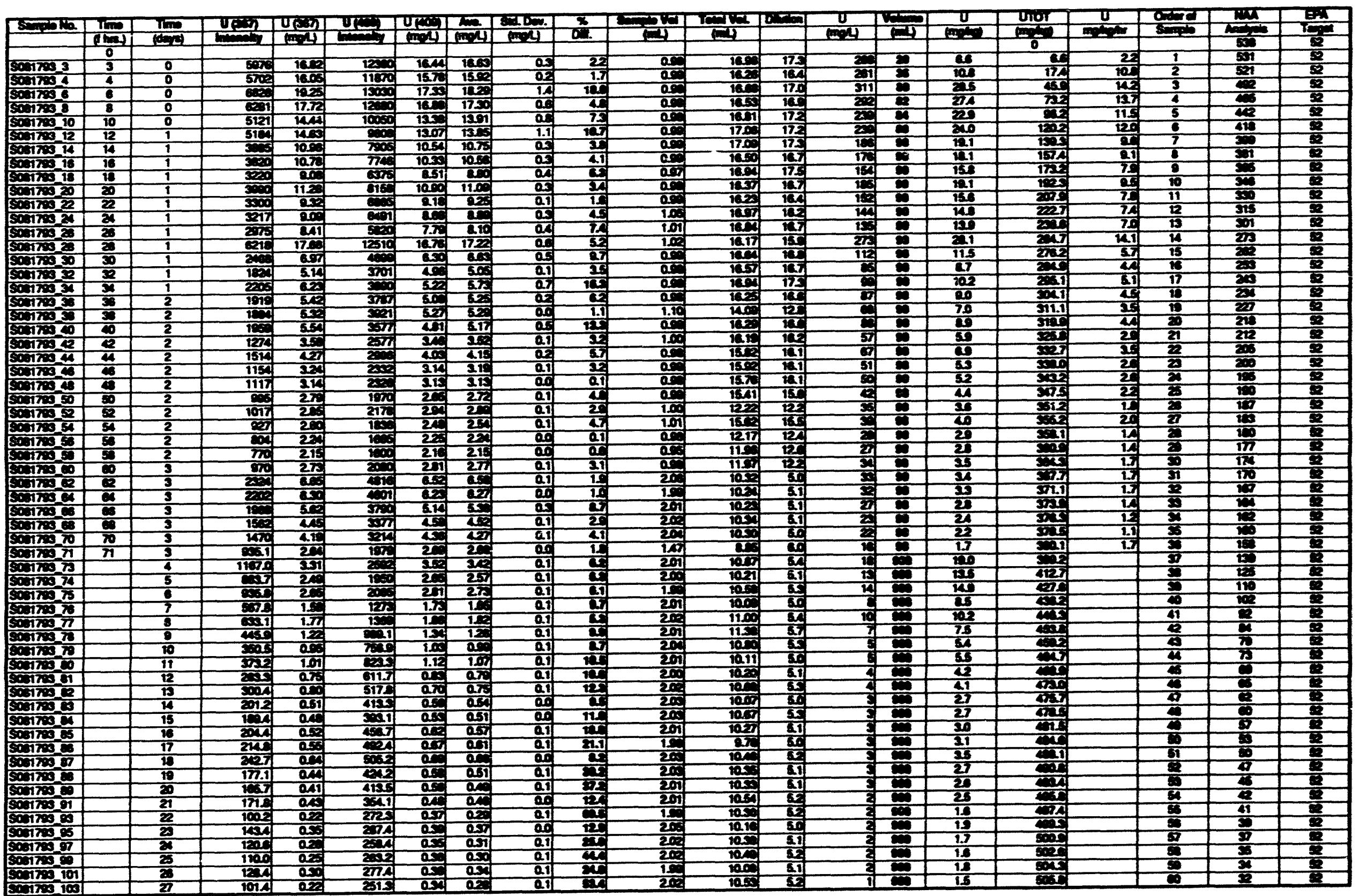


I.

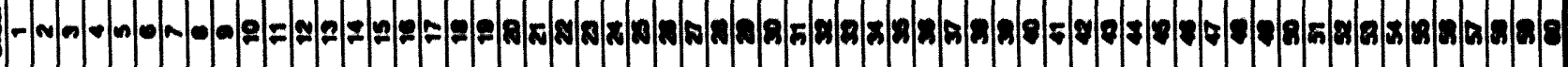

P.

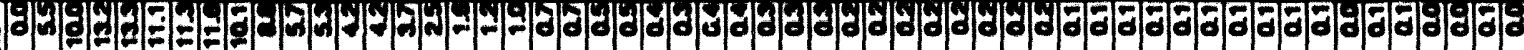

40 5

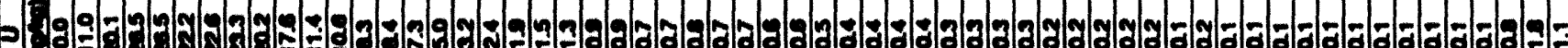

$P$

(2)

p.

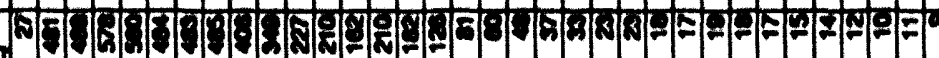

3

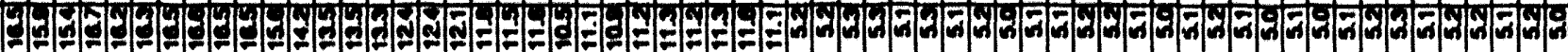

E.

3.7

.

3 : 8 :

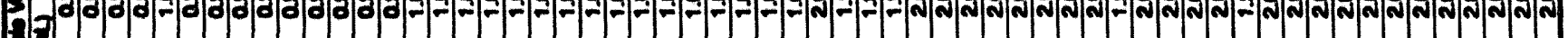
I.

a. 1 20 : है. 13

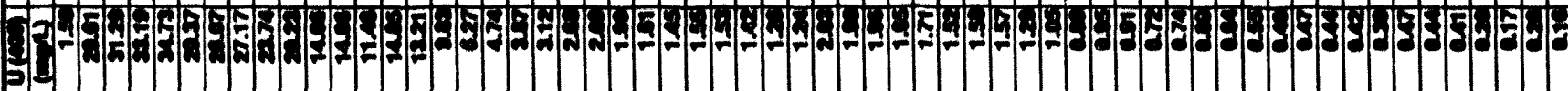
-1)

6.

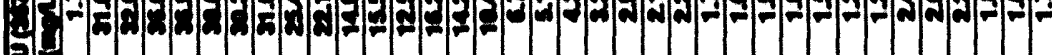
7 - 00 - 0 6.

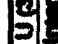

B. 00.00.

6

2.

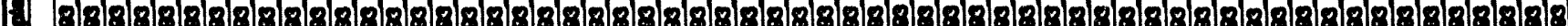

16

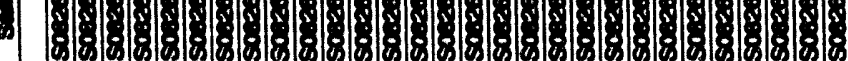




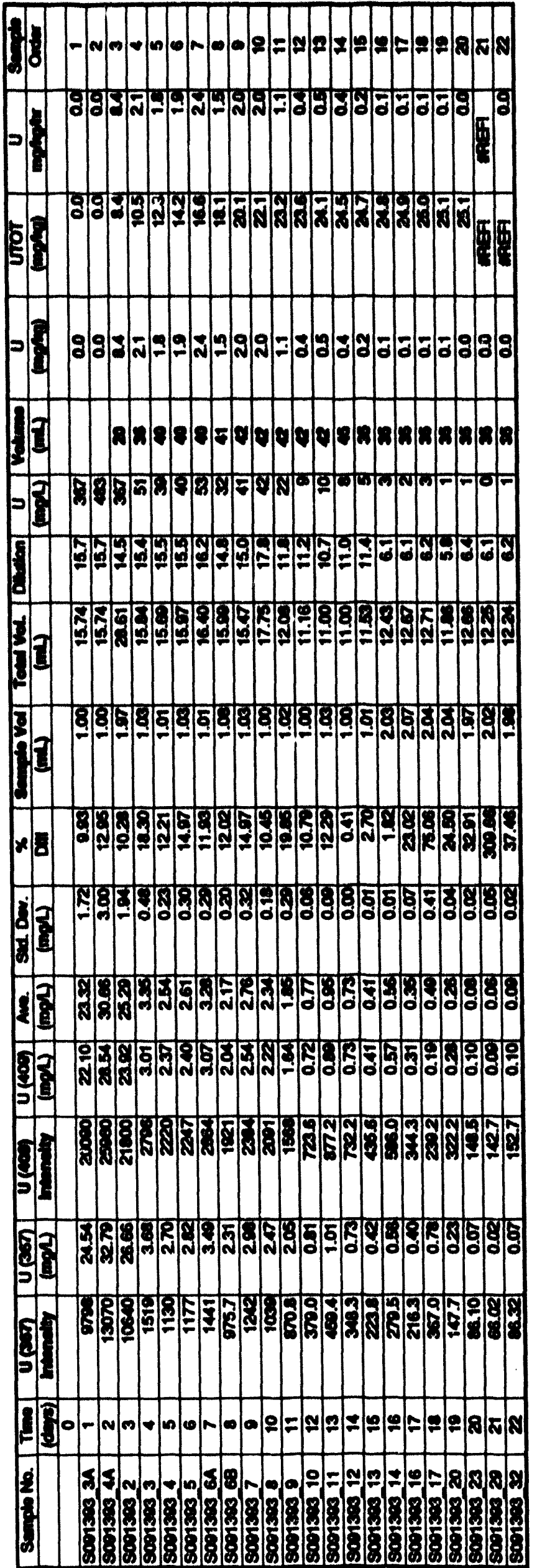




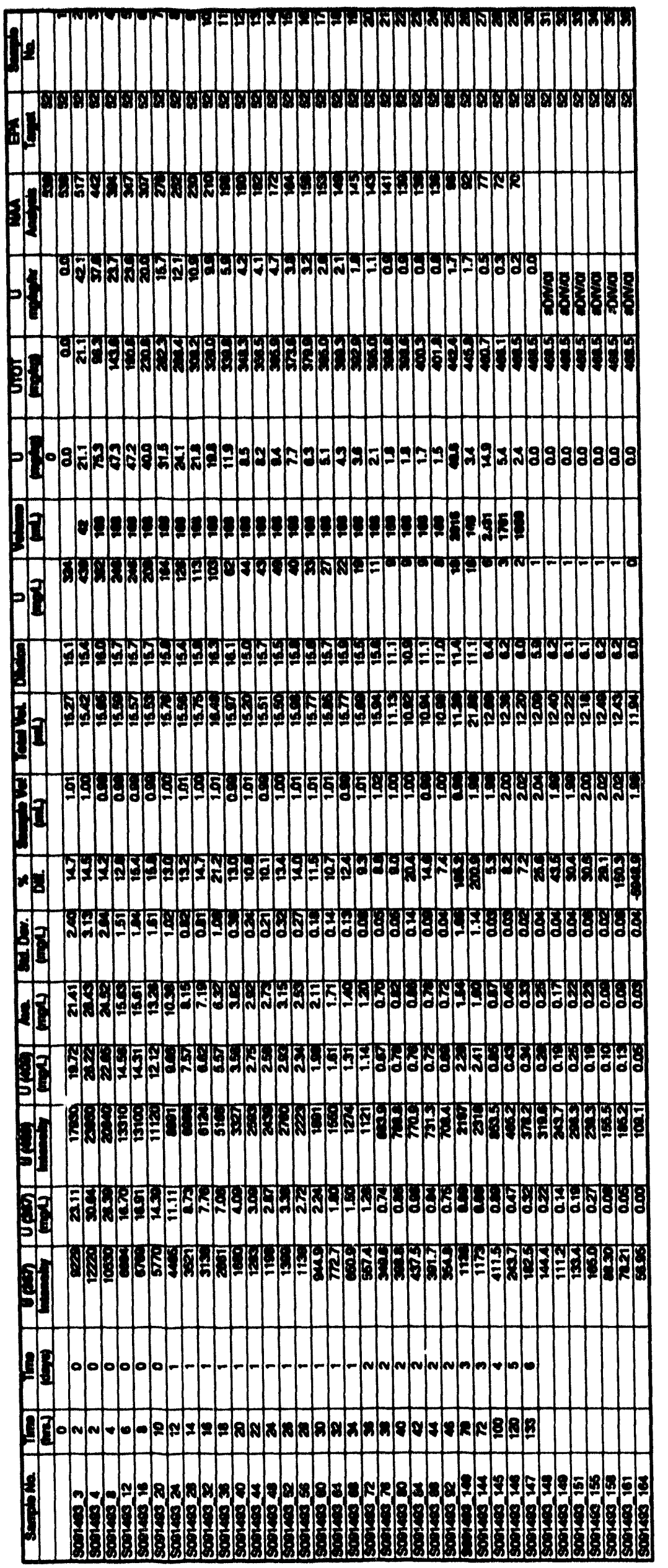

A-11 


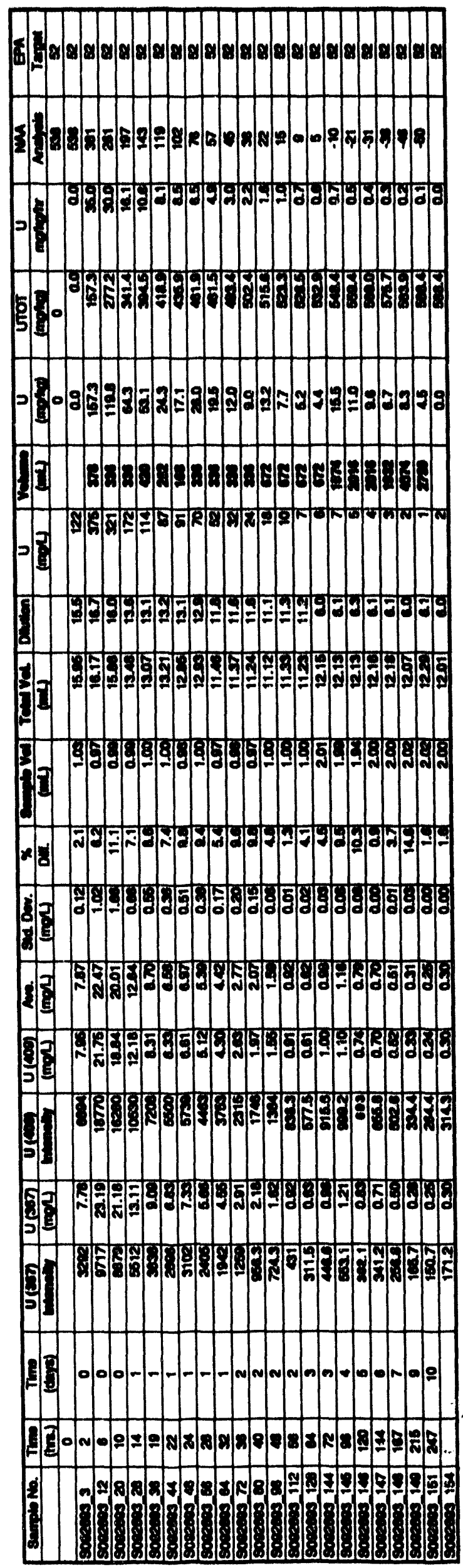




\begin{tabular}{|c|c|c|c|c|c|c|c|c|c|c|c|c|c|c|c|c|c|c|c|}
\hline Semplono. & Time & Thmo & O(En) & U(507) & UTin & $U(100)$ & Ano. & Sed Dow. & $\bar{x}$ & mad & Todval & Divition & U & Volm & $\mathrm{U}$ & UTO & $\mathrm{U}$ & ma & EPA \\
\hline & (thes.) & (ding) & monedy & $(m \cdot h)$ & monely & $(m \cdot h)$ & $(m, 4)$ & $(m ; 2)$ & & (mi) & $(m L)$ & & $(\operatorname{mon} 2)$ & $(m L)$ & $(\mathrm{m} \cdot \mathrm{ko})$ & (mokn) & mokem & Andycin & Tern \\
\hline & 0 & & & & & & & & & & & & & & & & & & 52 \\
\hline 5100193 & 3 & 0 & 5025 & 23.60 & 20010 & 23.10 & 23.44 & 0.35 & 2.1 & 0.00 & 15.20 & 16.3 & 302 & 0 & 0.0 & 0.0 & 0.0 & 538 & 52 \\
\hline$\$ 1001938$ & 6 & 0 & 8120 & 10.30 & 16000 & 18.64 & 10.00 & 0.59 & 3.8 & 0.5 & 16.20 & 15.8 & 20 & 12.3 & 2.7 & 42.7 & 142 & 45 & 82 \\
\hline 8100193 10 & 10 & 0 & 5012 & 13.03 & 12450 & 18.41 & 14.12 & 0.41 & 4.2 & 0.55 & 15.90 & 16.7 & 230) & 10 & 86.4 & 8.1 & 11.4 & 850 & 52 \\
\hline 3100193 14 & 14 & 1 & 60 & 15.72 & 12600 & 14.87 & 15.29 & 0.00 & 5.4 & 0.00 & 15.30 & 16.0 & 245 & 10 & 47.1 & 135.2 & 11.0 & 403 & 52 \\
\hline 810019310 & 18 & 1 & 5124 & 12.18 & 10420 & 12.06 & 12.11 & 0.00 & 1.1 & 0.97 & 15.87 & 16.4 & 109 & 10 & 30.1 & 173.3 & 2.6 & 336 & 52 \\
\hline 810019322 & 22 & 1 & 619 & 14.74 & 10010 & 12.80 & 13.62 & 1.50 & 16.2 & 0.97 & 15.80 & 18.4 & 223 & 10 & 42.9 & 216.2 & 10.7 & 322 & 52 \\
\hline S100103_24 & 24 & 1 & 6070 & 14.47 & 10000 & 12.60 & 13.59 & 1.32 & 12.0 & 0.07 & 13.24 & 13.6 & 185 & $\mathbf{a}$ & 17.7 & 223.9 & 8.9 & 304 & 62 \\
\hline 510019328 & 28 & $T$ & 4094 & 11.69 & C.16 & 11.35 & 11.40 & 0.20 & 24 & 0.97 & 13.31 & 13.7 & 150 & 10 & 30.3 & 204.2 & 7.0 & 274 & 82 \\
\hline 5100193,32 & 32 & 1 & 4287 & 10.12 & 8023 & 2.27 & 2.00 & 0.61 & 8.5 & 0.97 & 13.23 & 13.6. & 132 & 10 & 25.4 & 200.8 & 6.4 & 240 & 5 \\
\hline 310010338 & 36 & 2 & 3373 & 7.0 & 6200 & 7.21 & 7.00 & 0.54 & 0.6 & 0.00 & 12.0 & 13.2 & 101 & 10 & 10.3 & 300,0 & 2.4 & 220 & 52 \\
\hline 510019340 & $\infty$ & 2 & 2000 & 7.00 & 5320 & 6.13 & 6.61 & 0.67 & 13.4 & 0.6 & 12.92 & 13.2 & 87 & 100 & 16.7 & 326.7 & 42 & 212 & 52 \\
\hline 510010348 & 48 & 2 & 2540 & 6.00 & 4630 & 5.33 & 5.68 & 0.48 & 11.3 & 0.0 & 13.17 & 13.4 & 7 & $E$ & 20.3 & 365.0 & 3.7 & 183 & 5 \\
\hline 510010366 & 68 & 2 & 2220 & 5.23 & 2006 & 4.2. & 6.07 & 0.22 & 8.0 & 0.97 & 13.07 & 13.6 & 68 & $E$ & 26.3 & 301.3 & 3.3 & 157 & 52 \\
\hline 510010364 & 64 & 3 & 1772 & 4.14 & 3240 & 3.70 & 3.2 & 0.31 & 10.8 & 0.96 & 13.00 & 13.0 & 5a & 5 & 20.9 & 4022 & 29 & 136 & 82 \\
\hline 510010372 & 72 & 3 & 1420 & 3.31 & 2000 & 3.08 & 3.17 & 0.20 & 8.6 & 0.20 & 13.05 & 13.3 & 4 & $\mathbf{E}$ & 18.2 & 418.4 & 2.0 & 120 & 62 \\
\hline 510019373 & 116 & 5 & 1914.0 & 4.40 & 3367.0 & 4.20 & 4.34 & 0.20 & 6.2 & 1.00 & 11.75 & 5.0 & 20 & 100 & 542 & 472.6 & 1.2 & 65 & 82 \\
\hline 510019374 & 184 & 7 & 941 & 2.14 & 1007.00 & 2.04 & 2.00 & 0.07 & 40 & 2.00 & 12.10 & 6.1 & 13. & 2016 & 20.2 & 501.7 & 0.6 & 36 & E2 \\
\hline 510019376 & 209 & 2 & 873 & 1.50 & 1283.00 & 1.41 & 1.40 & 0.06 & 0.0 & 2.00 & 12.16 & 8.1 & J & 100 & 18.1 & 520.9 & 0.4 & 17 & 52 \\
\hline
\end{tabular}




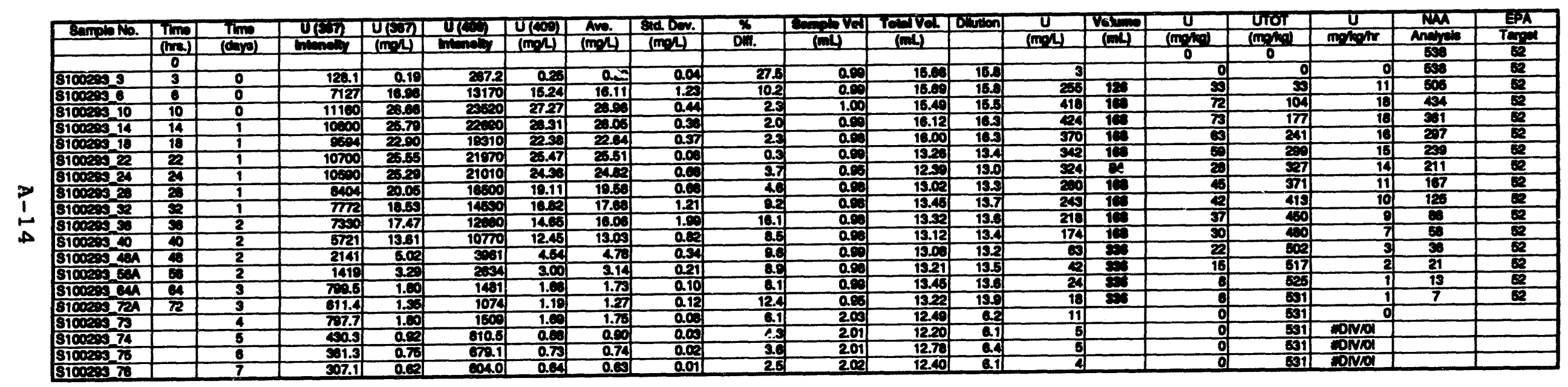


C021193 - 0.1 M Potassium-Carbonate-Bicarbonate, $1 X, 1 \mathrm{~kg} \mathrm{SP4}$, Homogenized

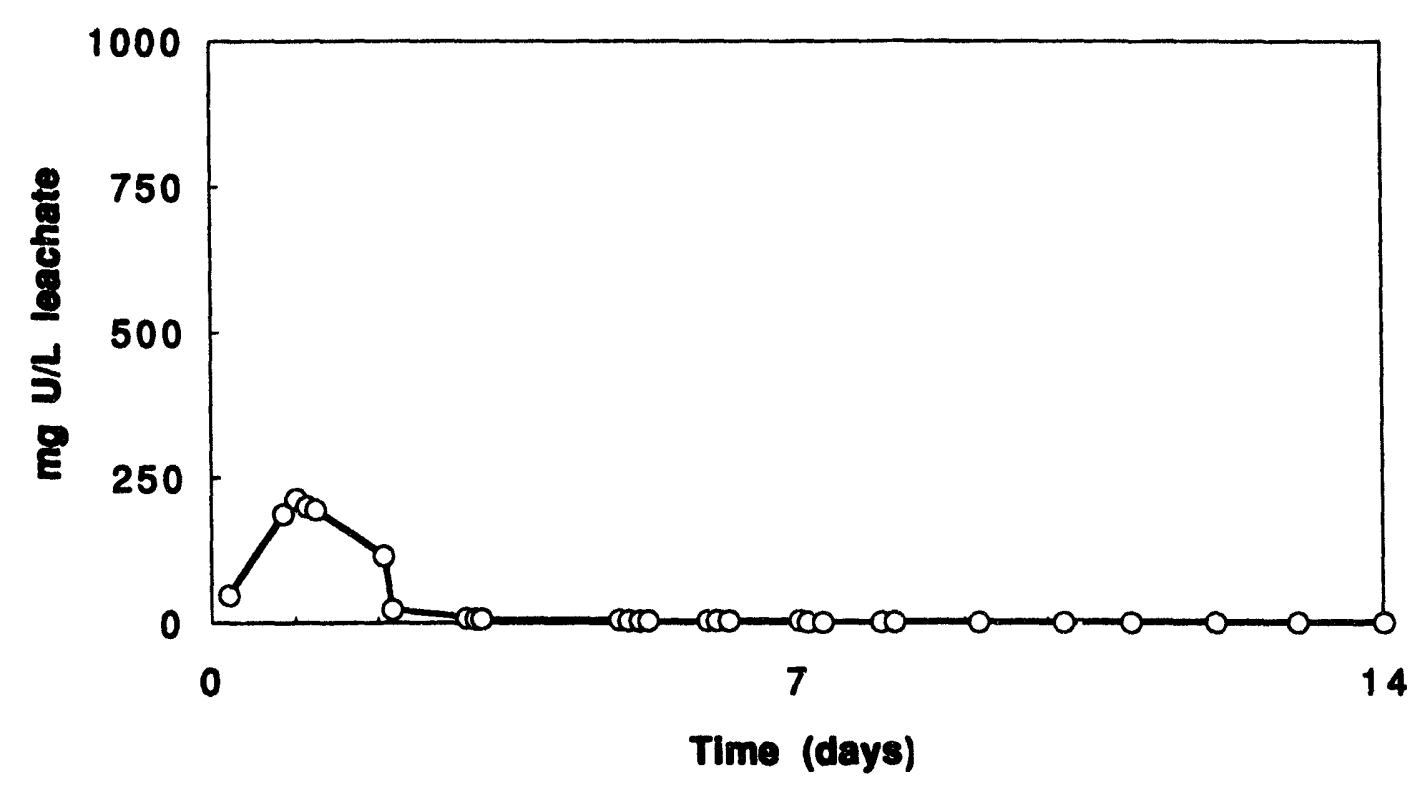

$0.1 \mathrm{M}$ Sodium-Carbonate-Bicarbonate, $1 \mathrm{X}, 1 \mathrm{~kg}$ SP9(93), Homogenized

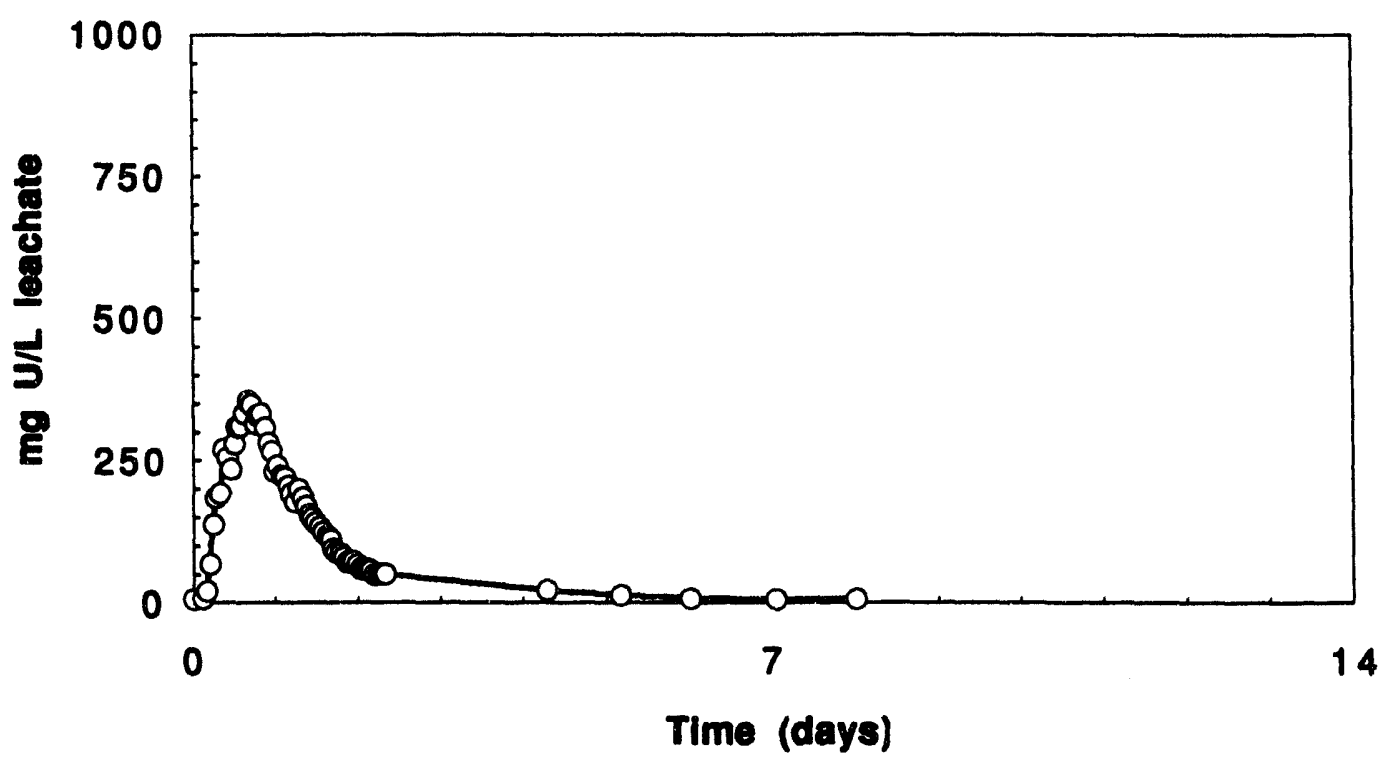


0.5 M Sodium-Carbonate-Bicarbonate, $1 X, 1 \mathrm{~kg}$ SP9(93), Homogenized

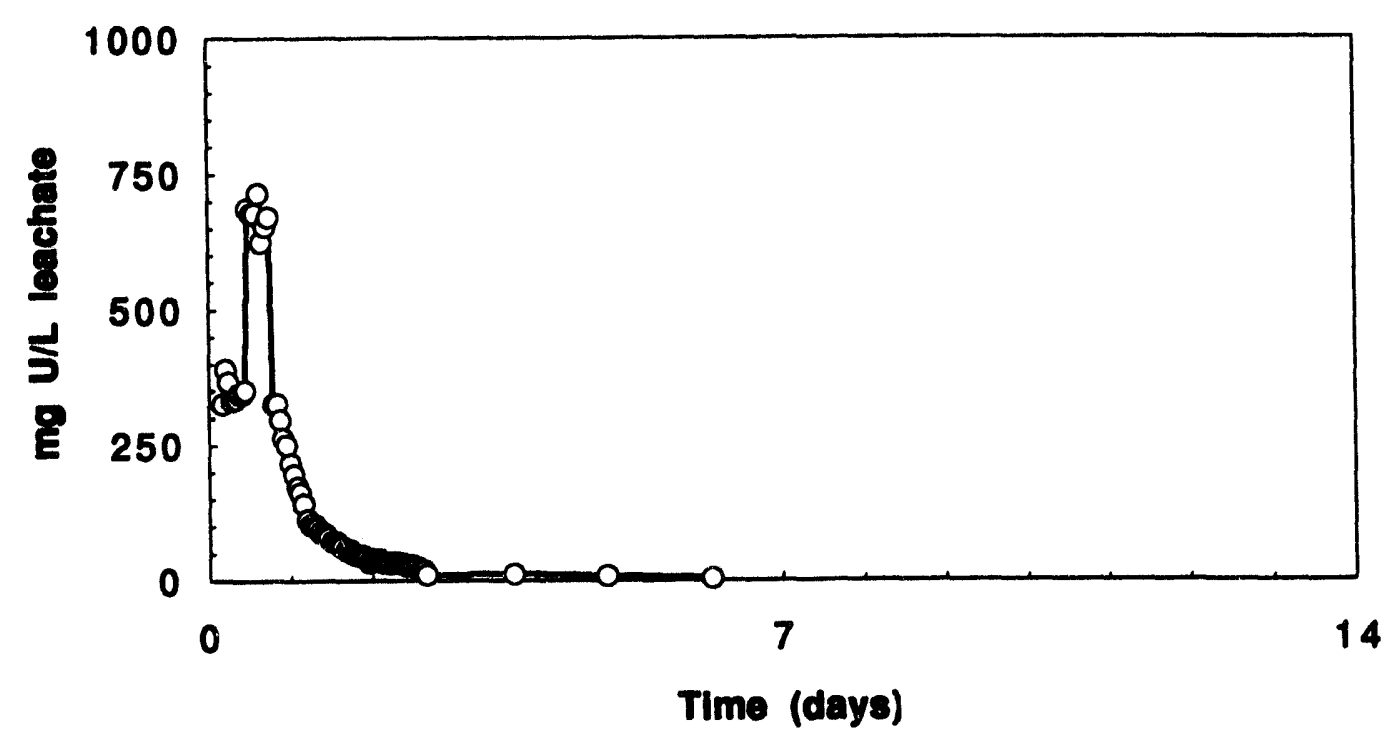

C060493 - 0.2 M Sodium-Carbonate-Bicarbonate, 1X, $1 \mathrm{~kg}$ SP9(93), Homogenized

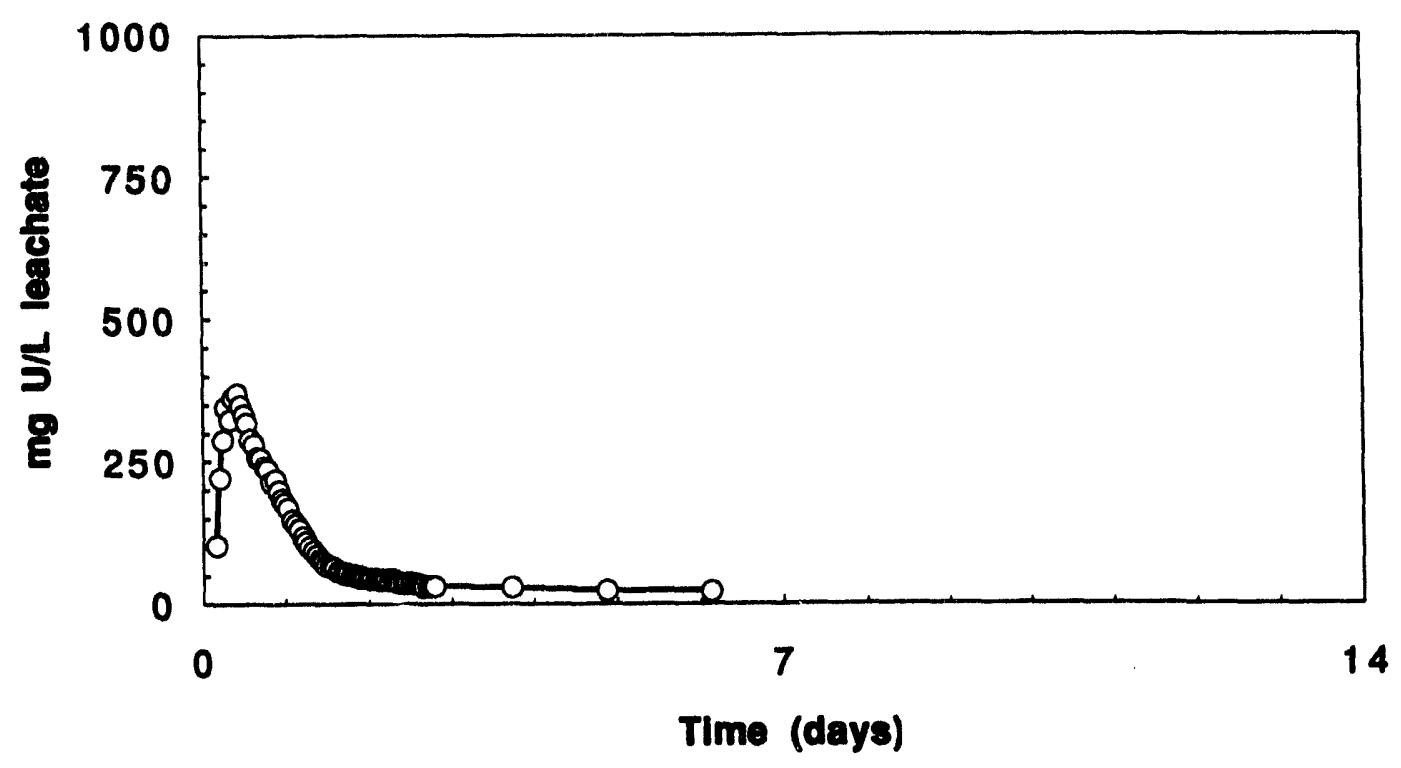

A-16 


\section{C081693 - 0.5 M Sodium0Carbonate-Bicarbonate, 1X, $1 \mathrm{~kg}$ (SP9(93), Homogenized}

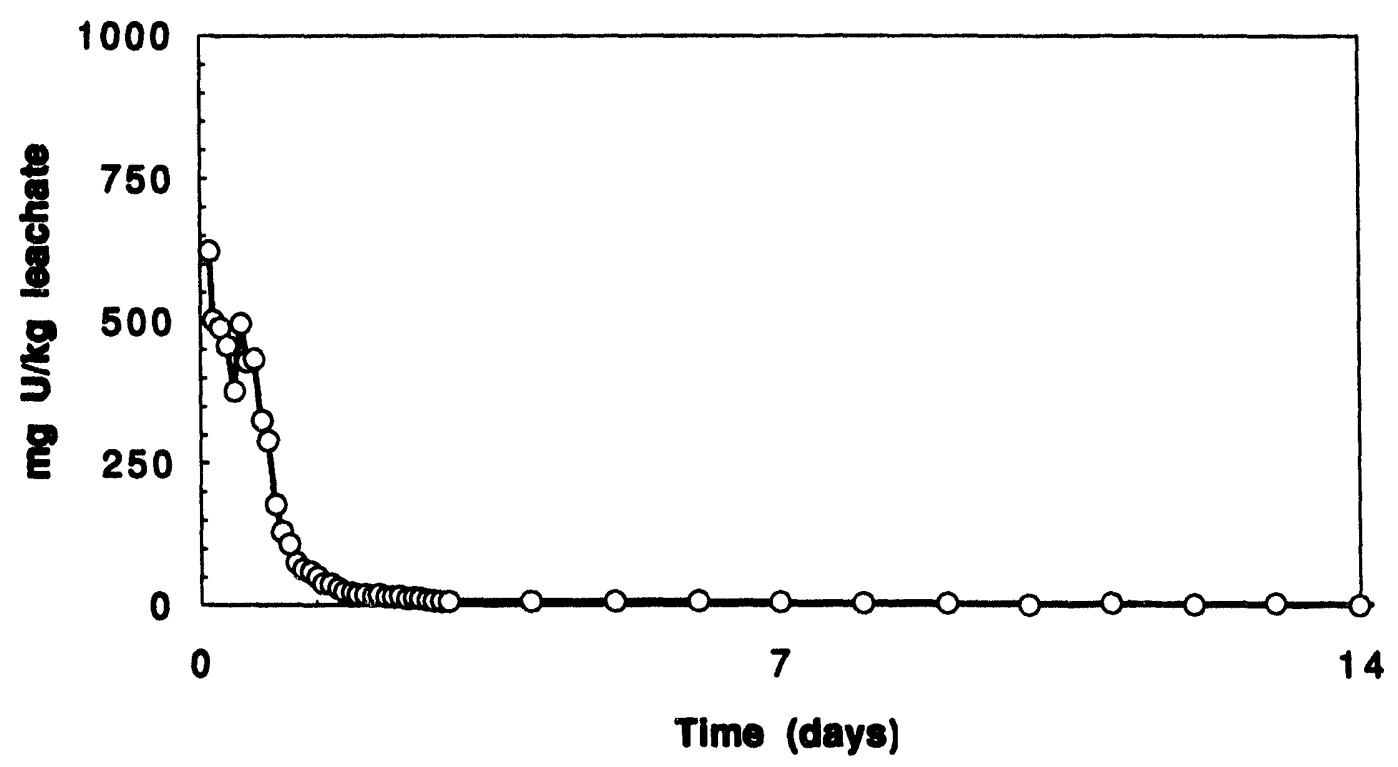

C081793 - $0.5 \mathrm{M}$ Sodium-Carbonate-Bicarbonate, 1X, $1 \mathrm{~kg}$ (SP9(93), Homogenized, Agglomerated with cement

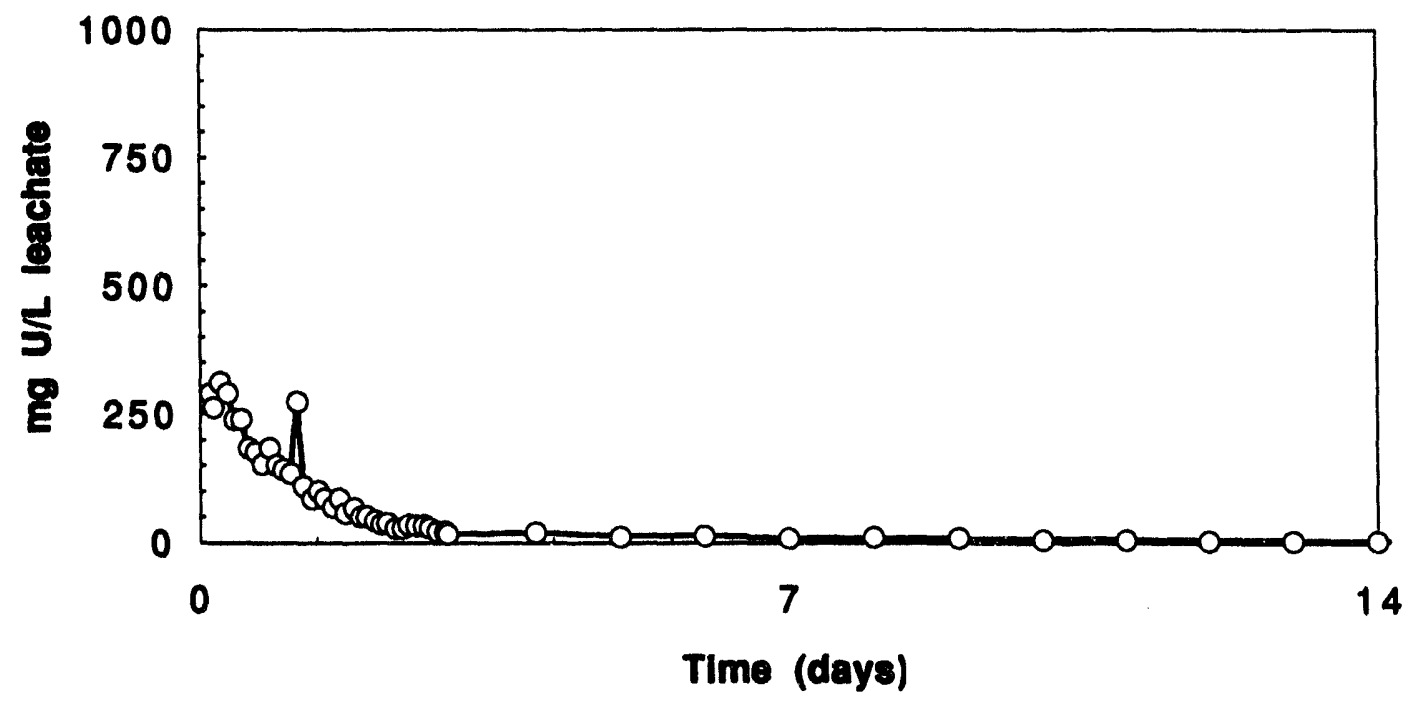


C082693 - 0.25 M Sodium-Carbonate-Bicarbonate, 1X, $1 \mathrm{~kg} \mathrm{SP9(93),} \mathrm{Homogenized}$

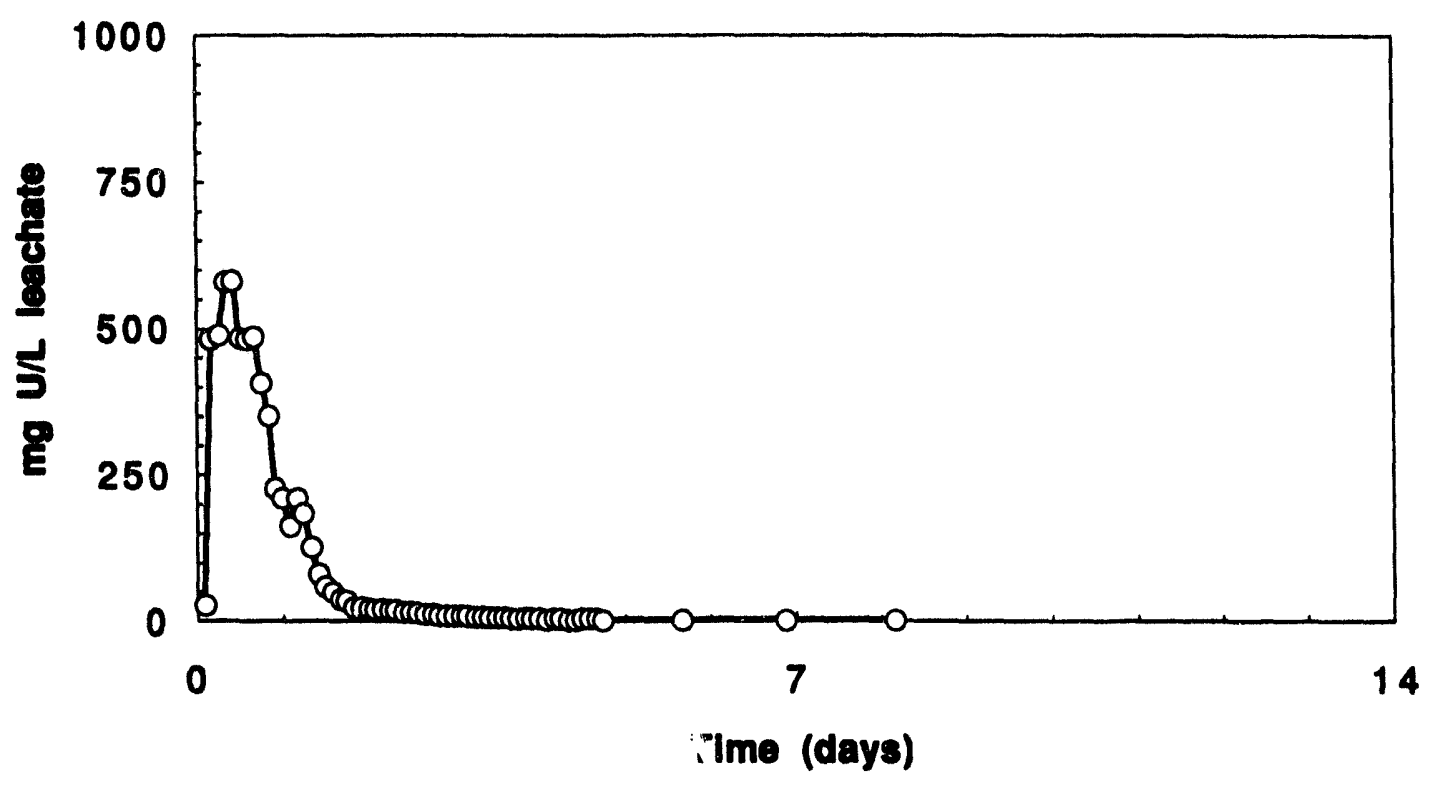

C091393 - 0.5 M Sodium-Carbonate-Bicarbonate, 2X, $1 \mathrm{~kg}$ SP9(93), Homogenized

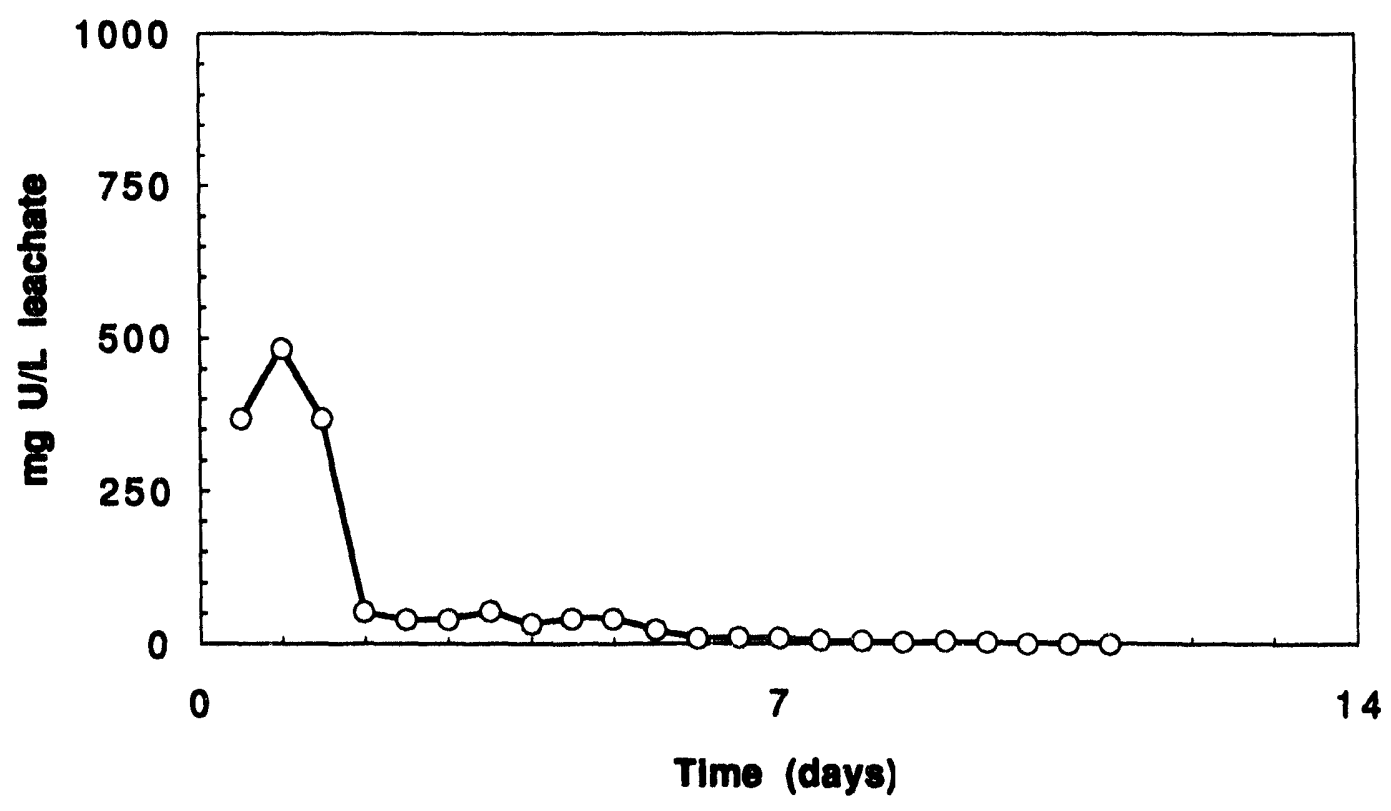


C091493 - 0.5 M Sodium-Bicarbonate-Carbonate, 2X, $1 \mathrm{~kg}$ SP9(93), Homogenized

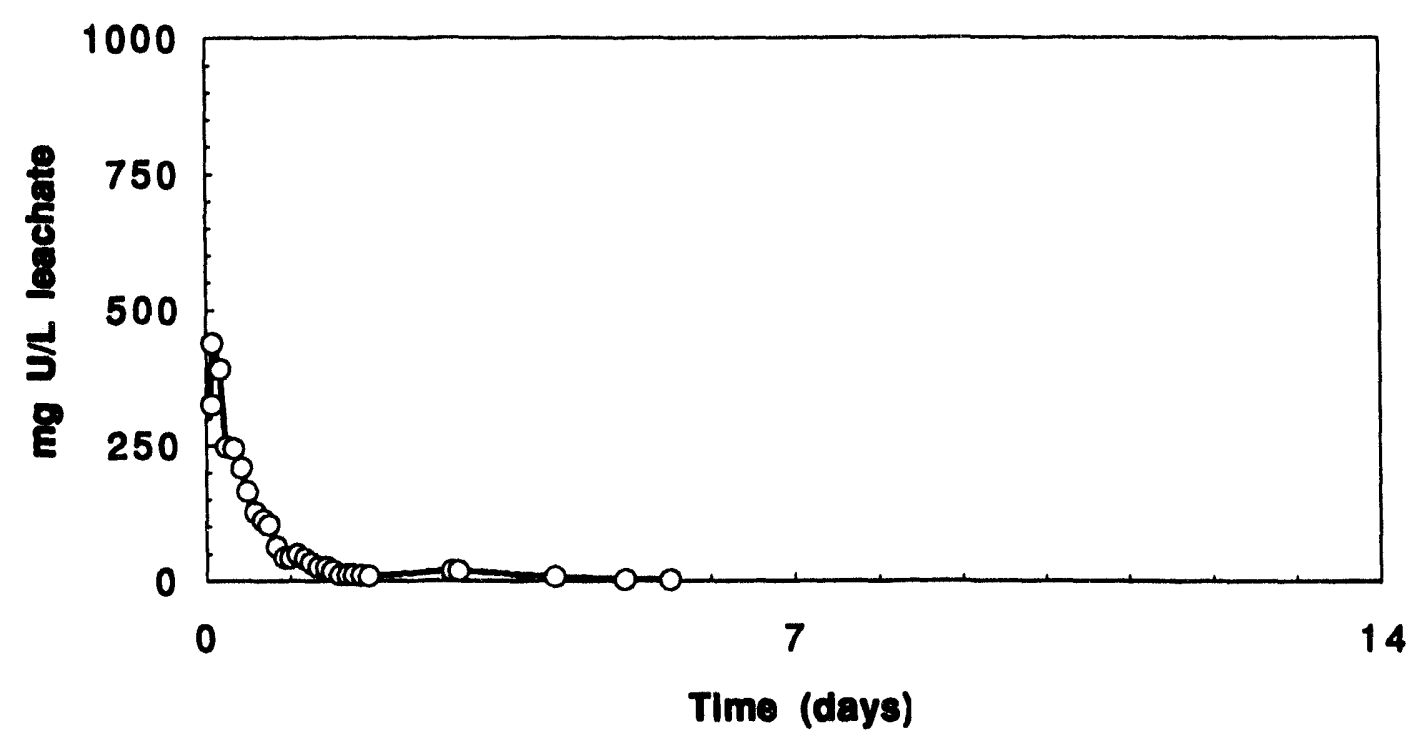

C092893 - 0.1 M Sodium-Carbonate-Bicarbonate, 2X, SP9(93), Homogenized

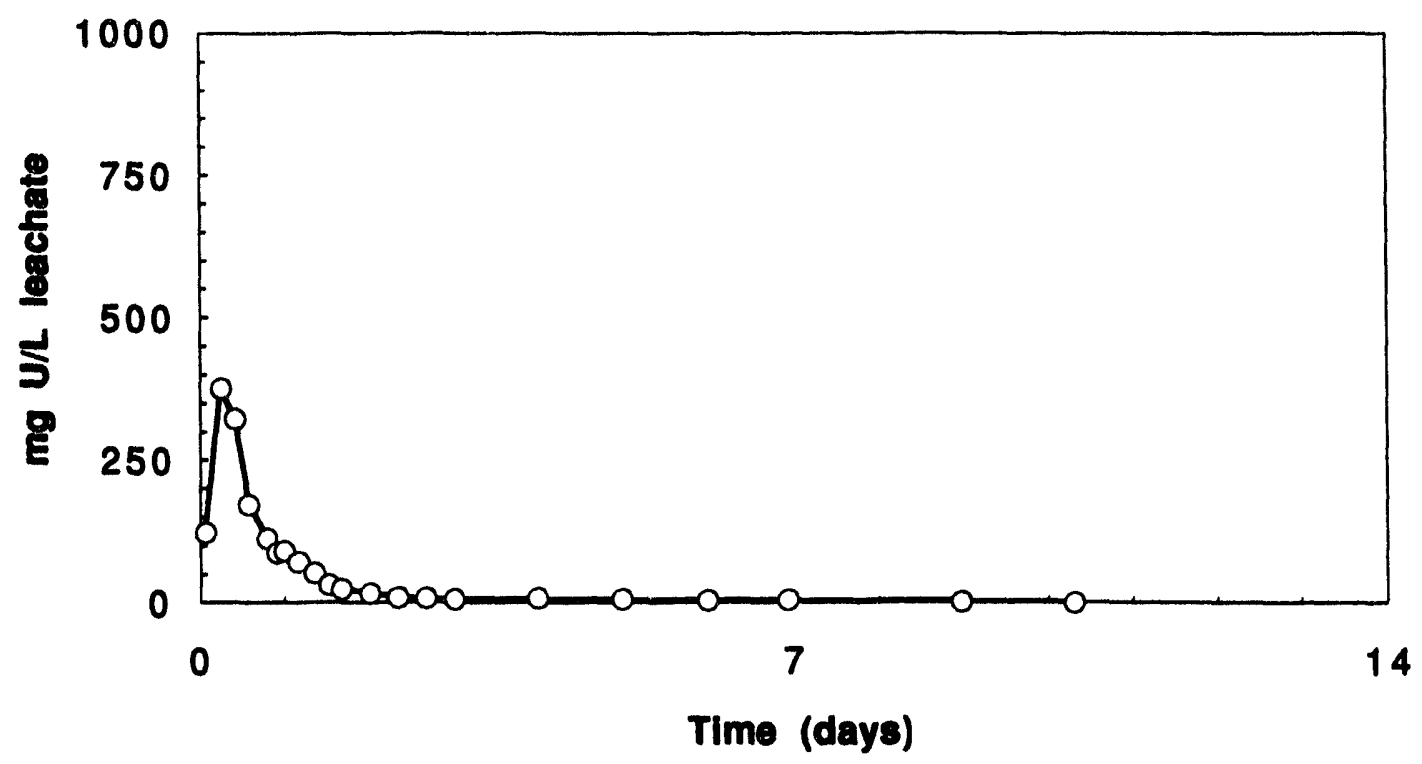


C100193 - 0.1 M Sodium-Carbonate-Bicarbonate, 1X, $1 \mathrm{~kg}$ SP9(93), Homogenized, Agglomerated with cement

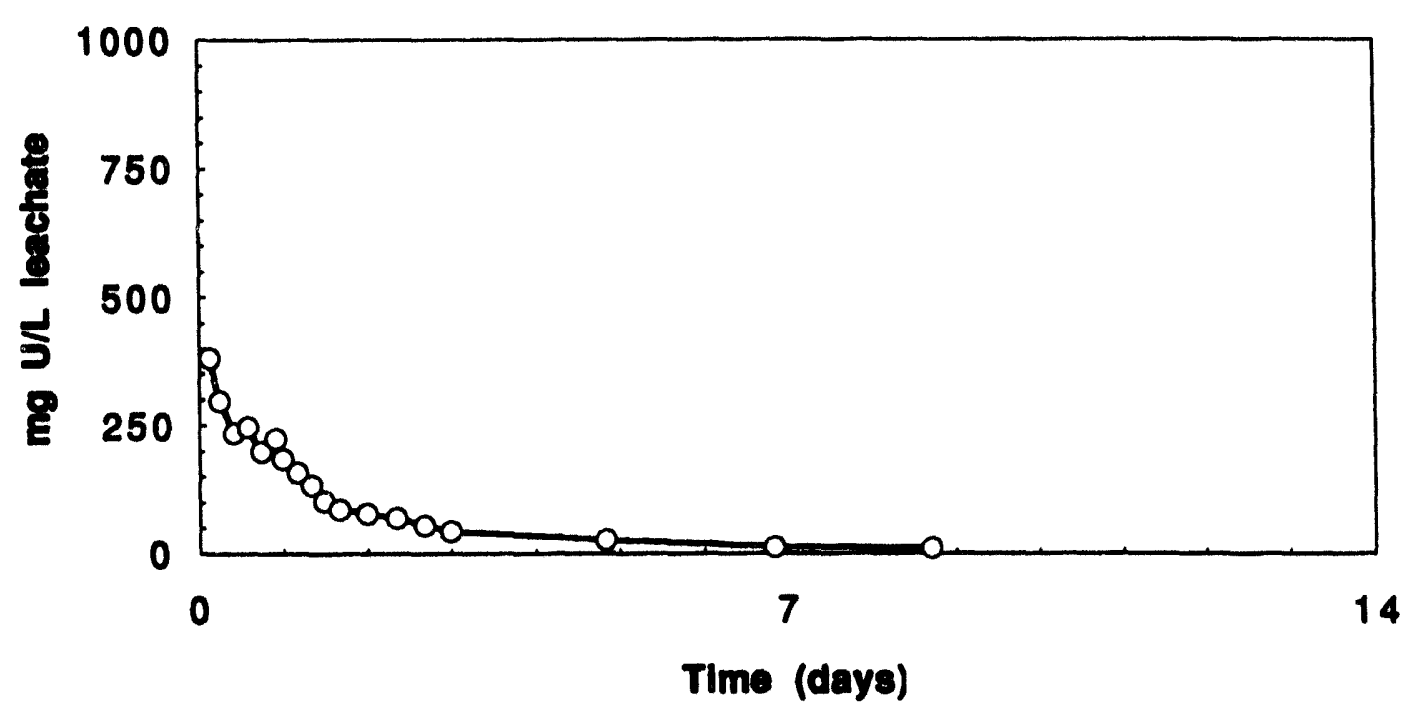

C100293 - 0.1 M Sodium-Carbonate-Carbonate, $1 \mathrm{X}, 1$ kg SP9(93), Homogenized

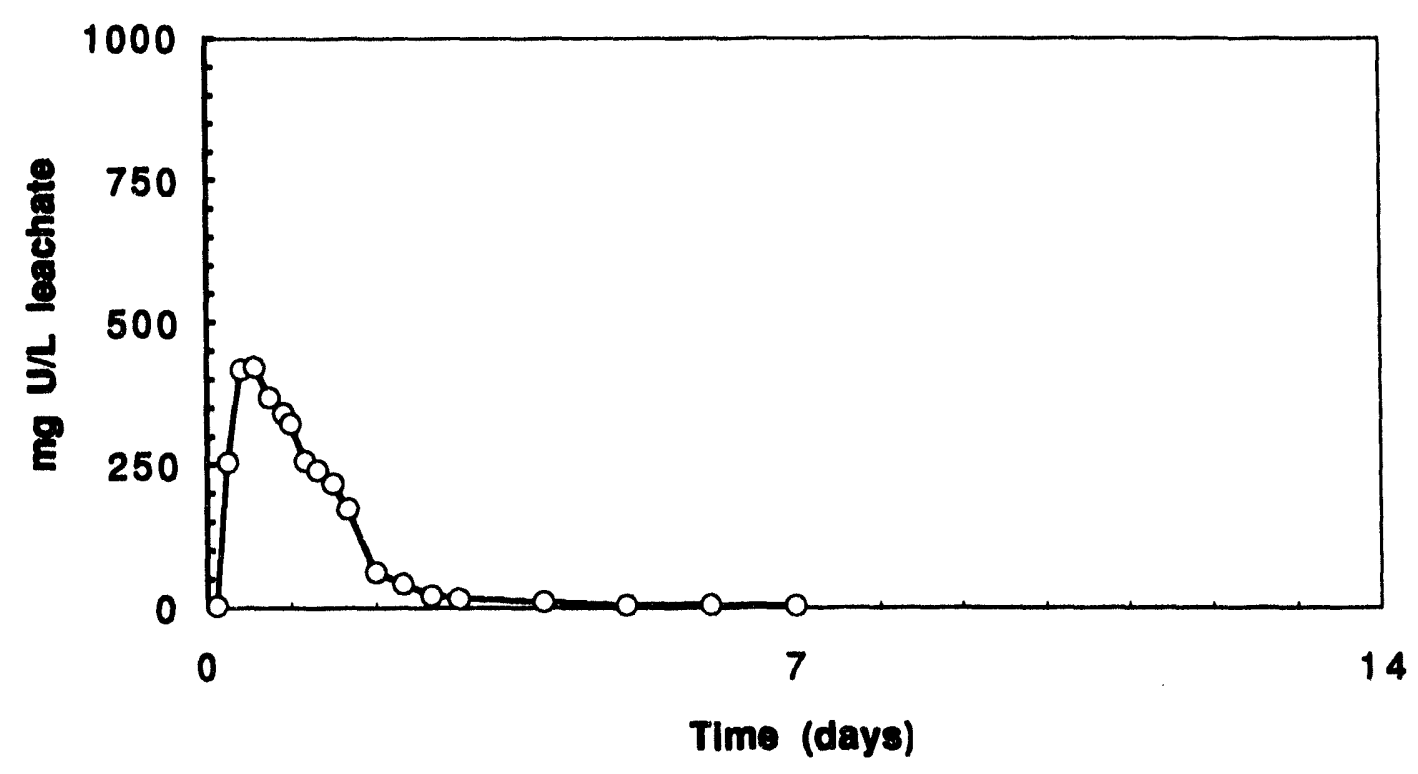




\section{TABLE A 1.2}

\section{SUMMARY OF COLUMN EXPERIMENTS \\ PEAFORMED IN FY 94}

\begin{tabular}{|c|c|c|c|c|c|c|c|}
\hline & $\begin{array}{l}\text { Column } \\
\text { Number }\end{array}$ & $\mathbf{M}$ & $\begin{array}{c}\text { Carbonate } \\
\text { Salt }\end{array}$ & $\begin{array}{l}\text { Flow } \\
\text { Rate }\end{array}$ & $\begin{array}{l}\text { Mases } \\
(\mathrm{kg})\end{array}$ & Soll & reparation \\
\hline & 4 & 0.5 & & 1) & 1 & & not \\
\hline & 4 & 0.5 & & 1) & 1 & & Hete \\
\hline & 02 & 0.5 & Sod & $0.3 x$ & 1 & SPQ(94) & thed with water \\
\hline & $\mathrm{Cos}$ & 0.5 & Sod & $0.3 x$ & 1 & SP9(94) & ith wator \\
\hline & Co & 0.5 & Sodium & $1 X$ & 3 & SP9(94) & Heterogeneous, Agglomerated with water \\
\hline & $\mathrm{C030894}$ & 0.5 & Sodium & $1 x$ & 3 & SP9(94) & Heterogeneous, \\
\hline & 4 & 0.5 & Soc & $1 \mathrm{x}$ & 10 & (94) & jeneous, \\
\hline & $\mathrm{Co32594}$ & 0.5 & Sodium & $1 x$ & 10 & SP9(94) & omerated with wa \\
\hline
\end{tabular}




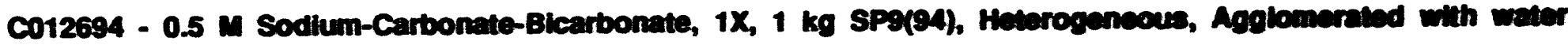

2
1
$N$
$N$

\begin{tabular}{|c|c|c|c|c|c|c|c|c|c|c|c|c|c|c|c|c|}
\hline Sample & Time sample pulled & Samplo & $\begin{array}{l}\text { Total } \\
\text { mass }\end{array}$ & Difution & $\begin{array}{c}\text { ppa U (19P } \\
367)\end{array}$ & $\begin{array}{c}\mathrm{Ppo} u(\cos ) \\
409)\end{array}$ & $\mid \begin{array}{cc}A m & 10 P \\
p p=0 & U\end{array}$ & $\begin{array}{l}\text { Sur. } \\
\text { Dew. }\end{array}$ & $\begin{array}{l}\text { Expentuent } \\
\text { Tines }\end{array}$ & $\begin{array}{l}0 \\
\text { un }\end{array}$ & m & $\begin{array}{c}\text { Empiy } \\
\text { contuiner } \\
\text { men }(\mathrm{f})\end{array}$ & 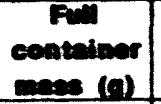 & $\begin{array}{l}\text { Fow } \\
\text { (Lday) }\end{array}$ & $\begin{array}{c}\text { ae } \\
\text { u/kg } \\
\text { sed }\end{array}$ & Comerolotion \\
\hline & & & & & & & & & & & & & & & & \\
\hline & & & & & & & & & & & & & & & & \\
\hline & & & & & & & & & & & & & & & & \\
\hline & 1 12604 11:00 AM & & & & & & & & & & & & & & & \\
\hline 50126942 & $1 / 26 / 941.00 \mathrm{PM}$ & 1.1038 & 19.8468 & 18.0 & 28.58 & 28.48 & 28.5 & 0.0 & 0 & 513 & 9.485 & 10.4150 & 15.51 & 0.96 & 3 & 3 \\
\hline 50126943 & $1 / 26 / 942.00 \mathrm{PM}$ & 1.0129 & 19.9532 & 19.7 & 24.37 & 24.44 & 24.4 & 0.0 & 0 & 481 & 9.346 & 10.3435 & 47.26 & 0.00 & 22 & 25 \\
\hline 5012694 & $1 / 26 / 043.00 \mathrm{PM}$ & 0.8653 & 20.1102 & 20.8 & 19.91 & 10.84 & 19.9 & 0.0 & 0 & 414 & 0.434 & 10.4289 & $\$ 0.98$ & 0.05 & 20 & 45 \\
\hline 50126945 & $1 / 26 \mathrm{MM} 4.00 \mathrm{PM}$ & 0.0055 & 20.1218 & 20.2 & 17.03 & 17.00 & 18.0 & 0.0 & 0 & 363 & 0.481 & 10.4183 & 51.71 & 0.09 & 10 & 64 \\
\hline 50126946 & $1 / 26 / 945.00 \mathrm{PW}$ & 1.0128 & 20.0392 & 19.8 & 16.46 & 16.42 & 16.4 & 0.0 & 0 & 325 & 0.520 & 10.4113 & 52.07 & 1.00 & 17 & 81 \\
\hline 50126947 & $1 / 269946.00 \mathrm{PAM}$ & 1.0178 & 20.2046 & 19.9 & 15.4 & 15.43 & 15.4 & 0.0 & 0 & 306 & 0.544 & 10.4406 & 52.48 & 1.01 & 16 & 9 \\
\hline $501269426 A$ & $1 / 2610411: 00$ PM & 1.0375 & 20.0086 & 10.3 & 13.4 & 13.44 & 13.4 & 0.0 & 1 & 250 & 0.567 & 51.7162 & 265.60 & 1.03 & 60 & 165 \\
\hline 5012604268 & $1 / 27 / 9411: 00 \mathrm{NM}$ & 1.0204 & 19.9442 & 19.5 & 10.15 & 10.11 & 10.1 & 0.0 & 1 & 108 & 9.508 & 124.2394 & 657.11 & 1.07 & 130 & 205 \\
\hline S012694_26C & $1 / 27 / 9411: 00 \mathrm{PM}$ & 1.0177 & 20.1311 & 19.8 & 8.884 & 8.834 & 8.9 & 0.0 & 2 & 175 & 0.607 & 124.3013 & 662.49 & 1.00 & 116 & 412 \\
\hline 5012694260 & 1/28194 11:00 MM & 4.1576 & 20.4337 & 4.9 & 24.23 & 23.79 & 24.0 & 0.2 & 2 & 118 & 9.61 & 124.3251 & 689.04 & 1.00 & 70 & 401 \\
\hline $501269426 E$ & $1 / 28047.00$ PM & 3.9308 & 10.9773 & 5.1 & 16.81 & 16.44 & 16.6 & 0.2 & 2 & 84 & 0.627 & 82.0020 & 451.43 & 1.11 & 38 & -2 \\
\hline 501269457 & $1 / 2019411: 00 \mathrm{AM}$ & 3.9892 & 20.0524 & 5.0 & 12.24 & 12.04 & 12.1 & 0.1 & 3 & 61 & 0.662 & 100.57 & 848.25 & 1.12 & 56 & 500 \\
\hline S012694_58 & $1 / 30 / 949: 35 \mathrm{AM}$ & 4.1809 & 20.1222 & 4.8 & 8.843 & 8.698 & 8.8 & 0.1 & 4 & 12 & 9.65 & 00.73 & 1162.27 & 1.13 & 55) & 641 \\
\hline 501269459 & $1 / 31 / 948: 12 \mathrm{AM}$ & 4.0283 & 20.0649 & 5.0 & 6.476 & 6.352 & 6.4 & 0.1 & 5 & 32 & 8.634 & $\infty .84$ & 1160.86 & 1.13 & 42 & 623 \\
\hline 501269460 & $2 / 1 / 947: 00 \mathrm{AM}$ & 4.1448 & 20.2221 & 4.9 & 5.26 & 5.167 & 5.2 & 0.0 & 6 & 25 & 9.638 & 100.134 & 1185.65 & 1.14 & 34 & 717 \\
\hline 501269461 & $2 / 194$ 5:25 PM & 4.2112 & 20.0835 & 4.8 & 5.424 & 5.314 & 5.4 & 0.1 & 6 & 26 & 9.636 & 100.58 & 585.36 & 1.12 & 15 & 732 \\
\hline 501269462 & $2 / 2944030 \mathrm{PM}$ & 3.0205 & 19.9502 & 5.1 & 5.478 & 5.396 & 5.4 & 0.0 & 7 & 28 & 9.627 & 100.305 & 1194.23 & 1.14 & 37 & 770 \\
\hline 501269463 & 2/3/94 3:15 PM & 4.1742 & 20.0773 & 4.8 & 4.750 & 4.623 & 4.7 & 0.1 & 8 & 23 & 9.627 & 100.564 & 1171.44 & 1.13 & 30 & 800 \\
\hline 501269464 & 2/404 3:30 PM & 3.7606 & 20.0134 & 5.3 & 3.640 & 3.531 & 3.6 & 0.1 & 9 & 10 & 9.618 & 100.979 & 1223.64 & 1.11 & 26 & 826 \\
\hline 501269465 & $2 / 4 / 944.00 \mathrm{PL}$ & 4.0665 & 18.9768 & 4.9 & 3.904 & 3.842 & 3.9 & 0.0 & 9 & 10 & 9.612 & 10.3493 & 32.12 & 1.04 & 1 & 227 \\
\hline 501269466 & $2 / 51948: 15 \mathrm{AM}$ & 3.8287 & 20.6103 & 5.4 & 2.067 & 2.891 & 2.9 & 0.0 & 10 & 16 & 0.62 & 100.646 & 879.5 & 1.15 & 15 & 842 \\
\hline 501269467 & $260947: 00 \mathrm{NM}$ & 4.0442 & 20.0666 & 5.0 & 2.522 & 2.489 & 2.5 & 0.0 & 11 & 12 & 9.621 & 100.597 & 1165.18 & 1.12 & 16 & 258 \\
\hline 501269468 & $2 / 6204$ 5:00 PM & 4.143 & 20.0137 & 4.8 & 2.126 & 2.075 & 2.1 & 0.0 & 11 & 10 & 0.612 & 100.543 & 577.36 & 1.14 & 6 & 864 \\
\hline 501269469 & $271943.25 \mathrm{PM}$ & 4.1900 & 19.9800 & 4.8 & 1.927 & 1.891 & 1.9 & 0.0 & 12 & 9 & 9.608 & 99.85 & 1156.94 & 1.13 & 12 & $87 e$ \\
\hline 501269470 & $2 / 894$ 3:15 PM & 4.0281 & 20.0296 & 5.0 & 1.623 & 1.576 & 1.6 & 0.0 & 13 & 8 & 0.626 & 100.60 & 1221.27 & 1.13 & 11 & 887 \\
\hline 501269471 & $2999410: 15 \mathrm{AM}$ & 4.1784 & 20.1715 & 4.8 & 1.742 & 1.650 & 1.7 & 0.0 & 14 & 8 & 9.619 & 100.03 & 90.05 & 1.14 & of & 896 \\
\hline 501269472 & $2 / 10049.05 \mathrm{AM}$ & 4.1730 & 20.0522 & 4.8 & 1.823 & 1.742 & 1.8 & 0.0 & 15 & 9 & 9.616 & 100.38 & 1173.3 & 1.13 & 11 & 907 \\
\hline 501269473 & 2111/94 8:15 AM & 4.1041 & 19.9008 & 4.9 & 1.345 & 1.243 & 1.3 & 0.1 & 16 & 6 & 9.616 & 100.01 & 1193.57 & 1.13 & of & 916 \\
\hline 501269474 & $2 / 11 / 945: 20 \mathrm{PW}$ & 4.1604 & 20.0157 & 4.8 & 1.118 & 1.070 & 1.1 & 0.0 & 16 & 5 & 8.600 & 100.18 & 534.41 & 1.15 & 3 & 918 \\
\hline 501269475 & $2 / 129412: 18$ PM & 4.1708 & 20.2847 & 4.9 & 1.016 & 0.9733 & 1.0 & 0.0 & 17 & 5 & 9.607 & 100.4 & 906.44 & 1.13 & 5 & 924 \\
\hline 501269476 & $2 / 13 / 949: 50 \mathrm{AM}$ & 4.1486 & 19.9690 & 4.8 & 0.8521 & 0.816 & 0.8 & 0.0 & 18 & 4 & 0.613 & $\infty .71$ & 1120.8 & 1.14 & 5 & 220 \\
\hline 501269477 & $2 / 14048221 \mathrm{NM}$ & 4.1741 & 19.2433 & 4.8 & 0.8230 & 0.7957 & 0.8 & 0.0 & 19 & 4 & 0.614 & 100.72 & 1164.26 & 1.13 & 5 & 934 \\
\hline 501269478 & $215194623 \mathrm{AM}$ & 4.1776 & 20.0403 & 4.8 & 0.753 & 0.7510 & 0.8 & 0.0 & 20 & 4 & 0.612 & 101.83 & 1140.91 & 1.13 & 5 & 939 \\
\hline 501269479 & 211694 12:03 AM & 4.1145 & 20.0723 & 4.0 & 0.7712 & 0.7233 & 0.7 & 0.0 & 21 & 4 & 0.618 & 102.80 & 933.71 & 1.13 & (4) & 243 \\
\hline 501269480 & $2 / 160410: 38 \mathrm{PM}$ & 4.1516 & 20.2529 & 4.0 & 0.7784 & 0.7473 & 0.8 & 0.0 & 21 & 4 & 9.620 & 102.63 & 1167.20 & 1.13 & 5 & 247 \\
\hline 501269481 & $2 / 17 / 043: 40$ PM & 4.1503 & 20.2378 & 4.0 & 0.8074 & 0.7978 & 0.8 & 0.0 & 22 & 4 & 9.633 & 101.25 & 89.16 & 1.11 & (4) & 951 \\
\hline 501260482 & $2 / 18941: 32 \mathrm{PM}$ & 4.1023 & 10.8003 & 4.9 & 0.824 & 0.7896 & 0.8 & 0.0 & 23 & 4 & 0.636 & 101.94 & 1115.35 & 1.11 & 5 & ose \\
\hline $5012694 \quad 83$ & $2 / 1004$ 11:37 M & 4.1645 & 20.2350 & 4.0 & 0.6545 & 0.6476 & 0.7 & 0.0 & 24 & 3 & 0.620 & 102 & 1131.22 & 1.12 & 4 & 960 \\
\hline 501269484 & $27201942: 40 \mathrm{PM}$ & 4.1955 & 20.0543 & 4.8 & 0.5701 & 0.5520 & 0.6 & 0.0 & 25 & 3 & 9.639 & 101.90 & 1187.87 & 0.06 & 4 & 964 \\
\hline 501269485 & $2221 / 940: 40 \mathrm{NM}$ & 4.1838 & 19.0020 & 4.8 & 0.5227 & 0.4856 & 0.5 & 0.0 & 26 & 2 & 9.631 & 101.90 & 900.4 & 1.11 & 3. & 96 \\
\hline S012694 86 & $2220048: 30 \mathrm{MM}$ & 4.1618 & 20.4453 & 4.9 & 0.5171 & 0.4895 & 0.5 & 0.0 & 27 & 2 & 0.633 & 101.803 & 1157.5 & 1.11 & 3 & 970 \\
\hline 501260487 & $2222941225 \mathrm{PL}$ & 4.1243 & 19.9503 & 4.8 & 0.5277 & 0.4921 & 0.5 & 0.0 & 27 & 2 & 9.617 & 101.0 & 284.65 & 1.12 & 1 & 970 \\
\hline 501269488 & $222010412-26 \mathrm{PM}$ & 4.1536 & 20.0500 & 4.8 & 0.505 & 0.5568 & 0.6 & 0.0 & 27 & 3 & 0.631 & 54.73 & 60.18 & 0.00 & of & 970 \\
\hline
\end{tabular}




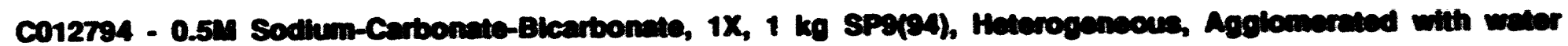

\begin{tabular}{|c|c|c|c|c|c|c|c|c|c|c|c|c|c|c|c|c|}
\hline Sample & $\operatorname{Tn}$ & Shes & $\begin{array}{l}\text { Total } \\
\text { mases }\end{array}$ & Datution & $\begin{array}{c}900 \mathrm{U} \\
367)\end{array}$ & 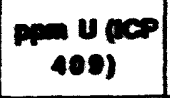 & 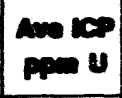 & $\begin{array}{l}\text { sed. } \\
\text { Den. }\end{array}$ & Expertment & $\begin{array}{c}p \\
0\end{array}$ & m & 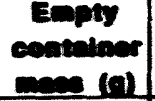 & 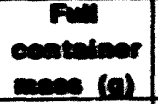 & (L/day) & $\begin{array}{c}\text { De } \\
\text { urteg } \\
\text { ean }\end{array}$ & $\begin{array}{c}0 \\
0,4 / 1 \\
c e n\end{array}$ \\
\hline & & & & & & & & & & & & & & & & \\
\hline & & & & & & & & & & & & & & & & \\
\hline & & & & & & & & & & & & & & & & \\
\hline & 1/20:04 11:00 AM & & & & & & & & & & & & & & & \\
\hline 50127943 & $1 / 26004200 \mathrm{PM}$ & 0.9067 & 10.9350 & 20 & 33.36 & 33.50 & 33.5 & 0.1 & 0 & 670 & 8.69 & 10.300 & 20.67 & 0.2 & 16 & 16 \\
\hline 50127944 & $1 / 2694 \quad 3.00 \mathrm{PM}$ & 1.0065 & 10.8036 & 20 & 28.43 & 28.53 & 28.5 & 0.1 & 0 & 560 & 0.164 & 10.3024 & 47.53 & 0.9 & 26 & 42 \\
\hline 50127945 & $1 / 2694 \quad 400 \mathrm{PM}$ & 1.0083 & 10.8338 & 20 & 23.33 & 23.47 & 23.4 & 0.1 & 0 & 460 & 0.320 & 10.3057 & 50.12 & 1.0 & 23 & \\
\hline 50127946 & $1 / 26194 \quad 5.00 \mathrm{PL}$ & 1.0106 & 20.0550 & 20 & 20.51 & 20.42 & 20.5 & 0.0 & 0 & 406 & 0.454 & 10.2042 & 51.07 & 1.0 & 20 & 85 \\
\hline 50127947 & $1 / 2604600 \mathrm{Fm}$ & 1.0108 & 20.1161 & 20 & 18.56 & 18.45 & 18.5 & 0.1 & 0 & 365 & 0.40 & 10.3007 & 51.0 & 1.0 & 10 & 108 \\
\hline 50127948 & $1 / 2694 \quad 7.00 \mathrm{PM}$ & 0.9068 & 20.1873 & 20 & 16.68 & 16.61 & 16.6 & 0.0 & 0 & 337 & 0.531 & 10.2495 & 5210 & 1.0 & 17 & 121 \\
\hline 50127949 & $1 / 26048000 \mathrm{PM}$ & 1.0172 & 20.7226 & 20 & 15.31 & 15.38 & 15.3 & 0.0 & 0 & 313 & 0.40 & 10.3685 & 52.7 & 1.0 & 16 & 137 \\
\hline $5012794 \quad 10$ & 1rQ694 9:00 PM & 1.0054 & 20.0200 & 20 & 14.06 & 14.9 & 14.0 & 0.0 & 0 & 207 & 0.521 & 10.369 & 52.89 & 1.0 & 16 & 153 \\
\hline 501270411 & \begin{tabular}{|ll}
$1 / 26104$ & $10.00 \mathrm{PW}$ \\
\end{tabular} & 0.9706 & 19.8008 & 20 & 14.00 & 14.01 & 14.1 & 0.0 & 0 & 288 & 0.517 & 10.363 & 53.14 & 1.0 & 15 & 16 \\
\hline 501279412 & $1 / 2694 \quad 11.00 \mathrm{Pu}$ & 1.0261 & 20.2064 & 20 & 14.35 & 14.20 & 14.3 & 0.0 & 0 & 282 & 0.531 & 10.36 & 53.41 & 1.0 & 15 & 105 \\
\hline 5012794 A & $1 / 27 / 94 \quad 11: 00 \mathrm{AM}$ & 0.0979 & 20.3600 & 20 & 12.67 & 12.56 & 12.6 & 0.1 & 1 & 257 & 0.552 & 123.0007 & 657.00 & 1.1 & 160 & 352 \\
\hline S012704 B & $1 / 27 / 94 \quad 11.00 \mathrm{PAM}$ & 1.0306 & 20.5760 & 20 & 10.83 & 10.76 & 10.8 & 0.0 & 1 & 216 & 0.506 & 124.2115 & 668.05 & 1.1 & 145 & 407 \\
\hline $5012704 \mathrm{C}$ & $\begin{array}{ll}12004 & 11.00 \mathrm{AM} \\
\end{array}$ & 1.0338 & 10.0004 & 10 & 7.720 & 7.646 & 7.7 & 0.0 & 2 & 140 & 0.609 & 124.4400 & 679.69 & 1.1 & 102 & 500 \\
\hline S012794 D & $1 / 2894 \quad 11: 00 \mathrm{PM}$ & 4.1820 & 10.0766 & 5 & 16.70 & 16.70 & 16.8 & 0.0 & 2 & 80 & 9.620 & 124.4663 & 685.16 & 1.1 & se & 655 \\
\hline S012794E & $1 / 2004 \quad 11.00 \mathrm{AM}$ & 4.1211 & 20.1752 & 5 & 10.83 & 10.71 & 10.8 & 0.1 & 3 & 53 & 9.651 & 123.0496 & 687.57 & 1.1 & 37 & 601 \\
\hline 501270473 & $1 / 30040.35 \mathrm{NM}$ & 3.9238 & 20.0729 & 5 & 7.204 & 7.070 & 7.1 & 0.1 & 3 & 37 & 0.637 & 100.33 & 1170.8 & 1.1 & 49 & 740 \\
\hline 501279474 & $1 / 31 / 94 \quad 8: 10 \mathrm{AM}$ & 4.1882 & 20.1898 & 5 & 4.067 & 4.034 & 5.0 & 0.0 & 4 & 24 & 0.620 & 100.30 & 1177.20 & 1.1 & 32 & 772 \\
\hline 501279475 & $21104 \quad 7: 00 \mathrm{NM}$ & 4.1856 & 20.3921 & 5 & 3.411 & 3.356 & 3.4 & 0.0 & 5 & 16 & 0.634 & 100.4 & 1107.1 & 1.2 & 22 & 700 \\
\hline 501279476 & $21 / 94 \quad 525 \mathrm{PM}$ & 3.8417 & 20.3490 & 5 & 2.653 & 2.605 & 2.6 & 0.0 & 6 & 14 & 8.633 & 100.11 & 504.09 & 1.1 & a & $\infty$ \\
\hline 50127947 & $22044: 30 \mathrm{PM}$ & 4.1402 & 20.0177 & 5 & 2.507 & 2.44 & 2.5 & 0.0 & 6 & 12 & 2.627 & 100.327 & 1210.87 & 1.2 & 19 & ate \\
\hline 501270478 & $2004 \quad 3: 15 \mathrm{FA}$ & 4.0218 & 20.1674 & 5 & 2.127 & 2.055 & 2.1 & 0.0 & 7 & 10 & 0.600 & 100.800 & 1100.09 & 1.1 & 14 & 893 \\
\hline 501279479 & $240 \mathrm{se} 3=0 \mathrm{PU}$ & 4.1286 & 20.3015 & 5 & 1.842 & 1.815 & 1.8 & 0.0 & 8 & 0 & 0.627 & 100.209 & 1211.58 & 1.1 & 12 & eas \\
\hline 501270480 & $24404 \quad 3: 55 \mathrm{FL}$ & 4.1164 & 20.4600 & 5 & 2.083 & 2.012 & 2.0 & 0.0 & 2 & 10 & 0.742 & 10.3409 & 20.10 & 1.1 & a & - \\
\hline \begin{tabular}{|l}
501279481 \\
\end{tabular} & 25se4 8:15 AM & 4.1468 & 20.7957 & 5 & 1.671 & 1.615 & 1.6 & 0.0 & 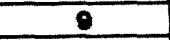 & 8 & 0.620 & 100.724 & 0.5 .20 & 12 & 8 & \\
\hline 501270482 & $20004 \quad 7: 00 \mathrm{AM}$ & 4.1541 & 10.0341 & 5 & 1.548 & 1.510 & 1.5 & 0.0 & 10 & 7 & 0.620 & 101.040 & 1106.67 & 1.1 & 10. & $\cos$ \\
\hline 501270483 & aspa 5:00 PU & 4.1204 & 20.4431 & 5 & 1.316 & 1.272 & 1.3 & 0.0 & 11 & 6 & 0.020 & 100.727 & 537.34 & 12 & 4 & Eq \\
\hline 501270484 & $27104325 \mathrm{PL}$ & 4.1820 & 19.0907 & 5 & 1.183 & 1.165 & 1.2 & 0.0 & 11 & 6 & 0.630 & 100 & 1176.34 & 1.2 & 7 & $\boldsymbol{e r e}$ \\
\hline 501270485 & 2ast 3:15 PM & 4.1402 & 20.3387 & 5 & 1.032 & 0.0000 & 1.0 & 0.0 & 12 & 5 & 0.631 & 100.72 & 1219.27 & 1.1 & 7 & \\
\hline 801270486 & $2004 \quad 10: 15 \mathrm{AM}$ & 4.1874 & 20.1005 & 5 & 1.121 & 1.009 & 1.1 & 0.0 & 13 & 5 & 0.620 & 100.60 & 1041.14 & 1.2 & 6 & \\
\hline 801270487 & $2100040.05 \mathrm{AM}$ & 4.1500 & 20.1317 & 5 & 1258 & 1.200 & 1.2 & 0.0 & 14 & 6 & 0.602 & 100.03 & 1212.64 & 1.2 & 으 & \\
\hline $5012:-88$ & 211104 8:10 M & 4.0197 & 20.5003 & 5 & 0.7950 & 0.7605 & 0.8 & 0.0 & 15 & 4 & 0.618 & 100.61 & 1220.06 & 1.2 & s & 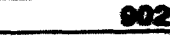 \\
\hline 501279480 & Stiwe 520 PU & 4.0538 & 20.2224 & 5 & 0.677 & 0.6454 & 0.7 & 0.0 & 16 & 3 & 8.611 & 100.26 & 551.48 & 12 & 2 & 900 \\
\hline 501270400 & 21204 12:18 PM & 4.1166 & 20.0605 & 5 & 0.642 & 0.5070 & 0.6 & 0.0 & 16 & 3 & 0.613 & 9.6 & 1024.41 & 1.2 & 3 & ent \\
\hline S012704 01 & $21304050 \mathrm{MM}$ & 4.0711 & 20.1361 & 5 & 0.5032 & 0.4651 & 0.5 & 0.0 & 17 & 2 & 0.610 & 100.44 & 1153.01 & 1.2 & 3 & ote \\
\hline so12704 02 & $21404 \quad 820 \mathrm{Mm}$ & 4.0774 & 20.0600 & 5 & 0.4954 & 0.4507 & 0.5 & 0.0 & 18 & 2 & 0.614 & 100.70 & 1107.13 & 1.2 & 3 & 213 \\
\hline 501279493 & $21504 \quad 622 \mathrm{MM}$ & 4.1250 & 20.5163 & 5 & 0.4604 & 0.4606 & 0.5 & 0.0 & 10 & 2 & 0.620 & 102.07 & 1174.00 & 1.2 & 3 & O1C \\
\hline 5012704 o4 & 216en $12.00 \mathrm{M}$ & 4.1820 & 10.0188 & 5 & 0.4005 & 0.4641 & 0.5 & 0.0 & 20 & 2 & 0.610 & 101.73 & 057.26 & 1.2 & 2 & e10 \\
\hline 5012704 o5 & 211604 10:25 PM & 4.1232 & 20.2285 & 5 & 0.5002 & 0.5015 & 0.5 & 0.0 & 21 & 2 & 0.600 & 101.85 & 1100.12 & 1.2 & 3 & $e$ \\
\hline 501279406 & $217704 \quad 350 \mathrm{PL}$ & 4.1544 & 20.1010 & 5 & 0.5737 & 0.5571 & 0.6 & 0.0 & 21 & 3 & 0.69 & 101.0 & 017.59 & 1.1 & 3 & ers \\
\hline \begin{tabular}{|l}
$5012704 \quad 07$ \\
\end{tabular} & 21804 1.31 PM & 4.0745 & 20.1563 & 5 & 0.5482 & 0.5575 & 0.6 & 0.0 & 22 & 3 & 0.643 & 101.07 & 1147.4 & 1.1 & 4 & \\
\hline $5012704 \quad 08$ & $2110 \mathrm{en} 11136 \mathrm{MM}$ & 4.1468 & 20.4438 & 5 & 0.4413 & 0.4111 & 0.4 & 0.0 & 23 & 2 & 0.630 & 102.36 & 1163.01 & 1.2 & 3 & 281 \\
\hline 5012794 क0 & $220004200 \mathrm{PM}$ & 4.1181 & 20.0473 & 5 & 0.333 & 0.3250 & 0.3 & 0.0 & 24 & 2 & 0.64 & 101.70 & 1100.49 & 1.0 & 2 & ess \\
\hline S012704_100 & $2721 / 040: 40 \mathrm{MM}$ & 4.0660 & 20.2020 & 5 & 0.3125 & 0.3161 & 0.3 & 0.0 & 25 & 2 & 0.839 & 101.07 & 1006.3 & 1.1 & 2 & 85 \\
\hline $5012794 \quad 101$ & 2rose $824 \mathrm{~m}$ & 4.1613 & 20.0378 & 5 & 0.35 & 0.3161 & 0.3 & 0.0 & 26 & 2 & 0.640 & 101.030 & 1105.31 & 1.1 & 2 & 937 \\
\hline \begin{tabular}{|l}
$5012794 \quad 102$ \\
\end{tabular} & $202094 \quad 12-25 \mathrm{FM}$ & 3.0040 & 20.2406 & 5 & 0.3155 & 0.2008 & 0.3 & 0.0 & 27 & 2 & 0.624 & 101.61 & 293 & 1.1 & 의 & 98 \\
\hline S012704 103 & 220804 12-5 pid & 4.0470 & 20.2653 & 5 & 0.3154 & 0.3030 & 0.3 & 0.0 & 27 & 2 & e.64) & 54.37 & 7120 & 0.0 & D & 97 \\
\hline
\end{tabular}




\begin{tabular}{|c|c|c|c|c|c|c|c|c|c|c|c|c|c|c|c|c|c|}
\hline & & & Told & & $207)$ & 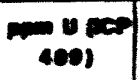 & | & a. & 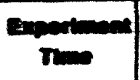 & $-\infty$ & $m$ & & & (Lent) & and & 1 & $+\mathrm{Ar}$ \\
\hline & & & & & & & & & & & & & & & & & \\
\hline & & & & & & & & & & & & & & & & & \\
\hline & $1700 \mathrm{M} 1100 \mathrm{Mm}$ & & & & & & & & & & & & & & & & \\
\hline $\operatorname{sen} 12 \log$ & $160 \mathrm{cos}$ fy & 0.7707 & $20.21 \mathrm{Ma}$ & 29 & 1.210 & 120 & 2. & क्व & 0 & 51 & 0 & 100 & 211 & 0.1 & a & of & 4 \\
\hline $\operatorname{sen} 2 \sec$ & 1roes 700 PU & 0.70 & 20.000 & 25.4 & 11.0 & 11.0 & 119 & o.e & 0 & 5 & a & 10.50 & 60. & 0.7 & 4 & 4 & 3 \\
\hline solases & $10004000 \mathrm{PD}$ & 0.7010 & 20.3500 & 25.7 & 27.04 & $28 \pi$ & as & 0.1 & 0 & $m$ & a & 102 & 940 & es & & 13 & 3 \\
\hline $\operatorname{sol} 20410$ & 1R:AM 9000 PU & 0.7000 & 20.1002 & 25.5 & 97.10 & 33.3 & $2 \pi$ & 0.4 & $\frac{0}{2}$ & क्ष & 7 & 10.0. & 49 & 0 & 12 & 2 & 2 \\
\hline sotes 11 & 1 resen $10000 \mathrm{Pe}$ & 0.702 & 20.0000 & 25.9 & 41.12 & 40.29 & 41.0 & 0.1 & 0 & $10 \mathrm{c}$ & a & 102 & 40 & en & 14 & ef & 2 \\
\hline so12e. 12 & $12 \operatorname{sen} 1150 \mathrm{Pm}$ & 0.7001 & 20.2009 & 250 & 41.59 & 41.09 & 41.9 & 0.2 & 1 & $10 \mathrm{se}$ & 므 & 10.2 & ace & en & $1 \mathrm{E}$ & 54 & 2 \\
\hline solzen 29u & $1201041100 \mathrm{AM}$ & 0.7400 & 20.100 & 27.0 & 3.50 & 37.72 & 32 & a. & 1 & 102 & a & $2 x$ & $\sin x$ & en & 17 & 29 & 2 \\
\hline $\operatorname{sot} 2 \times 420$ & $127 \mathrm{FA} 11500 \mathrm{Fm}$ & $0.7 \times 4$ & 20.027 & 25.3 & 3.23 & 30.00 & 32 & 0.1 & 2 & 212 & 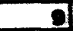 & 124.25 & 57.10 & 0 & 100 & 39 & 2 \\
\hline solzen 20c & $1 / 20011000 \mathrm{~m}$ & 0.0152 & 20.0201 & 24 & $3 . \pi$ & 30.70 & sea & 0.0 & 2 & 76 & ] & 124.58 & ciese & 10 & 150 & 57 & 2 \\
\hline 5012201200 & $12^{\circ} \mathrm{Al} 1100 \mathrm{Pm}$ & 0.0220 & 20.5005 & 250 & 239 & 23.17 & 201 & 0.2 & 3 & 8 & ] & 124.9 & 0.14 & 10 & 120 & a. & 3 \\
\hline solzacen $24=$ & $120 \times 11500 \mathrm{~m}$ & 0.022 & 20.477 & 34 & 16.52 & 10.20 & iea & 0.2 & 3 & 497 & a & 124.54 & ean 11 & 1.0 & 2 & 72 & 3 \\
\hline sot2en 73 & $1 / \sec 935 \mathrm{ar}$ & 0.034 & 20.1278 & 24.1 & 12.79 & 13.99 & 12 & 0.1 & 4 & 2 & $1 \mathrm{Ca}$ & 101.21 & 111020 & 1.1 & 13 & 2 & 3 \\
\hline sol2een 74 & 1rated e:12 M & 2.0177 & 20.1004 & 10.0 & 20.92 & 2040 & 20.7 & 0.2 & 5 & 30 & 10 & 1009 & $1122 \pi$ & 1.1 & es & EI & 3 \\
\hline sol2eos 75 & $21204700 \mathrm{M1}$ & 1.0317 & 20.437 & 10.5 & ined & 12.97 & 120 & 0. & $e$ & $14 \mathrm{~s}$ & 10 & 100.91 & 11147.4 & 1.1 & 81 & 1041 & 3 \\
\hline 501200476 & $21 \mathrm{~m} 525 \mathrm{PI}$ & 1.047 & 20.1091 & 10.4 & 11,07 & 1128 & 11.4 & 0.1 & 8 & 110 & 10 & 100.43 & 5722 & 1.1 & 22 & $10 \mathrm{ea}$ & 3 \\
\hline solzen $\pi$ & $2 \operatorname{sen} 4=0 \mathrm{FI}$ & 20077 & 20.0000 & .7 & $10.1 \mathrm{e}$ & 2.07 & 10.1 & 0.1 & 7 & 07 & 10 & 100.17 & 11024 & 1.1 & 4 & 1100 & 3 \\
\hline $50120 \times 78$ & $\operatorname{ses} 3: 15$ Pu & 2.0054 & 20.450 & ac & 2.25 & $2 \times$ & 2 & 0.0 & 8 & 9 & 10 & 1002 & 11420 & 1.1 & 34 & 11ee & 3 \\
\hline 501200470 & $20 \mathrm{~m} 3200$ PM & 2.0055 & 200000 & 0.7 & 7.300 & 7.100 & 72 & 0.1 & 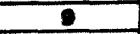 & 70 & 19 & 1002 & 1207.74 & 1.1 & 31 & 1171 & 4 \\
\hline $\operatorname{son} 2 \cos c 0$ & $24 \mathrm{M} 359 \mathrm{PP}$ & 2.062 & 20.3720 & 10.0 & 0.702 & 0.714 & E & o.e & - & 97 & 10 & 10.2 & 27.0 & 1.1 & e & 1172 & 4 \\
\hline s012ed 81 & $25 \mathrm{sel}$ e:15 $\mathrm{Mm}$ & 2.0707 & 20.3000 & 20 & 8.49 & 8.29 & E.4 & 0.1 & 10 & 6 & 10 & 100.0 & 2.7 & 1.1 & 12 & 1101 & 4 \\
\hline sol2os 22 & $2 \operatorname{cosec} 700 \mathrm{~cm}$ & 4.2011 & 20.2600 & A. & 11.0 & $10 . \ldots$ & II. & 0.1 & 11 & 5 & 10 & 100.5 & 1140 & 1.1 & 22 & 1213 & 4 \\
\hline sol2en es & $2000500 \mathrm{Pu}$ & 4.0210 & 20.1342 & 5.0 & S.411 & 0.265 & es & 0.1 & 11 & a & 10 & 102.5 & 671.09 & 1.1 & 0 & 1222 & 4 \\
\hline $\operatorname{sot} 200484$ & $27 x+325 \mathrm{Py}$ & 4.1781 & 20.3370 & 4. & ind & 2.21 & .3. & 0.2 & 12 & 4 & 10 & 100.0 & 11320 & 1.1 & 17 & 122 & 4 \\
\hline so12enes & $20013: 15 \mathrm{pm}$ & $3 \times 7$ & 20.1857 & 5.1 & 7.114 & $\mathrm{cen}$ & 7.0 & 0.1 & 13 & 30 & 10 & 100.20 & 1202.77 & 1.1 & 10 & 1259 & 4 \\
\hline sonzeses es & $25010: 15 \mathrm{am}$ & 3.7712 & 20.3270 & 5.4 & c.seg & $2 x$ & C. & 0.2 & 14 & 38 & 10 & 100.57 & 222 & 1.1 & 12 & $12: 7$ & 4 \\
\hline solzed i7 & 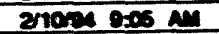 & 4.002 & 20.3310 & 5.0 & 7.499 & 7.310 & 7.4 & 0.1 & 15 & 37 & 10 & 100.25 & 11424 & 1.1 & $1 \mathrm{E}$ & 1229 & 4 \\
\hline solzen es & 21110 : $8: 15 \mathrm{M}$ & 3.0057 & 20.4200 & 5.2 & 5.01 & 5.090 & E. & 0.0 & 16 & 29 & 10 & 101.12 & 117.14 & 1.1 & 12 & 120 & 4 \\
\hline sol2en of & $2 \pi 104520 \mathrm{Fu}$ & 4.1002 & 20.0000 & 4.9 & 4.77 & 4.091 & 4.7 & 0.1 & 16 & 28 & 10 & 101.20 & $\sin 2 \pi$ & 1.1 & 4 & 120 & 4 \\
\hline solzeses co & 21214 12:18 Pu & 4.100 & 20.5010 & 4 & 4.187 & 4.209 & 4.1 & 0.9 & 17 & 29 & 10 & 20 & $m .30$ & 1.1 & 7 & 1307 & 4 \\
\hline sonzen o1 & zrses $0=0 \mathrm{am}$ & 4.114 & 20.1200 & as & 2.592 & 3231 & 3.4 & 0.1 & 18 & 17 & 10 & 25 & 1101.67 & 1.1 & 7 & 1313 & 4 \\
\hline sonzen ez & arees ex $M$ & 3.0047 & 20.5200 & 5.3. & $2 \ldots$ & 20 & 20 & 0.0 & 10 & 18 & 10 & ese & 1145.5 & 1.1 & 9 & 1320 & 4 \\
\hline 501200 & arcen exa AM & 3.9094 & 20.1744 & 8.1) & 2009 & 200 & 29 & o.d & 20 & 19 & 10 & 101.? & 1122.7 & 1.1 & 8 & $12 x$ & 4 \\
\hline solzoses on & $271 \mathrm{cos} 1200 \mathrm{~cm}$ & 4.1316 & 20.3800 & 4 & 3.170 & 3.110 & 3.1 & e.0 & 21 & 19 & 10 & 10207 & 912e? & 1.1 & 5 & 1931 & 4 \\
\hline sortaces os & 2nces $102 \mathrm{PPI}$ & 4.0514 & $20.06 \mathrm{en}$ & 5.1 & 208 & 2.707 & 20 & o.d & 21 & 14 & 10 & 1025 & 1180.1 & 1.1 & e & 1397 & 4 \\
\hline son2004 co & $2171043 \times 00 \mathrm{PM}$ & 4.1750 & 20.1008 & 4.9 & 3003 & $2=0$ & 3.0 & 0.1 & 22 & 14 & 10 & 101.2 & $\mathrm{com}$ & 1.1 & & 1301 & 4 \\
\hline solzen in & ginen $122 \mathrm{Fi}$ & 4.0000 & 20.0202 & 40 & 3.029 & 209 & 3.0 & o. & 23 & 15 & 10 & 1020 & 119278 & 1.1 & e & 1347 & 4 \\
\hline sorizes os & $210 \mathrm{~cm} 1137 \mathrm{~m}$ & 4.1300 & 20.0928 & A. & 2.27 & 2570 & 2.4 & 0.1 & 24 & 121 & 10 & 102.51 & 1117.40 & 1.1 & 5 & 1309 & 4 \\
\hline solzes 90 & $200042 \times 0 \mathrm{Pu}$ & 4.1246 & 20.5317 & 50 & $1 \ldots$ & 1910 & 20 & 0.0 & 26 & 10 & 10 & 101.70 & i19u1 & 1.0 & 4 & 135 & 4 \\
\hline $\operatorname{sen} 204100$ & 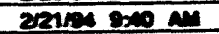 & 4.1007 & 20.329 & a.d & 1.726 & 1.024 & 1.7 & $a$ & 28 & a & 10 & 102.15 & eres: & 1.1 & 3 & 1589 & 4 \\
\hline $\operatorname{set} 204101$ & $2 \operatorname{cosec} 1=0 \mathrm{~cm}$ & 3.0449 & 20.0000 & 5.1 & $1.50 \%$ & 1.500 & 1.C) & 0.0 & 27 & $\underline{\theta}$ & 10. & 10250 & 1151.71 & 1. & & 1929 & 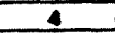 \\
\hline 501204 102 & $32 \mathrm{sen} 1225 \mathrm{PM}$ & 4.1224 & 20.1307 & 4.9 & 1. & 1.59 & 1.2) & 0.0 & 27 & & 10 & 10209 & 22.78 & 1.1 & & 1209 & 4 \\
\hline & 20001209 & & 20,3117 & 5.0 & 1819 & 1.91 & 18 & 0,01 & 27 & & & & 110.11 & 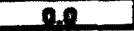 & & 1mal & 4 \\
\hline
\end{tabular}




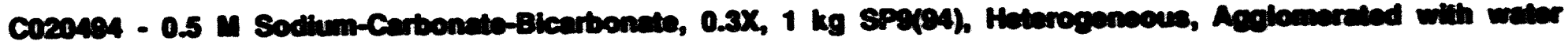

\begin{tabular}{|c|c|c|c|c|c|c|c|c|c|c|c|c|c|c|c|c|}
\hline 8a & $\mathbf{n}$ & 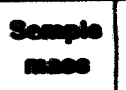 & Telal & Demelon & $\underset{367}{\mid}$ & $\operatorname{mos}_{400}$ & 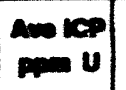 & and. & Expondenend & U/L & m & & & (Lidey) & $\infty$ & \\
\hline & & & & & & & & & & & & & & & & \\
\hline & & & & & & & & & & & & & & & & \\
\hline & & & & & & & & & & & & & & & & \\
\hline 50204949 & & $10 m$ & & & & & 3nd & & 0 & 816 & 9.30 & 10.3607 & 15.020 & 0.01 & 4 & \\
\hline \begin{tabular}{|l|l|}
5020404 & 0 \\
5020494 & 10
\end{tabular} & \begin{tabular}{ll|}
2000 & $0205 \mathrm{PL}$ \\
2001 & $1005 \mathrm{PL}$
\end{tabular} & $\frac{1.00 .35}{0.0095}$ & $\frac{20.1202}{20.2200}$ & $\frac{20}{20}$ & $\frac{30.87}{30.23}$ & $\frac{30.89}{30.82}$ & 30.0 & 0.1 & $\frac{0}{0}$ & 828 & 0.30 & 10.2543 & 10.002 & 0.20 & $\frac{7}{7}$ & 11 \\
\hline 502040411 & $214041105 \mathrm{PM}$ & 0.0185 & $\frac{20.24+1}{20.3557}$ & 22 & 28.32 & 30.09 & 29.5 & 1.2 & 0 & 654 & 0.32 & $10.3 \times 53$ & 20.1610 & 0.24 & 8 & 18 \\
\hline S020484 12 & $255 \mathrm{~s} \quad 1205 \mathrm{Mm}$ & 0.0000 & 20.0258 & 20 & 30.60 & 30.50 & 30.6 & 0.0 & 1 & 614 & 9.47 & 10.3062 & 20.2431 & 0.24 & 7 & 27 \\
\hline 5020494 A & $25841205 \mathrm{PL}$ & 0.9301 & 20.0230 & 22 & 24.58 & 24.50 & 24.5 & 0.0 & 1 & 528 & 9.30 & 124.27 & 249.02 & 0.25 & 80 & 107 \\
\hline $5020494 B$ & $1205 \mathrm{MM}$ & 0.0074 & 20.0643 & 20 & 10.20 & 19.00 & 10.1 & 0.1 & 2 & 385 & 0.54 & 124.37 & 252.04 & 0.29 & 60 & 187 \\
\hline $5020494 \mathrm{C}$ & $20 \mathrm{se} 1205 \mathrm{PI}$ & 0.0022 & 20.125 & 20 & 15.84 & 15.77 & 15.4 & 0.0 & 2 & 321 & 8.51 & 124.49 & 255.00 & 0.28 & 51 & 218 \\
\hline S020194 D & $200441025 \mathrm{PM}$ & 0.0460 & 20.0058 & 21 & 12.42 & 12.28 & 12.3 & 0.1 & 2 & 200 & 0.55 & 124.17 & 242.00 & 0.27 & 37 & $25 E$ \\
\hline S020404E & $27 \mathrm{ma} 1025 \mathrm{MM}$ & 0.0505 & 20.0009 & 21 & 11.61 & 11.47 & 11.5 & 0.1 & 3 & 241 & 0.54 & 124.10 & 250.05 & 0.27 & 40 & 205 \\
\hline 502049473 & $2 \operatorname{sen} 3: 15 \mathrm{PA}$ & 1.0344 & 20.1124 & 10 & 16.70 & 10.61 & 16.7 & 0.1 & 4 & 174 & 8.57 & 100.70 & 432.00 & 0.29 & 70 & 30 \\
\hline S020494 74 & \begin{tabular}{|ll}
20004 & $10: 15 \mathrm{Mm}$ \\
\end{tabular} & 1.9780 & 20.2720 & 10 & 13.34 & 13.28 & 13.3 & 0.0 & 5 & 138 & 0.50 & 100.51 & 314.71 & 0.27 & 36 & 401 \\
\hline 502049475 & $21094 \quad 005 \mathrm{NM}$ & 2.0413 & 20.3000 & 10 & 14.49 & 14.20 & 14.4 & 0.1 & 6 & 144 & 9.5e & 100.49 & 32.401 & 0.28 & 46 & 447 \\
\hline 502049476 & 2n1104 8:15 AM & 1.0000 & 20.1804 & 10 & 11.50 & 11.35 & 11.4 & 0.1 & 7 & 110 & 0.50 & 100.04 & 376.22 & 0.2 & 30 & 48 \\
\hline 502049477 & $2111 \% 4$ & 2.0309 & 20.0497 & 10 & 8.789 & 0.020 & 0.7 & 0.1 & 7 & est & 0.01 & 100.46 & 206.19 & 0.2 & 13 & 40 \\
\hline 502040478 & \begin{tabular}{|l|l|}
21204 & $12: 15 \mathrm{PA}$ \\
\end{tabular} & 1.8870 & 20.1534 & 10 & 8.203 & 8.100 & 8.2 & 0.0 & 8 & 34 & 8.61 & 54.43 & 200.60 & 0.20 & 23 & 522 \\
\hline so20404 70 & $2135 \mathrm{~A} \quad 050 \mathrm{MM}$ & 2.0036 & 20.3390 & 10 & 7.115 & 7.045 & 7.1 & 0.0 & 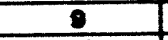 & 70 & 0.00 & 5.05 & 313.61 & 0.20 & 22 & 54 \\
\hline \begin{tabular}{|l|}
502049480 \\
\end{tabular} & \begin{tabular}{|ll}
21401 & $820 \mathrm{AM}$ \\
\end{tabular} & 1.0500 & 20.2841 & 10 & 5.607 & 5.800 & 5.9 & 0.0 & 10 & 61 & 8.81 & 55.14 & 305.64 & 0.29 & 20 & Ses \\
\hline \begin{tabular}{|l|}
502040481 \\
\end{tabular} & $\begin{array}{|ll|}21504 & 620 \mathrm{NM} \\
\end{array}$ & 1.0613 & 20.7450 & 11 & 5.505 & 5.409 & 5.5 & 0.1 & 11 & 50 & 0.02 & 54.75 & 317.92 & 0.20 & 10 & 5 \\
\hline \begin{tabular}{|l|}
502049482 \\
\end{tabular} & 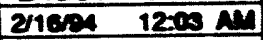 & 2.0450 & 20.1171 & 10 & 5.481 & 5.410 & 5.4 & 0.0 & 11 & 54 & 0.02 & 54.85 & 29.39 & 0.2 & 14 & Se \\
\hline \begin{tabular}{|l|l|}
5020494 & 83 \\
\end{tabular} & $2 / 1004$ 1:15 Pil & 2.0250 & 20.1354 & 10 & 5.341 & 5.282 & 5.3 & 0.0 & 12 & 53 & 0.65 & 54.40 & 00.09 & 0.09 & 2 & Ses \\
\hline 502049484 & $\begin{array}{|ll|}210 \% 4 & 1000 \mathrm{PM}\end{array}$ & 1.9314 & 20.1793 & 10 & 7.021 & 8.020 & 7.0 & 0.0 & 12 & 71 & 0.02 & 54.70 & 159.80 & 0.28 & 8 & 607 \\
\hline \begin{tabular}{|l|} 
So200494 o5 \\
\end{tabular} & $2 / 17 \mathrm{me} 3.37 \mathrm{PL}$ & 1.9210 & 20.1582 & 10 & 6.200 & 0.142 & 6.2 & 0.0 & 13 & 65 & 2.02 & 54.78 & 255.01 & 0.20 & 16 & 28 \\
\hline \begin{tabular}{|l|}
502049480 \\
\end{tabular} & 2heos 1:00 PM & 2.0205 & 20.0145 & 10 & 5.100 & 5.050 & 5.1 & 0.1 & 14 & 50 & 0.84 & 54.77 & 314.30 & 0.20 & 10 & as \\
\hline 502049487 & $2710 \mathrm{ce}$ 1134 PM & 2.0358 & 20.0479 & 10 & 4.097 & 4.008 & 4.0 & 0.0 & 15 & 40 & 8.05 & 54.49 & 310.18 & 0.10 & 13 & 852 \\
\hline 502049488 & 2 reope 2:40 PM & 2.0421 & 20.2050 & 10 & 3.705 & 3.650 & 3.7 & 0.0 & 16 & 30 & 0.05 & 55.10 & 39.30 & 0.52 & 15 & ces \\
\hline 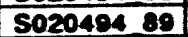 & $2 R 21040: 40 \mathrm{MM}$ & 2.0564 & 20.0100 & 10 & 3.540 & 3.400 & 3.5 & 0.0 & 17 & 34 & 8.65 & 54.77 & 201.60 & 0.20 & 2 & 97 \\
\hline 502049400 & $2222901822 \mathrm{MM}$ & 1.0570 & 20.5490 & 11 & 3.140 & 3.111 & 3.1 & 0.0 & 18 & 33 & 0.02 & 54.53 & 327.01 & 0.29 & 11 & $a n$ \\
\hline 5020494 o1 & 2 2rapes 8:43 PU & 2.0032 & 20.6050 & 10 & 2.051 & 2.001 & 2.2 & 0.0 & 10 & 30 & 0.09 & 55.00 & 346.79 & 0.10 & 11 & $\infty$ \\
\hline $5020494 \quad 22$ & $224948: 16$ AM & 1.0520 & 20.1801 & 10 & 2.750 & 2.009 & 2.7 & 0.0 & 20 & 28 & 8.09 & 55.00 & 336.43 & 0.59 & 10 & 707 \\
\hline 502040403 & $2525 \mathrm{Ne} 0205 \mathrm{NM}$ & 1.0425 & 20.1770 & 10 & 2.580 & 2.401 & 2.5 & 0.0 & 21 & 26 & 0.64 & 54.31 & 351.87 & 0.29 & 10 & 717 \\
\hline 502040404 & $2720041124 \mathrm{Am}$ & 2.0200 & 20.4620 & 10 & 2.612 & 2.552 & 2.6 & 0.0 & 22 & 20 & 0.84 & 55.17 & 370.57 & 0.20 & 10 & 727 \\
\hline \begin{tabular}{|l|}
502049495 \\
\end{tabular} & $2827 \mathrm{~N} \quad 10: 00 \mathrm{AM}$ & 2.0300 & 20.2907 & 10 & 2.500 & 2.493 & 2.5 & 0.0 & 23 & 25 & 8.69 & 55.18 & 329.12 & 0.29 & 8 & 735 \\
\hline 502040490 & 2raver 9:11 AM & 1.0492 & 20.4007 & 10 & 2.310 & 2.241 & 2.3 & 0.0 & 24 & 24 & 9.69 & 54.81 & 391.74 & 0.20 & 8 & 745 \\
\hline 502049497 & $31104850 \mathrm{AM}$ & 2.0211 & 20.0700 & 10 & 2.207 & 2.191 & 2.2 & 0.0 & 25 & 23 & 0.60 & 54.20 & 340.21 & 0.20 & 8 & 751 \\
\hline 502049400 & $3204855 \mathrm{AM}$ & 1.0745 & 20.2073 & 10 & 2.058 & 2.000 & 2.0 & 0.0 & 26 & 21 & 2.65 & 87.00 & 348.22 & 0.29 & 7 & 752 \\
\hline S02049400 & 3ave B:40 AM & 1.0563 & 20.3545 & 10 & 1.089 & 1.032 & 2.0 & 0.0 & 27 & 20 & 0.65 & 67.34 & 355.15 & 0.20 & 7 & 765 \\
\hline 5020404100 & s401 8223 AM & 2.0900 & 20.0584 & 10 & 2.000 & 1.050 & 2.0 & 0.0 & 28 & 20 & 0.68 & 102.20 & 305.39 & 0.29 & 7 & $\mathrm{~nm}^{2}$ \\
\hline $5020404 \quad 101$ & $35 \operatorname{sed} 12: 15$ PM & 2.0870 & 20.2511 & 10 & 2.045 & 1.000 & 2.0 & 0.0 & 20 & 20 & 0.67 & 60.64 & 400.46 & 0.29 & 8 & 700 \\
\hline $5020494 \quad 102$ & seren $11.00 \mathrm{AM}$ & 2.0020 & 20.4778 & 10 & 1.047 & 1.098 & 1.0 & 0.0 & 30 & 10 & 0.67 & 71.50 & 343.50 & 0.29 & 6 & 780 \\
\hline $5020494 \quad 103$ & $37 \times 411: 45$ AM & 2.0389 & 20.3250 & 10 & 1.810 & 1.800 & 1.9 & 0.0 & 31 & 10 & 0.67 & 60.61 & 384.67 & 0.20 & 7 & 708 \\
\hline 5020494104 & s7me 11:46 AM & 2.0642 & 20.180. & 10 & 2.137 & 2.091 & 2.1 & 0.0 & 31 & 21 & $0.6 \%$ & 14.49 & 30.42 & 0.001 & e & 72 \\
\hline
\end{tabular}




\begin{tabular}{|c|c|c|c|c|c|c|c|c|c|c|c|c|c|c|c|c|}
\hline 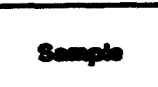 & Treos & semen & Total & Dilmation & 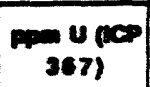 & 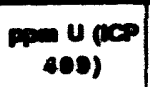 & 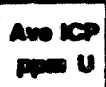 & Bed. & Exportane & $m$ un & Put & Enpory & frem & (Lican) & & mone un \\
\hline & & & & & & & & & & & & & & & & \\
\hline & & & & & & & & & & & & & & & & \\
\hline & $2 \operatorname{sen} 12005 \mathrm{PM}$ & & & & & & & & & & & & & & & \\
\hline $502050 A_{-1}$ & $244018005 \mathrm{PM}$ & 0.0015 & 20.5022 & 21 & 20.07 & 26.02 & 28.0 & 0.0 & 0 & 530 & 2.209 & 10.20 & 14.2 & 0.01 & 3 & \\
\hline 80205040 & $24040.005 \mathrm{PM}$ & 0.0977 & 20.2025 & 20 & 20.52 & 20.41 & 20.5 & 0.1 & 0 & 500 & $0.00 \mid$ & $\frac{10.3247}{104199}$ & 18.70 & $\frac{0.201}{0.231}$ & $\frac{6}{7}$ & $\frac{9}{15}$ \\
\hline 502050410 & $2 \mathrm{MPA} \quad 10.05 \mathrm{PP}$ & 0.920 & 20.4115 & 22 & 20.16 & 20.00 & 28.1 & 0.0 & $\div$ & 6929 & $\frac{0.070}{0.97}$ & $\frac{10.4105}{102029}$ & $\frac{12.00}{19.27}$ & $\frac{0.21}{0.21}$ & 7 & $\frac{15}{25}$ \\
\hline 5002050411 & $2 \mathrm{MPA} 11.05 \mathrm{PW}$ & 0.0000 & 20.4057 & 20 & 35.36 & 34.00 & 35.1 & 0.3 & 0 & 71g & 2.387 & 10.3424 & $\frac{19.27}{10.41}$ & $\frac{0.21}{0.23}$ & $\frac{0}{7}$ & $\frac{28}{31}$ \\
\hline 502059412 & $2550112005 \mathrm{MM}$ & 1.0032 & 20.3070 & 20 & 33.25 & 33.20 & 39.2 & 0.0 & 1 & 675 & 8.000 & $\frac{10.3000}{10.19}$ & 19.41 & 0.22 & $\frac{7}{78}$ & 31 \\
\hline 5020504 A & $250 \mathrm{Al} 12005 \mathrm{PP}$ & 1.0067 & 20.1074 & 20 & 20.34 & 29.27 & 20.3 & 0.0 & 1 & ses: & 0.139 & 124.0164 & 232.0 & $\frac{0.22}{0.39}$ & & $\frac{10 e}{109}$ \\
\hline $5020594 \mathrm{~B}$ & $2000 \mathrm{M} \quad 12.05 \mathrm{MM}$ & 1.0100 & 20.4000 & 20 & 23.00 & 23.54 & 29.6 & 0.0 & 2 & 475) & 2.505 & 124.2049 & 247.00 & 0.25 & $\frac{71}{68}$ & 100 \\
\hline sogosen C & $280 \mathrm{Al} \quad 1205 \mathrm{PP}$ & 1.0178 & 20.4500 & 20 & 18.50 & 18.28 & 18.4 & 0.1 & 2 & 370 & 0.478 & 124.2255 & 232.49 & 0.2 & 58 & $\frac{23}{m a}$ \\
\hline Sozosen D & $2 \pi \mathrm{d} \quad 1205 \mathrm{AM}$ & 1.0195 & 20.1657 & 20 & 14.47 & 14.31 & 14.4 & 0.1 & 3 & 205 & 2.593 & 124.1522 & 254.34 & 0.25 & 45 & 208 \\
\hline $50000501 \mathrm{E}$ & $2 \pi \mathrm{MM} \quad 10: 15 \mathrm{MM}$ & 1.0197 & 20.6972 & 20 & 11.51 & 11.34 & 11.4 & 0.1 & 3 & 232 & 0.570 & 123.7050 & 256.55 & 0.31 & 38 & 320 \\
\hline 502050473 & $20004 \quad 3.15 \mathrm{PD}$ & 2.0714 & 20.9126 & 10 & 17.60 & 17.55 & 17.6 & 0.1 & 4 & 170 & 0.569 & 100.002 & 427.79 & 0.27 & 71 & 301 \\
\hline 802050474 & $200 \mathrm{men} \quad 10: 15 \mathrm{Am}$ & 2.0685 & 20.1004 & 10 & 15.66 & 15.54 & 15.6 & 0.1 & 5 & 152 & 0.505 & 100.06 & 311.00 & 0.27 & 39 & 430 \\
\hline s020504 75 & $21100 \mathrm{~A} \quad 000 \mathrm{AM}$ & 2.0600 & 20.7452 & 10 & 12.09 & 11.20 & 11.9 & 0.1 & 6 & 120 & 0.570 & 100.09 & 355.37 & 0.27 & 37 & 467 \\
\hline 502059478 & $211104 \quad 8: 10 \mathrm{MM}$ & 2.0364 & 20.2023 & 10 & 0.720 & 0.54 & 0.6 & 0.1 & 7 & 20 & 0.587 & 101.40 & 30.70 & 0.22 & 31 & 40 \\
\hline 502059477 & $2 \pi 1104 \quad 5: 20 \mathrm{PW}$ & 1.9977 & 20.2512 & 10 & 7.000 & 7.022 & 0.0 & 0.0 & 7 & 81 & 8.005 & 100.87 & 200.94 & 0.27 & 10 & 500 \\
\hline 502059478 & $212941215 \mathrm{PM}$ & 2.0012 & 20.1284 & 10 & 7.458 & 7.305 & 7.4 & 0.0 & 8 & 72 & 0.001 & 55.06 & 278.91 & 0.22 & 10 & 526 \\
\hline 502050479 & 2 21304 $9.50 \mathrm{NM}$ & 2.1262 & 20.3000 & 10 & 8.550 & 6.430 & 6.5 & 0.1 & 9 & (62) & 0.017 & 54.91 & 300.07 & 0.2 & 19 & 547 \\
\hline 502059480 & $2 \pi 404 \quad 020 \mathrm{MM}$ & 2.1200 & 20.2001 & 10 & 5.607 & 5.556 & 5.8 & 0.0 & 10 & 54 & 0.019 & 55.00 & 320.02 & 0.20 & 16 & ses: \\
\hline so20sen 81 & 2nsou $6: 20 \mathrm{AM}$ & 2.0784 & 20.1430 & 10 & 4.000 & 4.700 & 4.8 & 0.0 & 11 & 47 & 0.615 & 55.10 & 312.70 & 0.20 & 15 & 50 \\
\hline sopesen a2 & 2 19e04 $1200 \mathrm{AM}$ & 2.0010 & 20.2017 & 10 & 4.613 & 4.522 & 4.0 & 0.0 & 11 & 44 & 0.010 & 55.15 & 20200 & 0.2. & 11 & 52 \\
\hline 502059483 & 2neen 10:20 PM & 2.0874 & 20.6400 & 10 & 4.241 & 4.139 & 4.2 & 0.1 & 12 & 41 & 0.629 & 55.02 & 321.77 & 0.2 & 13 & 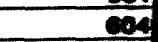 \\
\hline s020sed of & $241704303 \mathrm{Pu}$ & 1.0500 & 20.2705 & 10 & 4.145 & 4.000 & 4.1 & 0.0 & 13 & 49 & 2.040/ & SA.44 & 251.78 & 0.22 & 10 & 615 \\
\hline S020509 85 & 2nesen 130 PM & 1.2019 & 20.7600 & 11 & 3.677 & 3.059 & 3.7 & 0.0 & 14 & 39 & 0.091 & sa.en & 300.4 & 0.22 & 12 & 627 \\
\hline 50205048 & 2 neen $1134 \mathrm{PM}$ & 2.0976 & 20.2000 & 10 & 3.474 & 3.440 & 3.5 & 0.0 & 15 & 34 & 8.692 & 54.ce & 313.00 & 0.90 & 11 & 6037 \\
\hline 502050487 & $2200042: 00 \mathrm{PW}$ & 2.0900 & 20.2000 & 10 & 3.201 & 3.145 & 3.2 & 0.0 & 16 & 32 & 0.092 & 55.00 & 374.74 & 0.51 & 12 & $\cos 0$ \\
\hline 50205048 & $2211040: 40 \mathrm{MM}$ & 2.0246 & 20.1530 & 10 & 3.191 & 3.130 & 3.2 & 0.0 & 17 & 32 & 0.005 & $55.01 \mathrm{~L}$ & 278.1 & 0.27 & 8 & est \\
\hline so205en & $202204820 \mathrm{ML}$ & 1.0600 & 20.4341 & 10 & 2.016 & 2.020 & 2.0 & 0.0 & 18 & 30 & 2.04 & $55.22 \mathrm{ma}$ & 321.0 & 0.22 & 10 & at \\
\hline 502050400 & 2rapa s:43 PM & 2.1112 & 20.2039 & 10 & 3.000 & 2.036 & 3.0 & 0.0 & 10 & 28 & .020 & 54.39 & 200.99 & 0.19 & 10 & $\theta \pi$ \\
\hline 502059401 & $2224048: 17 \mathrm{MM}$ & 2.1081 & 20.1011 & 10 & 2.007 & 2.818 & 2.8 & 0.0 & 20 & 27 & 0.020 & 55.00 & 330.05 & 0.57 & 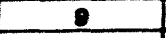 & at \\
\hline 502050482 & $2 R 2504900 \mathrm{AM}$ & 1.2650 & 20.4757 & 10 & 2.500 & 2.551 & 2.0 & 0.0 & 2 & 2T & 0.003 & 54.45 & 305.91 & 0.22 & - & con \\
\hline 502059403 & 2 reasen 11.24 AM & 2.0416 & 20.1292 & 10 & 2.712 & 2.714 & 2.7 & 0.0 & 28 & 27 & 0.091 & 54.7 & 309.87 & 0.20 & 10 & 707 \\
\hline soopses o4 & $222710410.05 \mathrm{AM}$ & 2.0504 & 20.1687 & 10 & 2.040 & 2.700 & 2.8 & 0.0 & 23 & 20 & 2. & 54.77 & 321.5 & 0. & 2 & $71 \mathrm{C}$ \\
\hline sozose4 95 & 2rzen $0.11 \mathrm{MM}$ & 2.0713 & 20.2070 & 10 & 2.000 & 2000 & 2.0 & 0.0 & 24 & 20 & 0.028 & 55.10 & 326.21 & 0.20 & 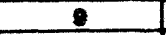 & 725 \\
\hline sorosed 96 & $3 M N 485 \mathrm{AM}$ & 2.0357 & 20.5405 & 10 & 2.700 & 2.710 & 2.7 & 0.0 & 25 & 28 & 2.000 & 54.70 & 334.34 & 0.8 & 1 & 734 \\
\hline 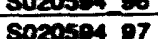 & $\operatorname{sen} 8.05 \mathrm{M}$ & 2.0501 & 20.1206 & 10 & 2000 & 2.647 & 2.7 & 0.0 & 26 & 26 & 0.009 & 67.57 & 342.21 & & 8 & 745 \\
\hline $\operatorname{soz} 0 \operatorname{sen}^{2}$ & $\operatorname{ses} 8.46 \mathrm{MM}$ & 1.095 & 20.699 & 10 & 2.443 & 2.423 & 2.4 & 0.0 & 27 & 25 & 2.095 & 67.10 & 3009 & 0 & & 752 \\
\hline senosen 09 & $3409 \mathrm{sen}^{M}$ & 19581 & 20.2223 & 10 & 2.400 & 2.351 & 24 & 0.0 & 20 & 25) & 2.00001 & 01.71 & 370.75 & - & 10 & 701 \\
\hline Sozosing os & 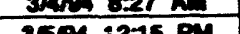 & 190 & & 10 & 2.35 & 2.301 & 2.3 & 0.0 & 20 & 24 & 8.053 & 71.56 & 305.10 & & 8 & 771 \\
\hline $\operatorname{sos} 0504100$ & 35sos i2:15 PW & 20sent & $\frac{2.9}{209}$ & 10 & 230 & 2220 & 2.3 & 0.0 & 30 & 23 & 2.246 & 71.37 & sac.e & 0.2 & 7 & $m$ \\
\hline 8020504101 & seen 1102 & 2.0409 & 20. & $\frac{10}{10}$ & $\frac{2.00}{2.126}$ & 2.131 & 2.1 & 0.0 & 31 & 21 & 8.642 & 71.46 & 300.20 & 0.29 & 7 & ins \\
\hline 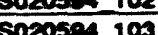 & 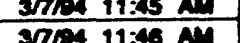 & $\frac{2.007}{1.9560}$ & 20.1521 & 10 & 2.2 & 2.201 & & 0.0 & 31 & 29 & 9.641 & 14.37 & 27.4 & 0.01 & 0 & E2 \\
\hline
\end{tabular}




\begin{tabular}{|c|c|c|c|c|c|c|c|c|c|c|c|c|c|c|c|c|c|}
\hline Semple & Time sample pulled & $\begin{array}{c}\text { somple } \\
\text { mases }\end{array}$ & $\begin{array}{l}\text { Total } \\
\text { maas }\end{array}$ & Dilution & \begin{tabular}{|c|} 
Ppm U (ICP \\
$367)$
\end{tabular} & \begin{tabular}{|c|} 
pPm U U (ICP \\
$409)$ \\
\end{tabular} & $\begin{array}{l}\text { Avo icp } \\
\text { ppom u }\end{array}$ & $\begin{array}{l}\text { sid. } \\
\text { Dov. }\end{array}$ & $\begin{array}{c}\text { Experiment } \\
\text { Time }\end{array}$ & $\begin{array}{l}m g \\
\text { U:L }\end{array}$ & PH & \begin{tabular}{|c|} 
Empty \\
contalner \\
metes (q)
\end{tabular} & $\begin{array}{c}\text { Full } \\
\text { contaliner } \\
\text { mees (o) }\end{array}$ & $\begin{array}{l}\text { Flow Rens } \\
\text { (Liday) }\end{array}$ & \begin{tabular}{|c|} 
mg \\
U/kg \\
coill \\
\end{tabular} & $\begin{array}{c}\text { Cumulative } \\
\text { mo uns coun }\end{array}$ & $-\log [U]$ \\
\hline & & & & & & & & & & & & & & & & & \\
\hline & & & & & & & & & & & & & & & & & \\
\hline & $22551946.05 \mathrm{PM}$ & & & & & & & & & & & & & & & & \\
\hline $5022394 \quad 10$ & $2126 / 94 \quad 1.05$ PM & 0.4936 & 20.2184 & 41.0 & & 의 & 0.0 & 0.0 & 1 & of & 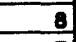 & 10.35 & 39.10 & 0.04 & $\underline{0}$ & & \\
\hline 502239420 & $2126194 \quad 2: 05$ PM & 0.4893 & 20.0887 & 41.1 & & & 0.0 & 0.0 & 1 & of & & 10.31 & 37.38 & 0.65 & & & \\
\hline 502239421 & $2 / 28 / 94 \quad 3: 05$ PM & 0.5295 & 20.1821 & 38.1 & & of & 0.0 & 0.0 & 1 & of & & 10.33 & 38.78 & 0.08 & of & - & \\
\hline $5022394 \quad 22$ & $222894 \quad 4.05 \mathrm{PM}$ & 0.5258 & 20.1882 & 38.4 & & & 0.0 & 0.0 & 1 & of & & 10.32 & 36.20 & 0.02 & of & of & \\
\hline $5022394 \quad 23$ & $2228 / 94 \quad 5.05$ PM & 0.5383 & 10.0913 & 18.8. & & & 0.0 & 0.0 & 1 & of & 7 & 10.22 & 49.07) & 0.93 & of & of & \\
\hline 502230424 & $2126 / 94 \quad 6.05 \mathrm{PM}$ & 0.5235 & 10.0688 & 19.2 & 0.01790 & 0.02883 & 0.0 & 0.0 & 1 & of & 8 & 10.31 & 38.13 & 0.87 & of & of & \\
\hline S022394_A & $22719996.05 \mathrm{AM}$ & 0.5189 & \begin{tabular}{|l|}
20.7348 \\
\end{tabular} & 40.1 & 0.1827 & 0.1813 & 0.2 & 0.0 & 1 & & 8 & 123.74 & 496.20 & 0.75 & of & of & \\
\hline 5020394 B & $2127 / 04 \quad 6: 05 \mathrm{PM}$ & 0.5121 & \begin{tabular}{|l|}
20.0783 \\
\end{tabular} & 39.2 & 4.941 & 4.958 & & 0.0 & $\frac{2}{5}$ & \begin{tabular}{|c|}
194 \\
199
\end{tabular} & & 123.44 & 548.46 & 0.85 & 10 & 11 & 3 \\
\hline 5022393 C & $2 / 28 / 94 \quad 6.05$ AM & 0.5170 & \begin{tabular}{|l|}
20.6484 \\
\end{tabular} & 39.9 & 35.88 & 35.86 & 36.9. & 0.0 & 2 & 1433 & & 123.67 & 542.19 & 0.04 & 74 & 85 & \\
\hline S022394 D & $272894 \quad 5.05 \mathrm{PM}$ & 0.5334 & \begin{tabular}{|l|}
20.6336 \\
\end{tabular} & 38.7 & 44.57 & 44.38 & 44.5. & 0.1 & 2 & 1720 & & 123.67 & 542.2 & 0.91 & 89 & 173 & \\
\hline SO22304 E & $3 / 1 / 94 \quad 5.06 \mathrm{AM}$ & 0.5311 & 20.1474 & 37.9 & 43.73 & 43.76 & 43.7 & 0.0 & $\frac{3}{9}$ & 1650 & 8 & 195.578 & 620.23 & 0.87 & 80 & 262 & 2 \\
\hline S022304 F & $3 / 104 \quad 6.05 \mathrm{PM}$ & 0.8104 & 20.3609 & 25.1 & 58.47 & 50.61 & 50.0 & 0.6 & 3 & 1483 & & 280.19 & 737.07 & 0.88 & 87 & 350 & \\
\hline $8022394 \quad 117$ & $3 / 294 \quad 8.05 \mathrm{PM}$ & 0.8260 & 20.5405 & 24.9. & 52.75 & 52.86 & 52.8 & \begin{tabular}{|l|}
0.1 \\
\end{tabular} & 4 & 1313 & & 103.62 & 1140.29 & 0.06 & 108 & 518 & \\
\hline $5022394 \quad 118$ & $3 / 3 / 94 \quad 330 \mathrm{PM}$ & 0.8099 & 20.7599 & 25.6 & 43.09 & 43.01 & 43.1 & 0.0 & 5 & 1103 & $\therefore$ & 101.39 & 8021.41 & 0.28 & 108 & 625 & \\
\hline $8022394 \quad 119$ & 3/404 2:45 PM & 0.8479 & \begin{tabular}{|l|}
20.6721 \\
\end{tabular} & 24.4 & 33.78 & 34.09 & 33.9 & 0.2 & $\frac{8}{7}$ & \begin{tabular}{|l|}
827 \\
579 \\
\end{tabular} & & 104.84 & 1078.48 & 1.01 & 90 & 725 & \\
\hline $5022394 \quad 120$ & 3/5/94 12:15 PM & 0.8333 & $20.5511 \mid$ & 24.7 & 23.80 & 23.08 & 23.4 & 0.4 & 7 & 578 & & 104.8 & 1039.31 & 1.04 & 67 & 702 & \\
\hline $5022394 \quad 121$ & $3 / 8094 \quad 11.01 \mathrm{AM}$ & 0.8161 & 20.6070 & 25.3 & 14.91 & 14.48 & $\frac{14.7}{1.9}$ & 0.2 & $\therefore$ & 371 & & 104.23 & 1130.52 & 1.08 & 47 & 839 & \\
\hline 5022394122 & 377194 12:30 PM & 0.8383 & \begin{tabular}{|l|}
20.1070 \\
20
\end{tabular} & 24.0 & 10.15 & 10.02 & 10.1 & 0.1 & $\frac{9}{10}$ & \begin{tabular}{|l|}
242 \\
148 \\
\end{tabular} & & 100.78 & 1263.86 & 1.10 & 35 & 873 & \\
\hline $5022394 \quad 123$ & $3 / 8904 \quad 12: 46$ PM & 0.8396 & \begin{tabular}{|l|}
20.1720 \\
0.020
\end{tabular} & 24.0 & 6.235 & 8.085 & 6.2 & 0.1 & $\frac{10}{11}$ & $\mid \frac{148}{100}$ & 10 & 100.81 & 1218.24 & 1.10 & 20 & 894 & \\
\hline 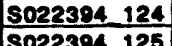 & seven $827 \mathrm{AM}$ & 0.8213 & $\mid$\begin{tabular}{|l}
20.4682 \\
200655 \\
\end{tabular} & 24.9 & 3.0996 & $\frac{4.000 \mid}{3.057}$ & $\frac{4.0}{3.1}$ & 0.0 & $\frac{11}{12}$ & \begin{tabular}{|r|}
100 \\
74 \\
\end{tabular} & $\frac{10}{10}$ & 100.83 & 1038 & 1.14 & 12 & 906 & \\
\hline$\frac{5022394,125}{502394,128}$ & 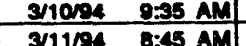 & $\frac{0.835 \mathrm{~g}}{0.8150}$ & \begin{tabular}{|c|}
20.0655 \\
20.2725 \\
\end{tabular} & \begin{tabular}{|l|}
24.0 \\
24 \\
\end{tabular} & $\frac{3.101}{2.526}$ & $\frac{3.007}{2.458}$ & $\frac{3.14}{2.5}$ & 0.0 & $\frac{12}{13}$ & \begin{tabular}{|c|}
-74 \\
62 \\
\end{tabular} & 10 & 101.31 & 1308.26 & 1.15 & 11 & 010 & \\
\hline 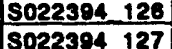 & \begin{tabular}{ll|}
$3 / 11 / 24$ & $8: 23 \mathrm{AM}$ \\
$3 / 12 / 294$ & $8: 40 \mathrm{AM}$
\end{tabular} & $\frac{0.8150}{0.8408}$ & \begin{tabular}{|l|l|}
20.2725 \\
20.1397 \\
\end{tabular} & $\frac{24.0}{24.0}$ & $\frac{2.566 .}{2.311}$ & $\frac{2.456}{2.282}$ & $\begin{array}{ll}2.5 .5 \\
2.3 \\
\end{array}$ & \begin{tabular}{|l|}
0.0 \\
0.0 \\
\end{tabular} & 14 & 52 & $\frac{10}{10}$ & $\frac{101.64}{100.95}$ & $\frac{1198.35}{128.54}$ & & 8 & 昂5 & \\
\hline $8022394 \quad 120$ & $\begin{array}{lll}3 / 13984 & 1.56 \text { PMA }\end{array}$ & 0.8150 & 20.6288 & 25.3 & 2.095 & 1.908 & 2.0 & 0.0 & 15 & & $\frac{10}{10}$ & $\frac{100.63}{90.9}$ & $\frac{128.664}{1518.76}$ & $\frac{1.174}{1.16}$ & a & $\frac{934}{942}$ & \\
\hline $8022304 \quad 120$ & $3 / 15 \mathrm{ped} \quad 8.00 \mathrm{AM}$ & 0.8487 & 20.2138 & 23.8 & 1.856 & 1.873 & 1.9 & 0.0 & 18 & 44 & 10 & 104.55 & 2146.73 & 1.10 & 11 & 253 & \\
\hline $5022394 \quad 130$ & $3 / 16 \mathrm{eP} \quad 8.00 \mathrm{AM}$ & 0.8107 & 20.3063 & 25.0 & i.837 & 1.800 & 1.8 & 0.0 & 18 & 46 & 10 & 100.78 & 1257.22 & 1.15 & 7 & ese & \\
\hline $5022394 \quad 131$ & $3 / 1700$ & 0.8080 & 20.1316 & 24.9 & 1.779 & 1.740 & 1.8 & 0.0 & 10 & 44 & 10 & 104.22 & 1257.62 & 1.15 & c) & 986 & \\
\hline $5022394 \quad 132$ & 219804 $8.00 \mathrm{AM}$ & 0.8116 & 20.1490 & 24.8 & 1.948 & 1.016 & 1.9 & 0.0 & 20 & (48) & 10 & 101.4 & 1155.13 & 1.08 & 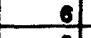 & 972 & \\
\hline $5022394 \quad 133$ & 31024 10:17 AM & 0.8126 & 20.1128 & 24.8 & 1.736 & 1.712 & 1.7 & 0.0 & 21 & 43. & 10 & 101.89 & 1182.2 & 0.29 & 8 & 977 & \\
\hline 5022394,134 & $3 \times 5 x=4 \quad 8: 37$ AM & 0.8221 & 20.5436 & 25.0 & 1.580 & 1.547 & 1.0 & 0.0 & 22 & 39 & 10 & 101.07 & 1109.47 & 1.15 & 5 & 983 & \\
\hline $5022304 \quad 135$ & $3 / 21 / 94 \quad 8: 37$ AM & 0.8182 & 20.2825 & 24.8 & 1.386 & 1.369 & 1.4 & 0.0 & 23 & 34 & 10 & 102.35 & 1182.58 & 1.08 & 5 & 987 & \\
\hline 5022394136 & $321044: 45$ PU & 0.818 & \begin{tabular}{|l|}
20.3300 \\
\end{tabular} & 24.8 & 1.292 & 1.287 & 1.3 & 0.0 & 24 & 32 & 10 & 101.70 & 454.6 & 1.04 & 1 & 289 & \\
\hline $\begin{array}{l}5022394 \quad 137 \\
\end{array}$ & $3122094 \quad 11: 14 \mathrm{AM}$ & 0.0168 & 20.2679 & 24.6 & 1.277 & 1.230 & 1.3 & 0.0 & 24 & 31 & 10 & 101.92 & 800.52 & 1.02 & & t & \\
\hline $5022394 \quad 138$ & 3:22P4 5:15 PM & 0.8330 & 20.2104 & 24.2 & 1.344 & 1.342 & 1.3 & 0.0 & $\frac{25}{25}$ & 33 & 10 & 101.71 & 294.19 & 0.77 & & 992 & \\
\hline 5022304 139 & 324848.00 AMI & 0.8219 & 20.5301 & 25.0 & 1.023 & 1.589 & 1.6 & 0.0 & 25 & 40 & 10 & 200.09 & 1509.08 & 0.85 & 7 & 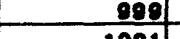 & \\
\hline $5022304 \quad 140$ & 3/24104 4:40 PM & 0.8180 & 20.2525 & 24.8 & 1.584 & 1.524 & 1.5 & 0 & 27 & 38 & 10 & 102.00 & 445.69 & 6. & 2) & 1001 & \\
\hline $5022304 \quad 141$ & $3125 / 04 \quad 3: 30$ PM & 0.8300 & 20.2168 & 24.1 & 1.4 & 1.417 & 1.4 & 0.0 & 27 & 34 & 10 & 102.08 & $\frac{99}{110}$ & & 4 & $\frac{10}{12}$ & \\
\hline $5022394 \quad 142$ & $3 / 26 / 94 \quad 0.07$ PM & 0.0500 & 20.4898 & 24.1 & 1.5 & 1.256 & 1.3 & 0.0 & 28 & 31 & 10 & 102.38 & 1127.33 & & 4 & 1008 & \\
\hline $5022304 \quad 143$ & 327004 4:34 PMI & 0.8472 & 20.0410 & 23.7 & 1.1 & 1.021 & 1.0 & 0.0 & 29 & 25 & 10 & 102.3 & 948.15 & $\frac{1.04}{1.1}$ & 3 & $\frac{1011}{1019}$ & \\
\hline $5022304 \quad 144$ & 3pesed 12:10 PM & 0.8241 & 20.5000 & 24.0 & 0.9 & 0.2116 & 0.9 & 0.0 & 30 & 23 & 10 & 100.25 & 1003.5 & $\frac{1.11}{0.09}$ & 3 年 & $\frac{1014}{1019}$ & 4 \\
\hline $5022304 \quad 145$ & $312094 \quad 11: 55 \mathrm{AM}$ & 0.7992 & 20.5011 & 25.7 & 0.7 & 25 & 0.8. & 0.0 & 31 & 20 & 10 & 100.37 & 968.62 & 0.86 & 2) & 1016 & 4 \\
\hline $5022394 \quad 146$ & 32:094 8:10 PM & 0.8311 & 20.5238 & 24.7 & 0.1 & 0.1 & 0.8 & 0.0 & 32 & 21 & 10 & 101.21 & 362.84 & 0.78 & & 1010 & 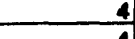 \\
\hline 5022304 147 & $330094 \quad 11: 15$ AM & 0.0396 & $20.5960 \mid$ & $\frac{24.5}{2.7}$ & 41 & & 0.8 & \begin{tabular}{l|l}
0.0 \\
0.0
\end{tabular} & $\frac{32}{39}$ & $\frac{19}{24}$ & $\frac{10}{10}$ & & & $\frac{0.85}{0.45}$ & 2 & $\frac{1017}{1020}$ & 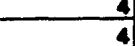 \\
\hline \begin{tabular}{|l|l|l|}
5022394 & 148 \\
\end{tabular} & 4104 4:30 AM & 0.8208 & \begin{tabular}{|l|}
20.2536 \\
201119 \\
\end{tabular} & $\frac{24.7}{2.7}$ & 0.9714 & $\frac{0.9880}{1.823}$ & $\frac{1.0}{1.0}$ & \begin{tabular}{l|l}
0.0 \\
0.0
\end{tabular} & $\frac{33}{34}$ & 24 & $\frac{10}{10}$ & $\frac{02.03}{01.99}$ & 781.35) & $\frac{0.45}{0.00}$ & $\frac{2}{2}$ & $\frac{1020}{1022}$ & \\
\hline 0223944149 & wios 4:31 AML & 0.8159 & 20.1141 & 24.71 & & .8731 & & & 3 & & & & & & & & \\
\hline
\end{tabular}




\begin{tabular}{|c|c|c|c|c|c|c|c|c|c|c|c|c|c|c|c|c|c|c|}
\hline Sample & Timo eample pullod & $\begin{array}{c}\text { sample } \\
\text { maces }\end{array}$ & $\begin{array}{l}\text { Total } \\
\text { maese }\end{array}$ & Dilution & $\begin{array}{c}\text { ppon U (CCP } \\
367)\end{array}$ & $\begin{array}{c}\text { Fom U (ICP } \\
408)\end{array}$ & $\begin{array}{l}\text { Ave ICP } \\
\text { ppm U }\end{array}$ & $\begin{array}{l}\text { 8td. } \\
\text { Dev. }\end{array}$ & $\begin{array}{c}\text { Exporimont } \\
\text { Time }\end{array}$ & $\begin{array}{c}\text { Conter Timo } \\
\text { step }\end{array}$ & $\stackrel{p p m}{U}$ & PH & $\begin{array}{l}\text { Empty } \\
\text { contalner } \\
\text { mees }(q)\end{array}$ & $\begin{array}{c}\text { Full containe } \\
\text { maces }(g)\end{array}$ & $\begin{array}{l}\text { Flow Rate } \\
\text { (L/day) }\end{array}$ & $\begin{array}{c}\mathrm{mg} \\
\mathrm{eoll}\end{array}$ & $\begin{array}{c}\text { Cumuiative } \\
\mathrm{mg} U \text { I bo } \\
\text { soll }\end{array}$ & Temp \\
\hline & & & & & & & & & & & & & & & & & & \\
\hline & & & & & & & & & & & & & & & & & & \\
\hline & & & & & & & & & & & & & & & & & & \\
\hline & 3yoped 2:15 PM & & & & & & & & & & & & & & & & & \\
\hline 50308041 & $3 \mathrm{pos} \quad 825 \mathrm{AM}$ & 0.8018 & 20.1747 & 25 & 27.11 & 27.20 & 27.2 & 0.1 & 1 & 1 & 684 & & 101.04 & 758.07 & 0.9 & 185 & 185 & \\
\hline 50308042 & $3 / 11104 \quad 9: 47$ NM & 0.8390 & 20.4840 & 24 & 25.48 & 25.36 & 25.4 & 0.1 & 1 & 2 & 620 & & 101.34 & 2084.60 & 1.0 & 506 & 691 & \\
\hline 50308943 & $3 / 129948: 40 \mathrm{AM}$ & 0.8452 & 20.1823 & 24 & 10.45 & 10.34 & 10.4 & 0.1 & 3 & 2 & 248 & & 100.89 & 1138.89 & 1.1 & 108 & 797 & \\
\hline 50308944 & $3 / 13 / 94 \quad 1: 55 \mathrm{PM}$ & 0.8560 & 20.4200 & 24 & 5.674 & 5.557 & 5.6 & 0.1 & 4 & 4 & 134 & & 100.38 & 1390.12 & 1.1 & 71 & 868 & \\
\hline 50308945 & $3 / 15 / \mathrm{Am} \quad 8.05 \mathrm{NM}$ & 0.8463 & 20.2058 & 24 & 3.346 & 3.262 & 3.3 & 0.0 & 5 & 5 & 70 & & 102.26 & 1962.28 & 1.1 & 60 & 929 & 10 \\
\hline 50308946 & $3 / 16 / 94 \quad 8: 10 \mathrm{AM}$ & 0.8561 & 20.1314 & 24 & 2.595 & 2.548 & 2.6 & 0.0 & 7 & 6 & 60 & & 100.95 & 1164.31 & 1.1 & 26 & 955 & 19.6 \\
\hline 50308947 & $3 / 178948: 10 \mathrm{AM}$ & 0.8442 & 20.2643 & 24 & 2.12 & 2.037 & 2.1 & 0.0 & 8 & 8 & 50 & & 101.39 & 1171.15 & 1.1 & 22 & 977 & 19.8 \\
\hline 50308948 & $3 / 18 / 94 \quad 8: 07 \mathrm{AM}$ & 0.8564 & 20.4980 & 24 & 1.817 & 1.797 & 1.8 & 0.0 & 9 & 2 & 43 & & 103.74 & 1172.41 & 1.1 & 19 & 996 & \\
\hline 50308949 & $3 / 19 \mathrm{MA} \quad 10: 19 \mathrm{AM}$ & 1.0159 & 19.9805 & 20 & 1.736 & 1.701 & 1.7 & 0.0 & 10 & 10 & 34 & & 102.04 & 1193.88 & 1.0 & 15 & 1011 & \\
\hline 503089410 & $3200 \mathrm{94} \quad 8: 38 \mathrm{AM}$ & 0.9966 & 20.0010 & 20 & 1.431 & 1.350 & 1.4 & 0.0 & 11 & 11 & 28 & & 101.00 & 1102.98 & 1.1 & 12 & 1023 & 21.5 \\
\hline 503089411 & $3 / 21 / 94 \quad 8: 38 \mathrm{AM}$ & 0.9985 & 20.0747 & 20 & 1.246 & 1.158 & 1.2 & 0.0 & 12 & 12 & 24 & & 102.15 & 1172.42 & 1.1 & 11 & 1034 & \\
\hline 503089412 & $321 / 94 \quad 5: 45$ PM & 1.0010 & 20.0401 & 20 & 1.149 & 1.13 & 1.1 & 0.0 & 13 & 12 & 23 & & 102.06 & 465.42 & 1.0 & 3 & 1037 & \\
\hline 503089413 & $3122 \mathrm{MOM} \quad 11: 12 \mathrm{AM}$ & 4.0803 & 20.0840 & 5 & 3.099 & 3.938 & 4.0 & 0.0 & 13 & 13 & 20 & & 102.10 & 919.41 & 1.1 & 7 & 1044 & \\
\hline 503089414 & $32294 \quad 5: 18 \mathrm{PM}$ & 4.0301 & 20.1965 & 5 & 3.878 & 3.772 & 3.8 & 0.1 & 14 & 14 & 18 & & 102.18 & 374.00 & 1.1 & 2 & 1046 & \\
\hline 503089415 & $3 / 24194 \quad 8: 10 \mathrm{MM}$ & 4.0365 & 20.0530 & 5 & 3.744 & 3.655 & 3.7 & 0.0 & 14 & 15 & 18 & & 206.46 & 1931.60 & 1.1 & 13 & 1050 & \\
\hline 503089416 & $32494 \quad 4: 50 \mathrm{PM}$ & 4.0141 & 19.9932 & 5 & 3.547 & 3.488 & 3.5 & 0.0 & 16 & 15 & 18 & & 101.71 & 487.99 & 1.1 & 3 & 1082 & \\
\hline $5030894 \quad 17$ & $3255 \mathrm{PA} \quad 3: 35 \mathrm{PM}$ & 4.0203 & 19.9769 & 5 & 3.521 & 3.406 & 3.5 & 0.1 & 16 & 16 & 17 & & 101.80 & 1106.88 & 1.1 & 7 & 1069 & \\
\hline 503089418 & $3 / 2694 \quad 8: 22 \mathrm{PM}$ & 3.9888 & 19,0933 & 5 & 3.166 & 3.01 & 3.1 & 0.1 & 17 & 17 & 15 & & 102.19 & 1160.25 & 0.9 & 7 & 1075 & \\
\hline 503089419 & $3 / 27194 \quad 4: 35 \mathrm{PM}$ & 4.0338 & 20.0630 & 5 & 2.636 & 2.566 & 2.6 & 0.0 & 18 & 18 & 13 & & 102.31 & 976.47 & 1.0 & 5 & 1080 & \\
\hline 503089420 & 3128/94 12:10 PM & 3.9075 & 10.0611 & 5 & 2.252 & 2.16 & 2.2 & 0.0 & 19 & 19 & 11 & & 102.09 & 968.80 & 1.1 & 4 & 1084 & \\
\hline 503089421 & $329 \mathrm{ga} \quad 11: 55 \mathrm{AM}$ & 4.0261 & 20.5515 & 5 & 1.858 & 1.70 & 1.8 & 0.0 & 20 & 20 & 9 & & 103.54 & 1151.69 & 1.1 & 4 & 108 & \\
\hline 503089422 & $3 / 30 / 2405 \mathrm{PM}$ & 3.9888 & 20.1220 & 5 & 1.81 & 1.723 & 1.8 & 0.0 & 21 & 21 & 8 & & 102.30 & 1138.22 & 1.0 & 4 & 1092 & \\
\hline $503089422 A$ & $3 / 30 / 94 \quad 4.00 \mathrm{PPM}$ & & & 5 & 1.769 & 1.7095 & 1.7 & 0.0 & 22 & 21 & a & & 71.40 & 166.36 & 1.1 & 0 & 1092 & \\
\hline 503089423 & $3 / 31 / 942.03 \mathrm{PM}$ & 4.0114 & 19.9633 & 5 & 1.728 & 1.696 & 1.7 & 0.0 & 22 & 22 & g & & 102.47 & 1184.48 & 1.2 & 4 & 1008 & 18 \\
\hline $5030894 \quad 23 A$ & $411 / 948 \times 10 \mathrm{AM}$ & & & 5 & 1.6925 & 1.657 & 1.7 & 0.0 & 23 & 23 & 8 & & 71.46 & 629.46 & 0.7 & 2 & 1098 & 21.3 \\
\hline 503089424 & N1/94 $4.32 \mathrm{PM}$ & 4.0005 & 20.0230 & 5 & 1.657 & 1.618 & 1.6 & 0.0 & 24 & 24 & g| & & 69.34 & 421.49 & 1.1 & 1 & 1009 & \\
\hline 503089425 & 1:294 3:13 PM & 3.9739 & 20.0833 & 5 & 1.786 & 1.714 & 1.8 & 0.0 & 24 & 24 & 9 & & 101.88 & 1138.57 & 1.1 & 4 & 1103 & \\
\hline 503089426 & $4394 \quad 3: 00 \mathrm{PM}$ & 3.9167 & 20.1800 & 5 & 1.717 & 9.67 & 1.7 & 0.0 & 25 & 25 & 9 & & 102.08 & 1194.38 & 1.1 & 4 & 1107 & \\
\hline 503089427 & $44 / 94 \quad 10: 40 \mathrm{AM}$ & 4.0042 & 19.6481 & 5 & 1.665 & 1.607 & 1.6 & 0.0 & 26 & 26 & 8 & & 101.08 & 927.59 & 1.0 & 3 & 1110 & \\
\hline 503089428 & 45/94 $10: 45 \mathrm{AM}$ & 4.0691 & 20.5799 & 5 & 1.675 & 1.624 & 1.6 & 0.0 & 27 & 27 & 8 & & 102.21 & 1188.31 & 1.1 & 4 & 1113 & \\
\hline 503089429 & $4 / 6 / 94 \quad 830 \mathrm{AM}$ & 4.0319 & 19.8303 & 5 & 1.56 & 1.495 & 1.5 & 0.0 & 28 & 28 & 7 & & 102.34 & 1082.64 & 1.1 & 3 & 1116 & \\
\hline 503089430 & 47I94 $9 \times 10 \mathrm{AM}$ & 4.0444 & 20.3170 & 5 & 1.278 & 1.288 & 1.3 & 0.0 & 29 & 29 & 6 & & 102.17 & 1184.47 & 1.0 & 3 & 1110 & 17.3 \\
\hline 503089431 & Nero4 $8.30 \mathrm{AM}$ & 4.0511 & 19.9784 & 5 & 1.369 & 1.296 & 1.3 & 0.0 & 30 & 30 & 7 & & 100.46 & 1130.42 & 1.1 & $3 \mid$ & 1122 & 20.1 \\
\hline 503089432 & 4/9/94 $: 18 \mathrm{AM}$ & 3.9952 & 20.4327 & 5 & 1.264 & 1.221 & 1.2 & 0.0 & 31 & 31 & 6 & & 99.85 & 1204.17 & 1.1 & 3 & 1125 & 10.9 \\
\hline 503089433 & N10194 12:10 PM & 4.0526 & 20.7205 & 5 & 1.222 & 1.174 & 1.2 & 0.0 & 32 & 32 & 6 & & 102.07 & 1205.18 & 1.0 & 3 & 1128 & 18.9 \\
\hline 503089434 & $4 / 11 / 94 \quad 10: 55 \mathrm{AM}$ & 3.9676 & 20.3781 & 5 & 1.016 & 0.9954 & 1.0 & 0.0 & 33 & 33 & 5 & & 102.74 & 1113.84 & 1.1 & 2 & 1130 & 18.4 \\
\hline $5030894 \quad 35$ & 412294 11:07 AM & 3.9434 & 20.2787 & 5 & 0.2415 & 0.8798 & 0.9 & 0.0 & 34 & 34 & 5 & & 101.97 & 1181.80 & 1.1 & 2 & 1132 & 18.6 \\
\hline 503089436 & N12/94 $5: 55 \mathrm{PM}$ & 4.0098 & 20.6151 & 5 & 0.9036 & 0.8625 & 0.8 & 0.0 & 35 & 35 & 5 & & 41.42 & 346.70 & 1.1 & 1 & 1132 & 18.4 \\
\hline 503089437 & N14MOA $11: 30 \mathrm{AM}$ & 4.0617 & 20.4670 & 5 & 1.037 & 0.9563 & 1.0 & 0.0 & 35 & 36 & 5 & & 202.64 & 2033.80 & 1.1 & 4 & 1136 & 21.8 \\
\hline 503089438 & $416194 \quad 12.55 \mathrm{PM}$ & & & enrv/oI & & & sorviol & Exend & 37 & 37 & texten & & 199.44 & 2370.16 & 1.1 & eply/oil & DIVIVI & 22.5 \\
\hline 503089439 & N1894 $8: 55 \mathrm{AM}$ & & & $010 / 01$ & & & DIVIOII & momat & 39 & 39 & setwen & & 204.06 & & -0.1 & eDIV/OII & ofrviol & 23.5 \\
\hline 503089440 & S19/9: 5:10 PM & & & DIV/OI & & & DIIVIOI & ment & 41 & 41 & tens & & 203.17 & 1637.48 & 1.1 & coiviol & Dolviol & 23.3 \\
\hline 5030894 & & & & DIV/01 & & & Divioi & & 42 & 41 & stits & & 206.21 & & 0.0 & Divioil & Diviol & 25 \\
\hline
\end{tabular}


C012694 - 0.5 M Sodium-Carbonate-Bicarbonate, 1X,

$1 \mathrm{~kg}$ SP9(94), Heterogeneous, Agglomerated with water

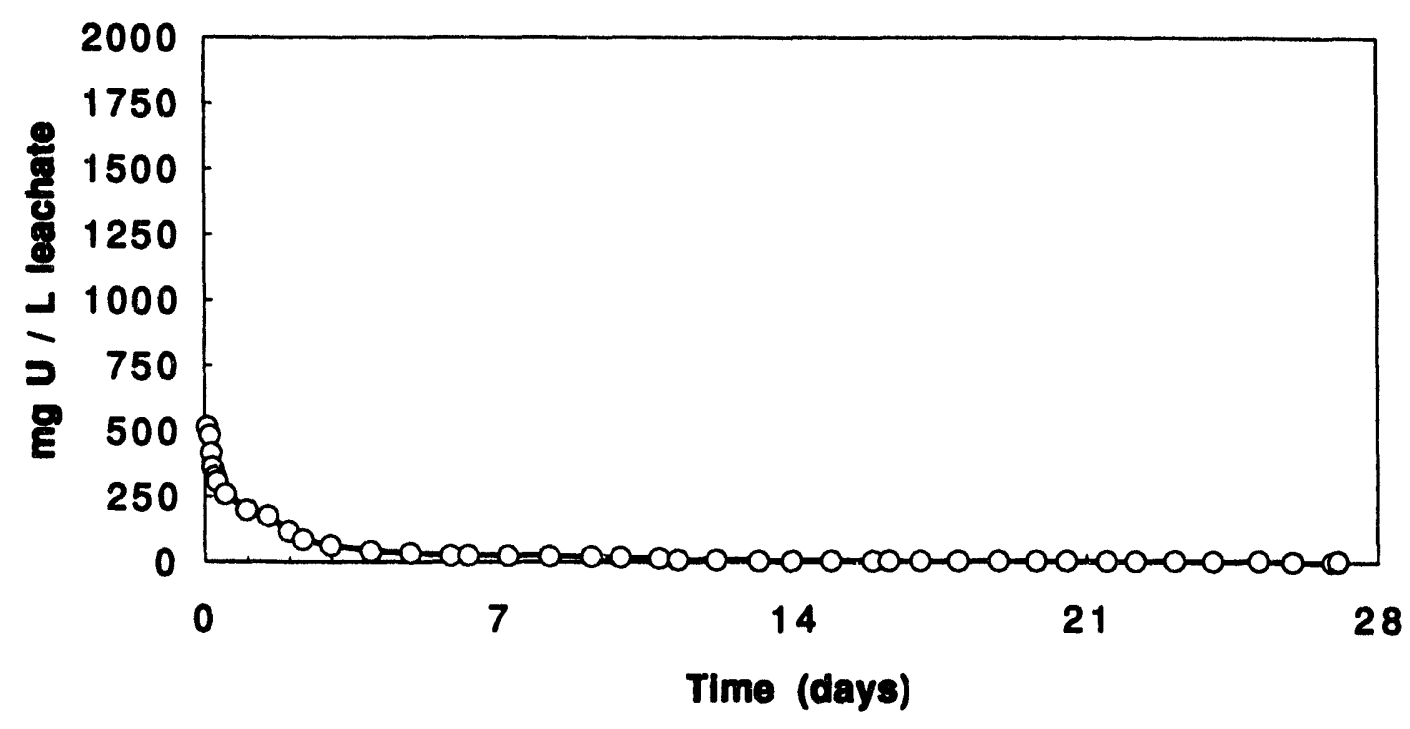

C012694 - 0.5 M Sodium-Carbonate-Bicarbonate, 1X, $1 \mathrm{~kg} \mathrm{SP9(94),} \mathrm{Heterogeneous,} \mathrm{Agglomerated} \mathrm{with}$ water

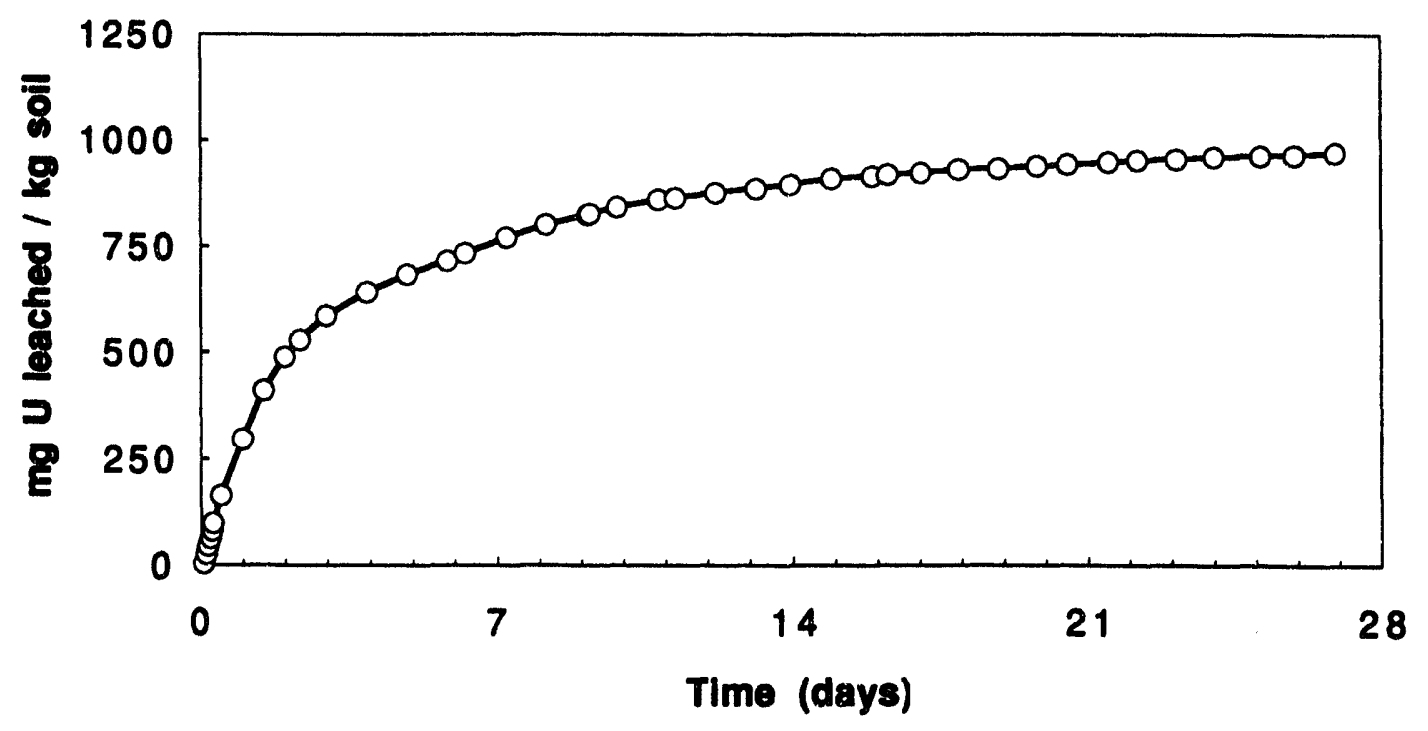


C012793 - 0.5 M Sodium-Carbonate-Bicarbonate, 1X,

$1 \mathrm{~kg}$ SP9(94), Heterogeneous, Agglomerated with water

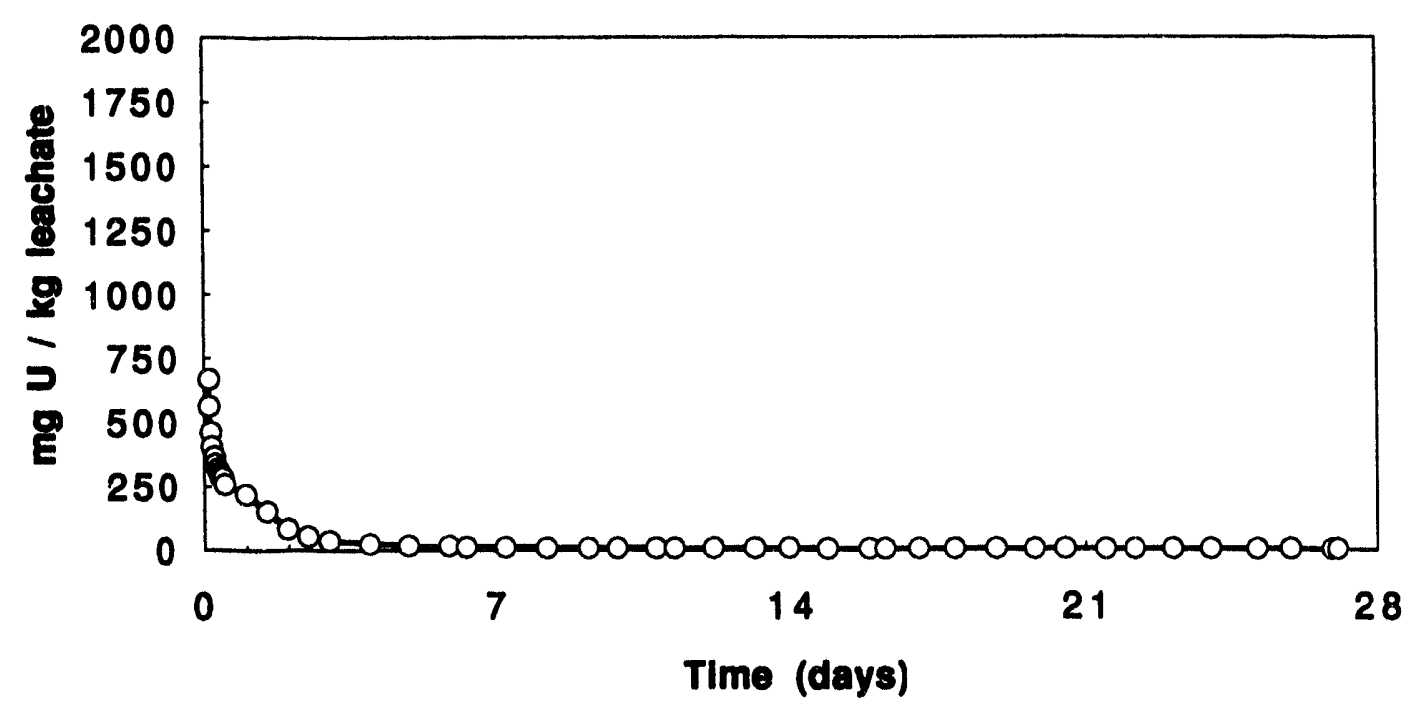

C012793 - 0.5 M Sodium-Carbonate-Bicarbonate, 1X, $1 \mathrm{~kg}$ SP9(94), Heterogeneous, Agglomerated with water

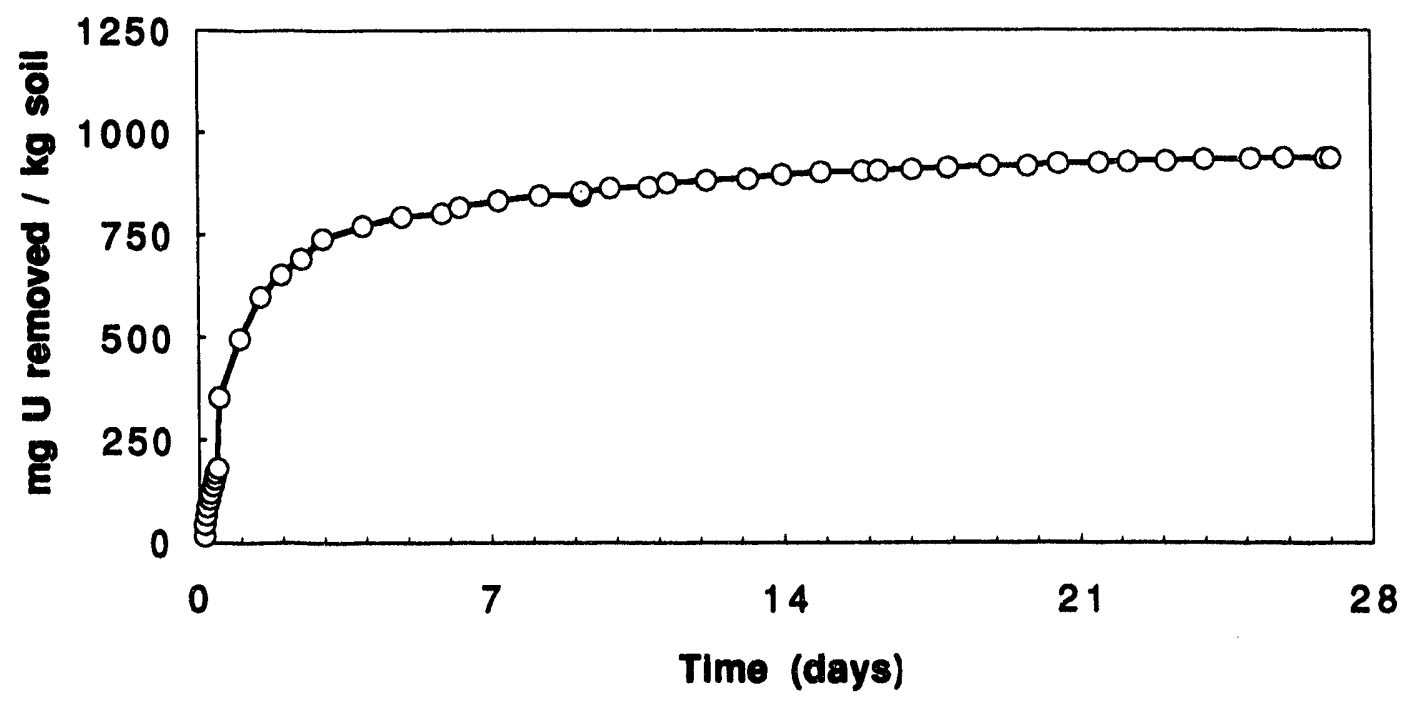


C012894 - 0.5 M Sodium-Carbonate-Bicarbonate, 1X,

$3 \mathrm{~kg}$ SP9(94), Heterogeneous, Agglomerated with

water

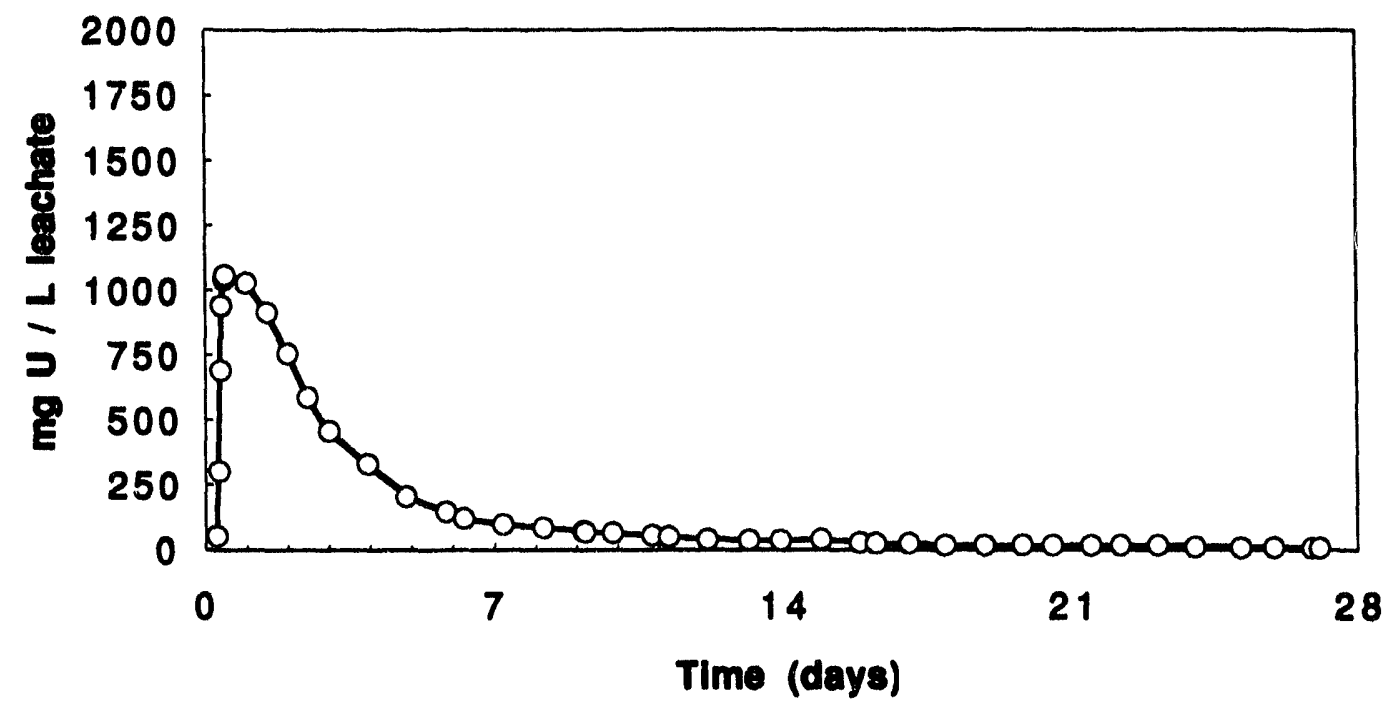

C012894 - 0.5 M Sodium-Carbonate-Bicarbonate, 1X,

$3 \mathrm{~kg} \mathrm{SP9(94),} \mathrm{Heterogeneous,} \mathrm{Agglomerated} \mathrm{with}$ water

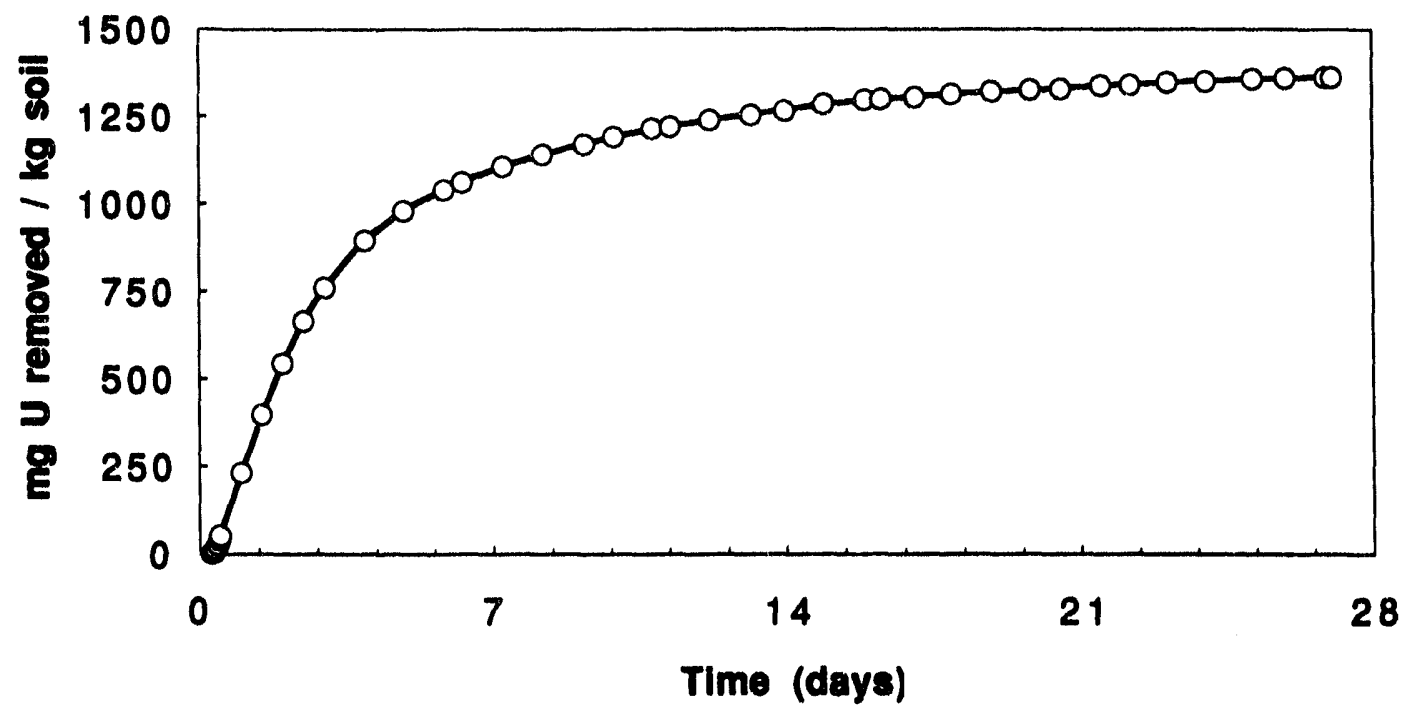


C020494 - 0.5 M Sodium-Carbonate-Bicarbonate, 0.3X, $1 \mathrm{~kg}$ SP9(94), Heterogeneous, Agglomerated with water

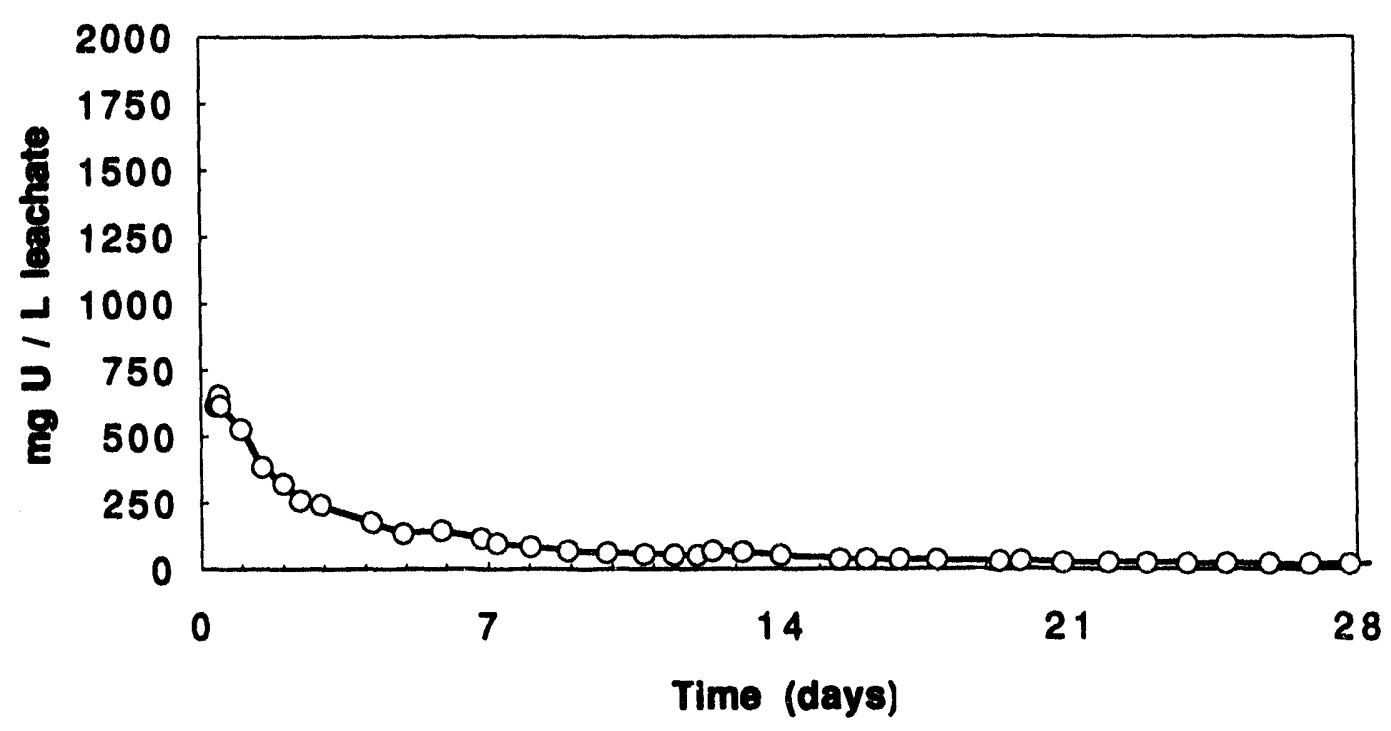

C020494 - 0.5 M Sodium-Carbonate-Bicarbonate, $0.3 \mathrm{X}, 1 \mathrm{~kg}$ SP9(94), Heterogeneous, Agglomerated with water

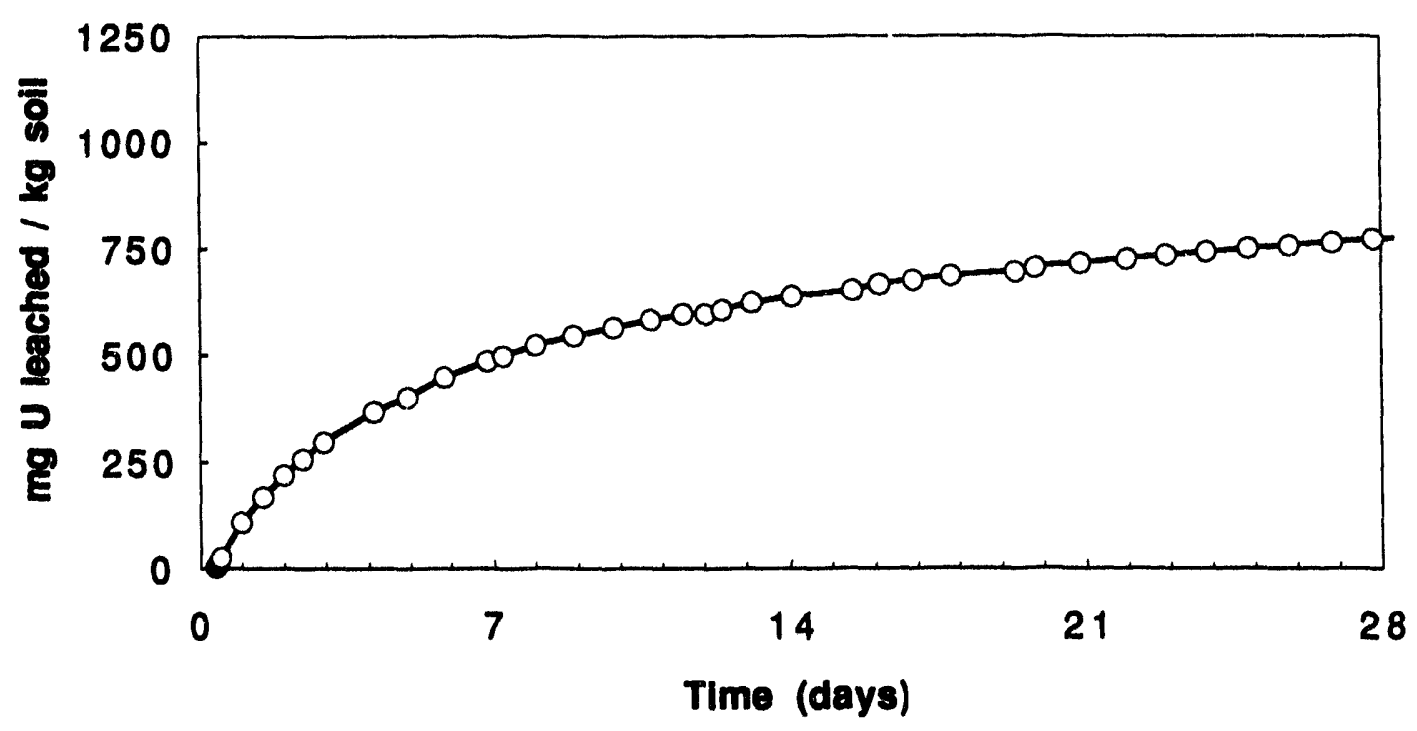


C020594 - 0.5 M Sodium-Carbonate-Bicarbone, 0.3X,

$1 \mathrm{~kg} \mathrm{SP9}(94)$, Heterogeneous, Agglomerated with

water

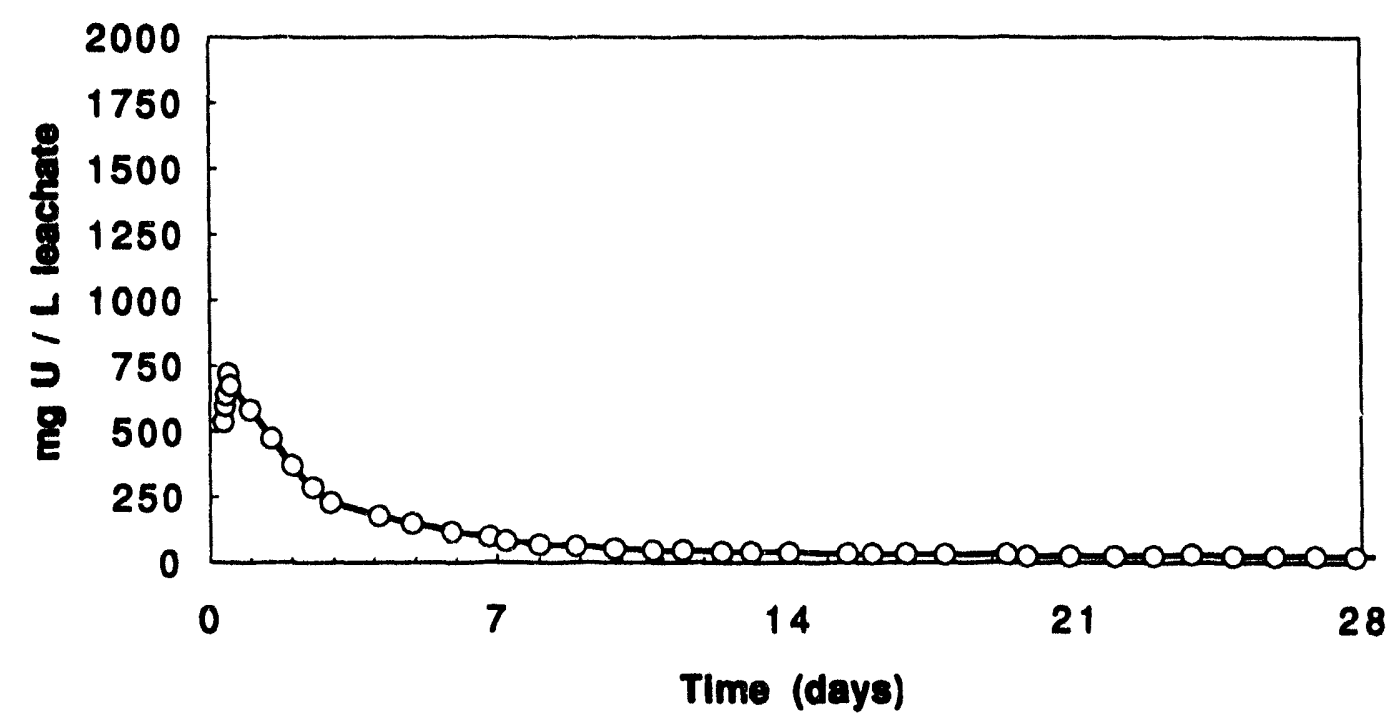

C020594 - 0.5 M Sodium-Carbonate-Bicarbone, 0.3X, $1 \mathrm{~kg} \mathrm{SP9(94),} \mathrm{Heterogeneous,} \mathrm{Agglomerated} \mathrm{with}$ water

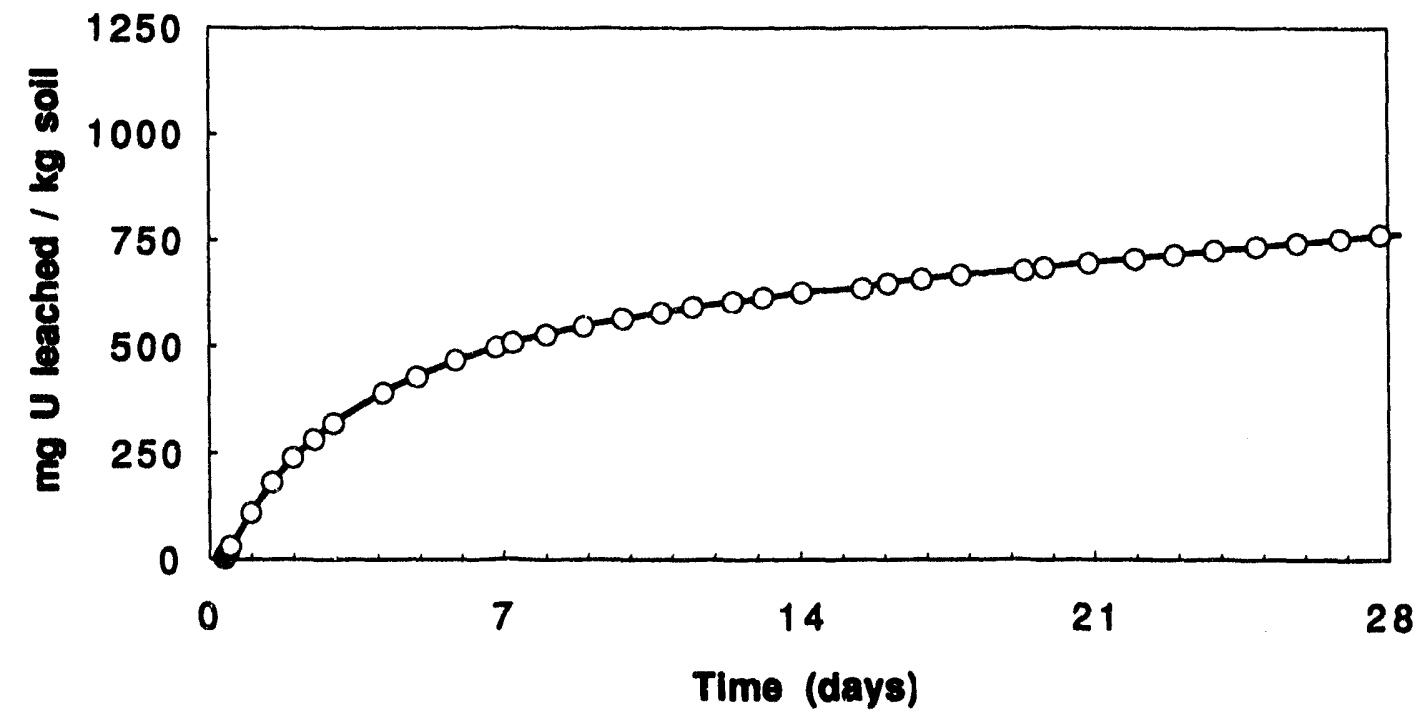


C022394 - 0.5 M Sodium-Carbonate-Bicarbonate, $1 X$, $10 \mathrm{~kg} \mathrm{SP9}(94)$, Heterogeneous, Agglomerated with water

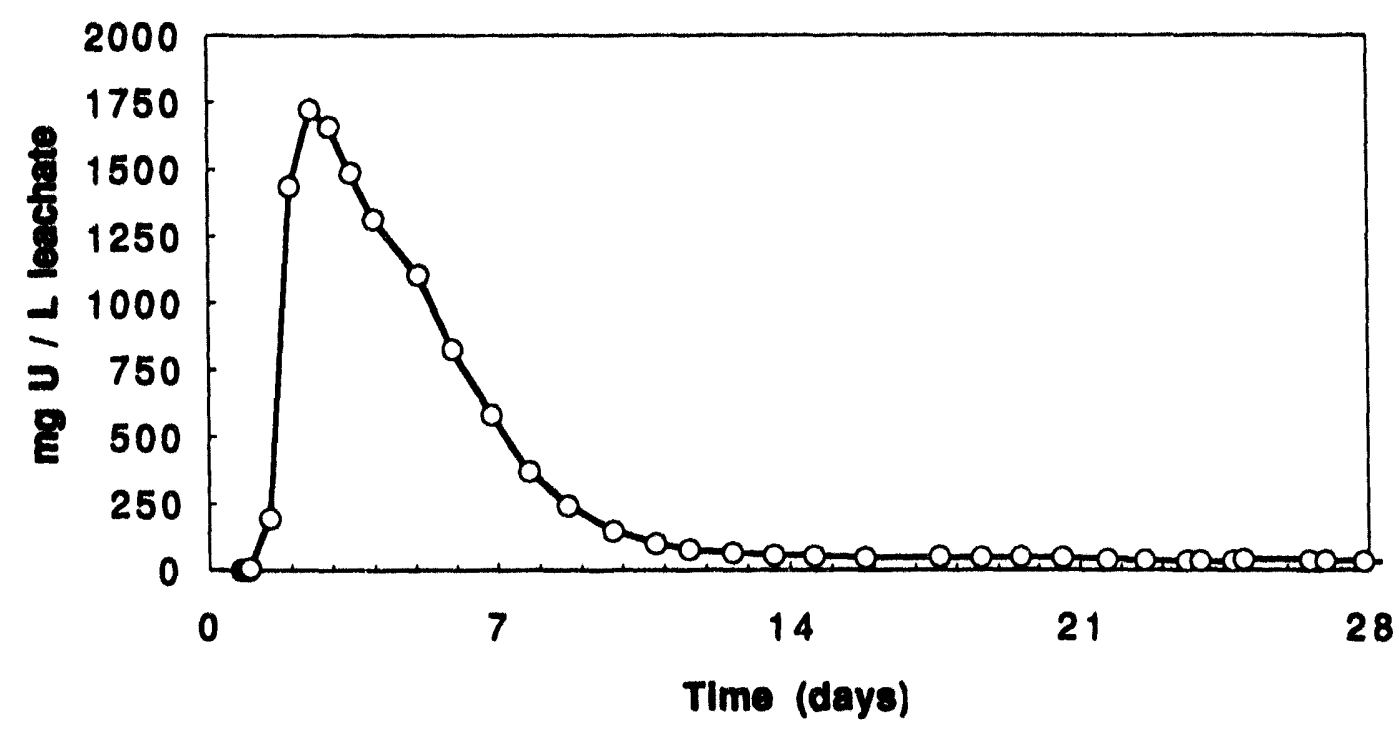

C022394 - 0.5 M Sodium-Carbonate-Bicarbonate, 1X, $10 \mathrm{~kg}$ SP9(94), Heterogeneous, Agglomerated with water

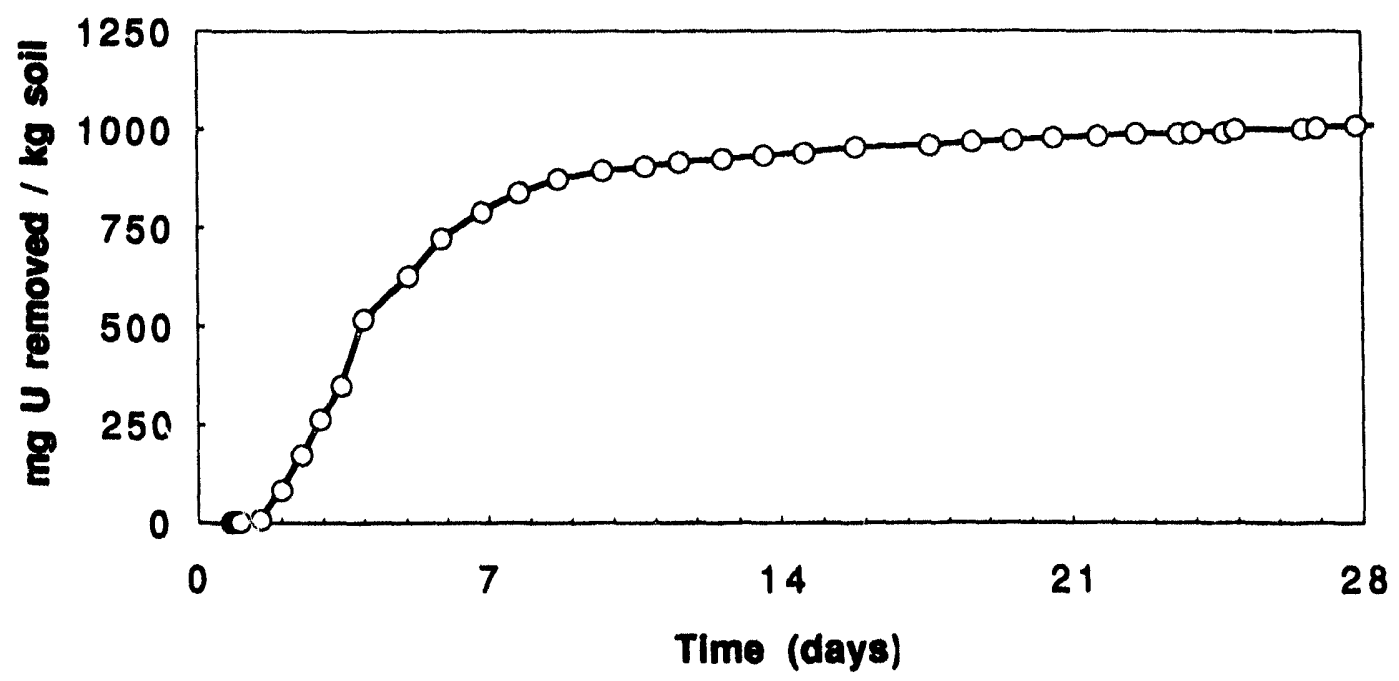


C030894 - 0.5 M Sodium-Carbonate-Bicarbonate, 1X, $3 \mathrm{~kg} \mathrm{SP9(94),} \mathrm{Heterogeneous,} \mathrm{Agglomerated} \mathrm{with}$ water

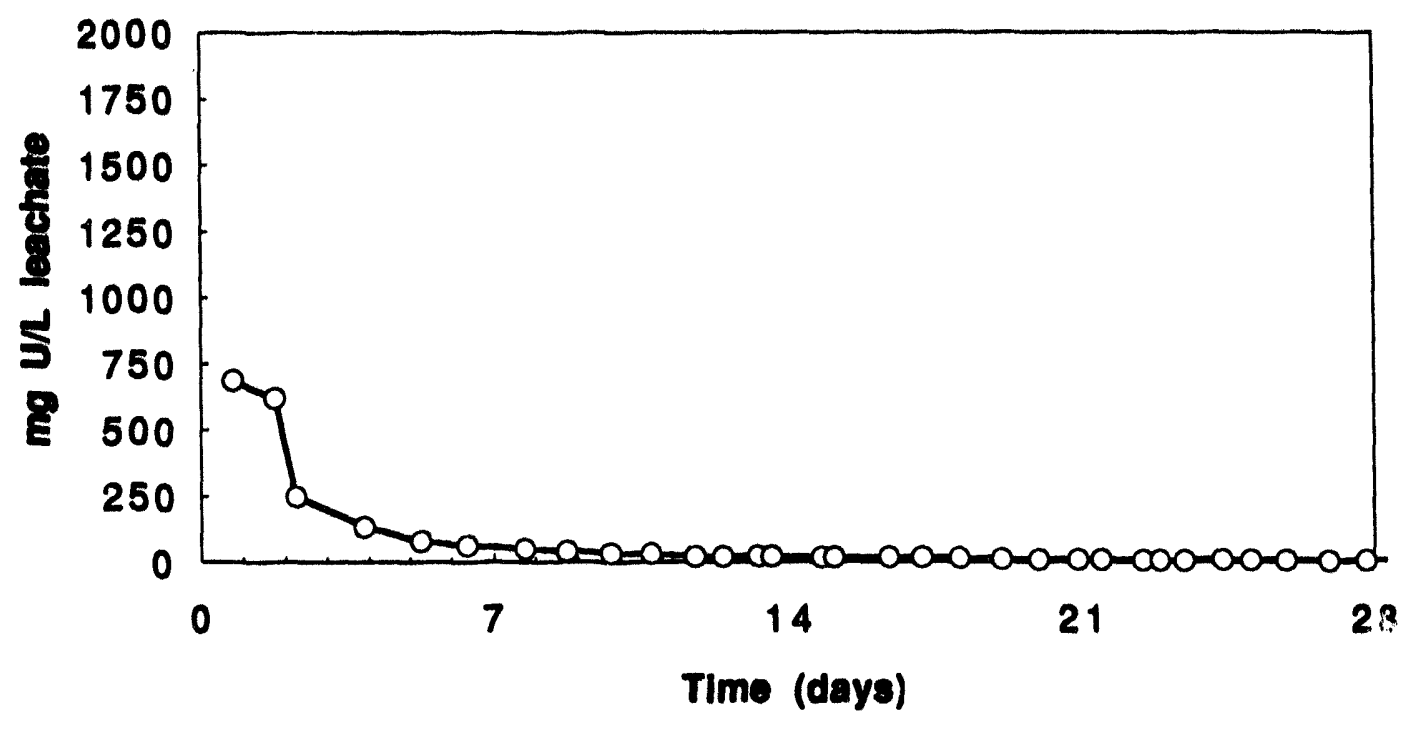

C030894 - $0.5 \mathrm{M}$ Sodium-Carbonate-Bicarbonate, $1 \mathrm{X}$, $3 \mathrm{~kg}$ SP9(94), Heterogeneous, Agglomerated with water

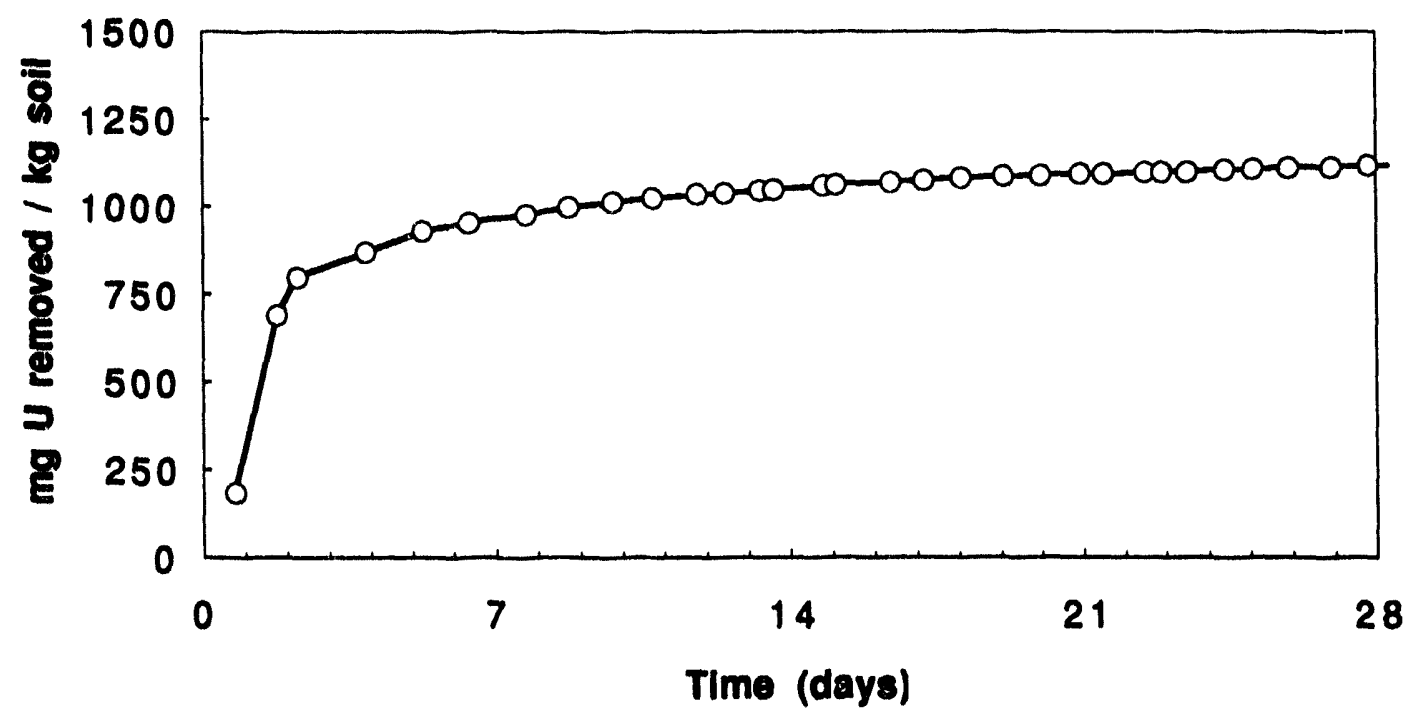




\section{Appendix B.}

Papers presented at Waste Management 94

(i) Predictive Geochemical Modeling of Uranium and other Contaminants in Laboratory Columns in Relatively Oxidizing, Carbonate-Rich Conditions.

Patrick Longmire, William R.J. R.Turney, Caroline F. V. Mason, David C. Dander, and

Don A. York

(ii) Carbonate Heap Leach of Uranium-Contaminated Soils.

William R.J. R.Turney, Catherine J. Chisholm-Brause, Caroline F. V. Mason, Patrick

Longmire, David C. Dander, Don A. York and Bruce M. Thomson

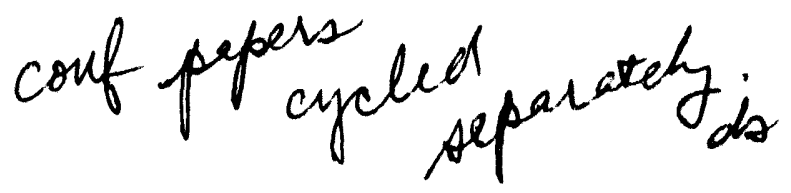




\section{Appendix C.}

\section{COST STUDY OF HEAP LEACHING \\ AND BATCH-REACTOR LEACHING \\ (using data available for gold)}

\section{SUMMARY CONCLUSIONS:}

The study was conducted on gold because heap leach data on gold are readily available whereas heap leach data on uranium are not.

The following summary conclusions were reached during this study.

- Heap leaching of gold can be performed for one-third to one-half of the cost of batchreactor leaching of gold.

- On large-scale, gold heap-leaching operations, ore can be processed for less than $\$ 150 /$ cu yd and, in many cases, for less than $\$ 100 /$ cu yd. These costs can be expected to be one-third to one-half of the costs for gold batch-reactor leaching.

- Up to 50 tons of ore can be processed to obtain 1 oz of gold; this work must be done for less than the current price of gold ( $\$ 370 / 0 z)$, otherwise, the mining company loses money.

- When gold leaching is completed, the gold left in the depleted ore is measured in parts per billion. EPA regulations for allowable contamination in soil are expressed in parts per million. Therefore, leaching of soil for contamination removal can be terminated sooner than for leaching of gold from gold ore. Shorter leaching times should result in lower costs.

Except for exact dollar costs, these conclusions can be extrapolated to heap leach of contamination from soil.

\section{WHAT ARE THE COSTS OF LEACHING:}

The costs of heap leaching are readily available in the current-day mining literature. The following table is partially taken from the Homestake Mining Company 1991 Annual Report and partially calculated. 


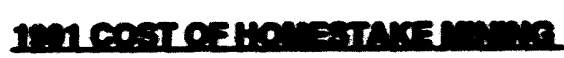

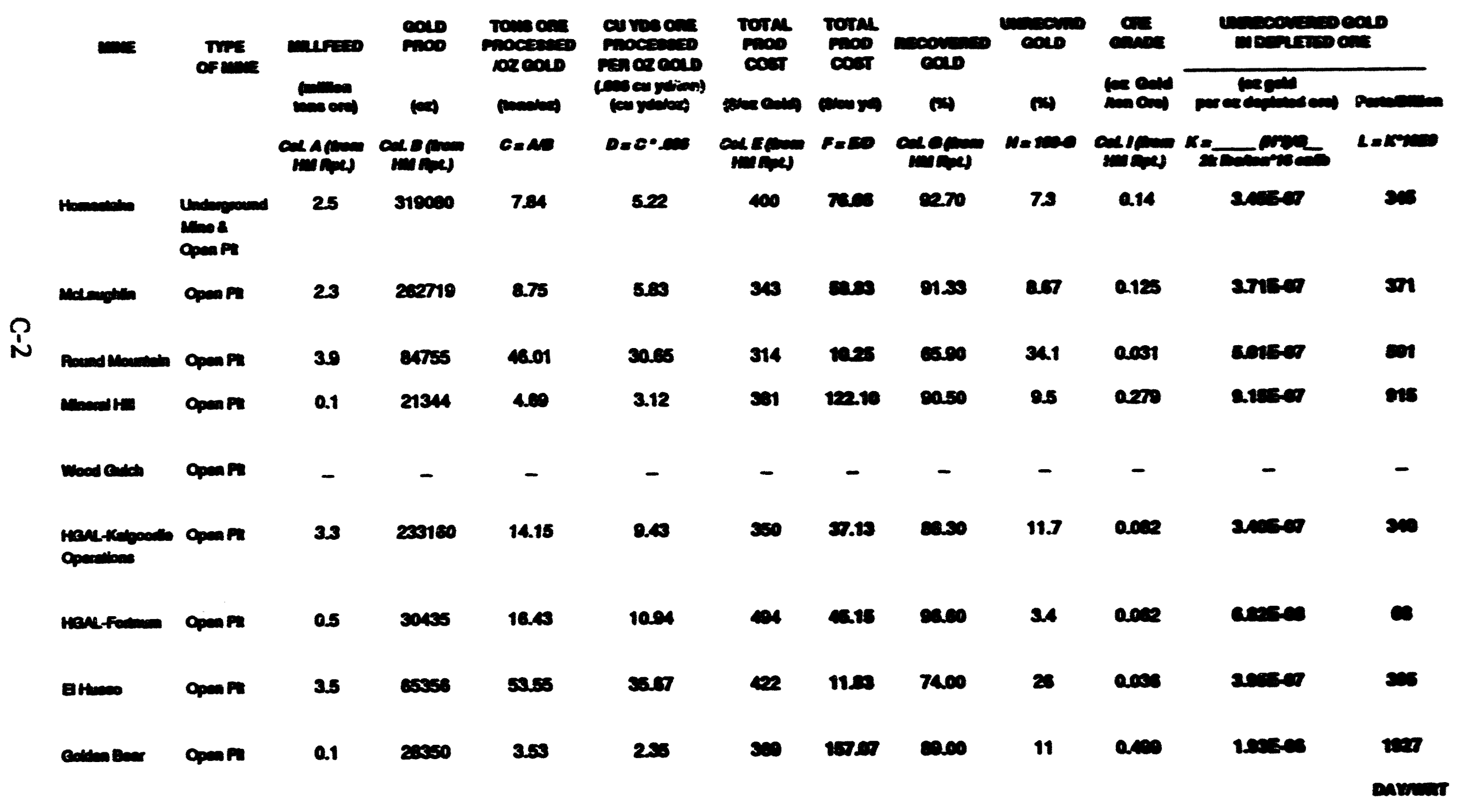




\section{NOTES ON MATRIX}

\section{Or \\ 1991 COST OF HOMESTAKE MINING}

1. Columns A, B, E, O, and I on the matrix are taken from the Homestake Mining Company 1991 Annual Report.

2. Columns $C, D, F, H, K$, and $L$ are calculated based upon Columns $A, B, E, G$, and $I$.

3. The TOTAL PROD COSTS (i.e., Columns E \& F) are achievable only with scaleup of the leaching process to the amounts shown in MILFEED (Column A). Smaller scale leaching can be expected to produce higher costs.

4. In all cases, the leaching process (on any heap) was halted because it was no longer profitable to continue. Further leaching was technically possible. As an example, recovery of gold at Wood Gulch was terminated in 1990 because it was no longer profitable.

5. In Column D, the ore was assumed to weigh 1.5 tons/cu yd (or $.666 \mathrm{cu} \mathrm{yd} / \mathrm{ton}$ ).

6. Note that the UNRECOVERED GOLD IN DEPLETED ORE (Columns $\mathrm{K} \& \mathrm{~L}$ ) are considerably lower than the EPA limits on uranium in soil (i.e., $52 \mathrm{ppm}$ or 52,000 ppb).

7. In the Homestake Mining Company 1991 Annual Report it is not clear if the units of tons are long tons $(2240 \mathrm{lb}$.) or short tons $(2000 \mathrm{lb}$.). Likewise, the units of ounces are not specifically called out as troy ounces $(14.58 \mathrm{oz} / \mathrm{b}$ ) or avoirdupois $(16 \mathrm{oz} / \mathrm{hb})$ ounces. The matrix assumes short tones and avoirdupois ounces. The difference, however, is not important. 
Following are two comparisons of the costs of heap leaching to the costs of batch-reactor leaching. The first comparison is a relattve cast comparison and the second is a quantitative cost comparison.

\section{RELATIVE COST COMPARISON:}

TOTAL PROD COSTS (i.e., Columns E \& F) on the preceding table, entitled 1991 COST OF HOMESTAKE MINING include:
a. exploration
b. mine development (property purchase, roads, mill construction, overburden removal, leach pad, leachate recovery system, etc.)
c. excavation of ore
d. transportation of ore to mill
e. crushing
f. agglomeration
g. heap stacking and sprinkler installation
h. leaching
i. rinsing of depleted ore
j. recovery of gold from leachate
k. heap and sprinkler system dismantling
1. transportation of depleted ore back to pit
m restoration of site

When comparing the costs of heap leaching to the costs of batch-reactor leaching, many of the items above are common to both processes and, therefore, can be ignored in a relative cost comparison. That is, their costs cancel each other out. The only exceptions are the items discussed below.

leach pad -

Heap leaching requires an impermeable pad that can cover acres and be constructed of standard road building materials.

Batch-reactor leaching requires no leach pad. Instead, a reactor (large vessel for agitation) is required. To maintain high throughput, multiple reactors are required.

\section{agglomeration -}

Some ores require agglomeration before leaching. If required, the cost of agglomeration includes (1) agglomerator, (2) power, (3) water, and (4) $\sim 6$ pounds of Portland cement per ton of ore.

Batch-reactor leaching does not require agglomeration of the ore.

heap stacking and sprinkler installation -

In heap leaching, the heap is built with a retreating stacker, i.e., an inclined belt conveyor that rotates left and right and moves backward when the heap reaches the proper height.

Distribution of the leaching reagent on the top of the heap is accomplished either with sprinklers or drip irrigation equipment. The reagent distribution system has 
connecting hoses and pumps. The costs here include (1) the stacker, (2) operational costs of the stacker, (3) sprinklers or drip emitters, hoses, \& pumps, and (4) labor for laying and connecting the distribution system on top of the heap.

In this phase of batch-reactor leaching, the reactor loading machinery and operator are required as often as the reactor is to be loaded (approximately full time, i.e., 3 shifts/day, if throughput is to be maintained).

\section{leaching -}

In this phase of heap leaching, the only moving equipment consists of pumps and sprinklers. The cost of actual leaching includes (1) supply and sump pumps, (2) leaching reagents, (3) rinse water, and (4) power to operate the pumps. A full-time operator is not required, only someone to checkup the pumps and sprinklers (or emitters) on a daily basis. Chemical analysis of the leachate does not have to be done in real time. The end of the leaching process can be predicted days in advance, allowing for sampling and analysis at a remote laboratory.

In this phase of batch-reactor leaching, the costs consist of (1) a large agitating (rotating) vessel(s), (2) labor to operate the batch reactor(s), (3) leaching reagents, (4) rinse water, and (5) a full-time, on-site, chemical analysis system with chemist. The full-time chemical analysis system is needed to determine when the batch reactor should be emptied and recharged with new ore. Power costs for the batchreactor system can be quite large. At least one full-time operator is required to (1) frequently sample the batch and (2) operate the equipment to maximize throughput.

The cost of leaching reagents and rinse water should be the same for both heap and batch-reactor leaching.

\section{heap and sprinkler dismantling -}

In this phase of heap leaching, the costs would include (1) labor to remove the hoses and sprinklers or emitters from the heap for future use, (2) a front-end loader, and (3) a dump truck.

In this phase of batch-reactor leaching, the reactor unloading machinery and operator are needed on approximately a full-time basis, i.e., three shifts/day. Removal of the liquid fraction from the solid fraction requires (1) a filtering system, (2) a settling pond, (3) a centrifuge, or (4) some other dewatering device. Each method of dewatering requires power.

The following is a relative comparison table of heap leaching costs vs. batch-reactor leaching costs. 


\section{COST COMPARISON}

\section{ITEM DESCRIPTION}

\section{HEAP}

LEACHING

\section{Equipment:}

leach pad

agglomerator (if required)

retreating stacker

sprinklers/emitters and hoses

pumps for reagent distribution

batch reactor vessels

reactor load/unload machinery

dewatering filter, pond, etc.

pumps for dewatering

Agglomeration (if required):

Portland cement

labor for agglomeration

Heap/Batch Preparation: heap stacking/sprinkler installation Low labor for heap/batch prep

Low

Low

Low

Moderate

Low

Low

Low

Low

None

None

None

None

Leaching:

leaching reagents

chemical analysis

rinse water

labor for leaching

Dewatering:

labor for dewatering

Same

Low

Same

None

None

High

Heap/Batch Dismantling:

labor for heap/batch dismantling Low

Power:

power for agglomerator power for pumps/sprinklers

power for agitation

power for reactor pumps

power for dewatering

All Other Operations:
Low

None

None

None

Same
Low

\section{BATCH}

REACTOR

LEACHING

None

None

None

None

None

High

Low

High

Moderate

None

None

None

High

Same

High

Same

High

High

None

None

High

Moderate

High

Same 


\section{QUANTITATIVE COST COMPARISON:}

According to Wentz, C. A., (Hazardous Waste Management, McGraw-Hill, New York, 461 pages, 1989) the capital costs of heap leaching are $20 \%$ to $36 \%$ of the same costs for batch-reactor leaching. Also, Wentz states that the operating costs for heap leaching are $40 \%$ to $55 \%$ of the same costs for batch-reactor leaching.

Low Side Comparison: for every $\$ 1$ of capital spent on batch-reactor leaching, only $\$ .20$ of capital is spent on heap leaching. And, for every \$1 of operating spent on batch reactor leaching, only $\$ .40$ of operating is spent on heap leaching. That is,

$\begin{array}{lcccc} & \text { Capital } & \text { Operating } & \text { Total } & \text { Gold } \\ \text { Batch Reactor (i.e., BRL) } & 1.00 & 1.00 & 2.00 & \mathrm{X}_{\mathrm{BRL}} \\ \begin{array}{l}\text { Heap (i.e., HL) } \\ \$ 2.00_{\mathrm{BRL}}\end{array} & \$ .20 & \$ .40 & \$ .60 & \$ 276.00^{*} \\ \frac{\mathrm{X}_{\mathrm{BRL}}}{\$ .60_{\mathrm{HL}}} & = & & \\ \mathrm{X}_{\mathrm{BRL}}= & \$ 276.00_{\mathrm{HL}} & & \\ & \$ 920 / \mathrm{oz} & & & \end{array}$

* \$276 is the average total cost of heap-leach gold production per ounce by US companies in 1991.

High Side Comparison: for every $\$ 1$ of capital spent on batch-reactor leaching, only $\$ .36$ of capital is spent on heap leaching. And, for every $\$ 1$ of operating spent on batch reactor leaching, only $\$ .55$ of operating is spent on heap leaching. That is,

$\begin{array}{lcccc}\text { Batch Reactor (i.e., BRL) } & \begin{array}{c}\text { Capital } \\ \text { Heap (i.e., HL) }\end{array} & \begin{array}{c}\text { Operating } \\ 1.00\end{array} & \begin{array}{c}\text { Total } \\ 2.00\end{array} & \begin{array}{c}\text { Gold } \\ \mathrm{X}_{\mathrm{BRL}}\end{array} \\ \frac{\$ 2.00_{\mathrm{BRL}}}{\$ 26} & \$ .55 & \$ .91 & \$ 276.00 \\ \frac{\mathrm{X}_{\mathrm{BRL}}}{\$ .91_{\mathrm{HL}}} & =\frac{}{\$ 276.00_{\mathrm{HL}}} & & \\ \mathrm{X}_{\mathrm{BRL}}=\$ 606 / 02 & & \end{array}$

It is therefore concluded from Wentz and Homestake Mining (Ref.) that the cost of batchreactor leaching ranges from approximately $\$ 600$ to $\$ 900 / 0 z$ of gold. This is two to three times that of heap leaching of gold (i.e., $\$ 276 / 0 z$ ). 


\section{OTHER COST COMPARISON DATA:}

According to Harmat World, September 1991, Geochem Inc. of Lakewood, CO, evaluated a process to recover lead from contaminated soil at a former battery manufacturing plant near Melbourne, Australia. According to Hazmat World, the "lead concentrations were reduced in three days from more than 8000 parts per million (ppm) to $300 \mathrm{ppm}$ using a modified heap leach mining method. The method will cost about $\$ 30$ per ton, one-tenth as much as transporting the contaminated soil to a secure landfill."

\section{REFERENCES FOR COST STUDY:}

1. 1991 Annual Report, Homestake Mining Company, 650 California Street, San Francisco, CA 94108.

2. Wentz, C. A., Hazardous Waste Management, McGraw-Hill, New York, 461 pages, 1989.

3. Hazmat World, September 1991. 

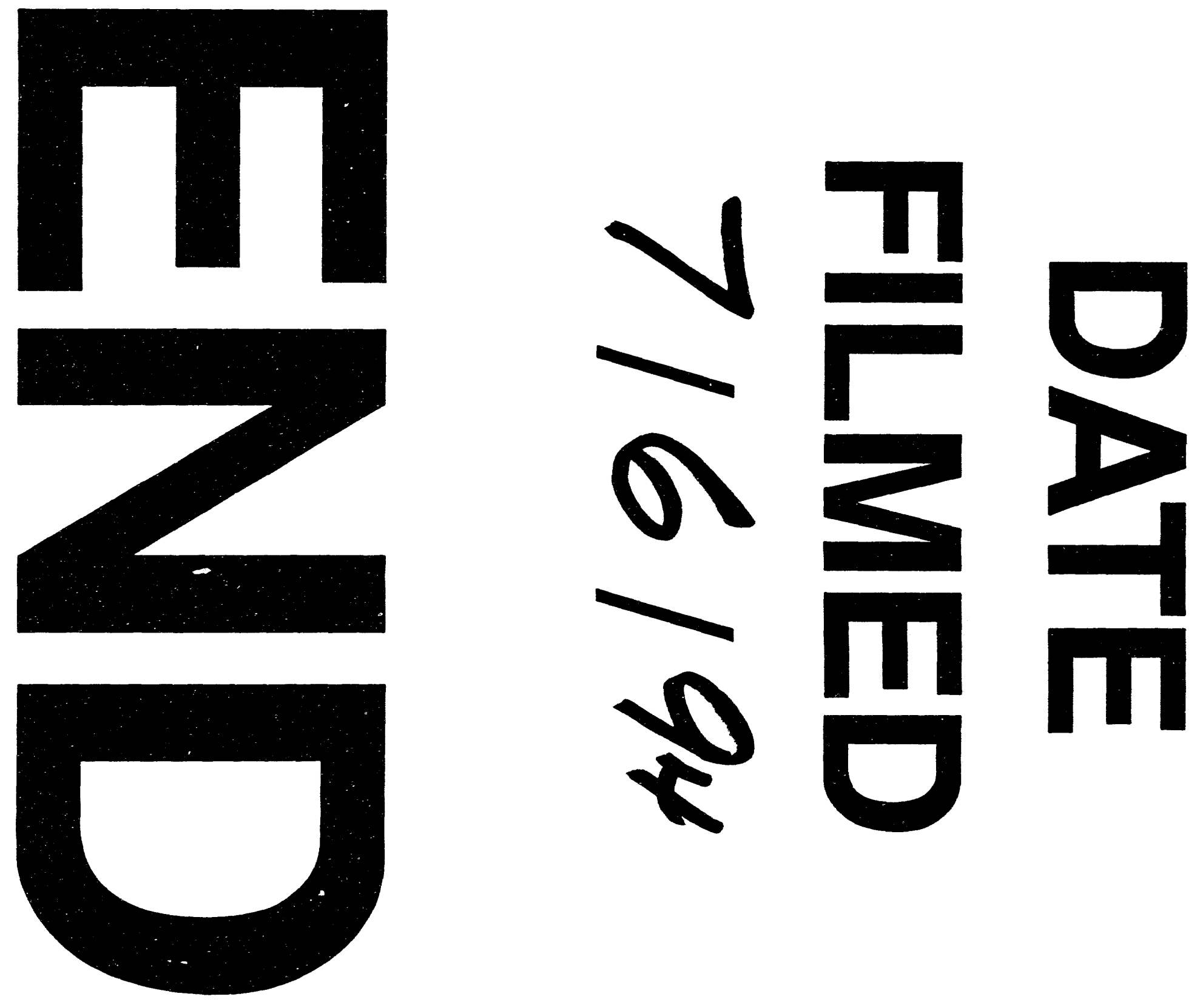

$v$ 


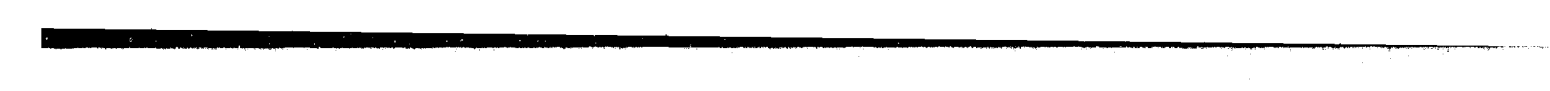

